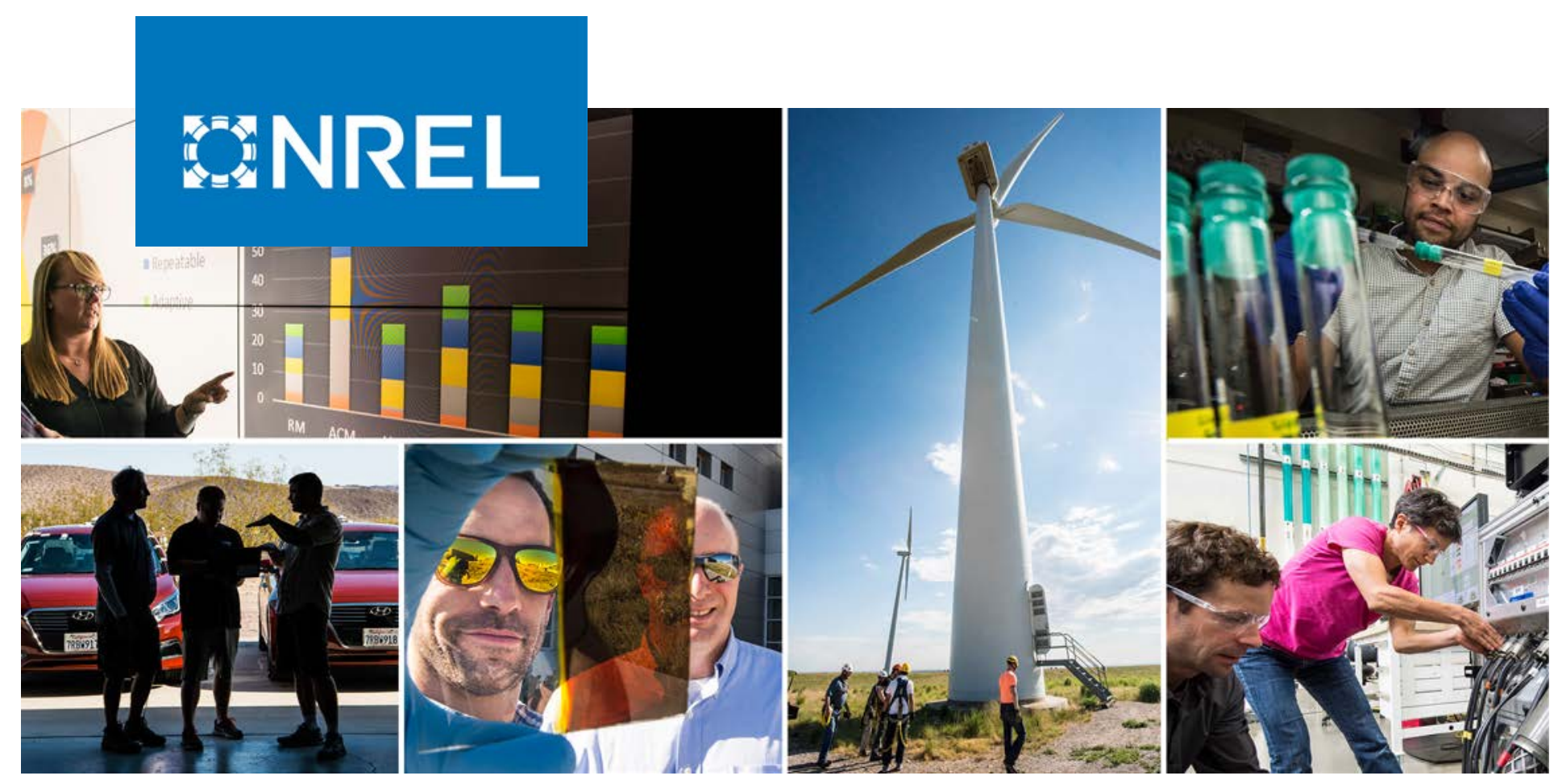

\title{
The Potential for Electrons to Molecules Using Solar Energy
}

Alex Badgett, William Xi, and Mark Ruth

National Renewable Energy Laboratory

NREL is a national laboratory of the U.S. Department of Energy

Office of Energy Efficiency \& Renewable Energy

Operated by the Alliance for Sustainable Energy, LLC

This report is available at no cost from the National Renewable Energy Laboratory (NREL) at www.nrel.gov/publications.
Technical Report

NREL/TP-6A20-78719

September 2021 


\title{
GHREL
}

\section{The Potential for Electrons to} Molecules Using Solar Energy

\author{
Alex Badgett, William Xi, and Mark Ruth
}

National Renewable Energy Laboratory

\section{Suggested Citation}

Badgett, Alex, William Xi, and Mark Ruth. 2021. The Potential for Electrons to Molecules Using Solar Energy. Golden, CO: National Renewable Energy Laboratory. NREL/TP6A20-78719. https://www.nrel.gov/docs/fy21osti/78719.pdf.

NREL is a national laboratory of the U.S. Department of Energy Office of Energy Efficiency \& Renewable Energy Operated by the Alliance for Sustainable Energy, LLC

This report is available at no cost from the National Renewable Energy Laboratory (NREL) at www.nrel.gov/publications.

Contract No. DE-AC36-08GO28308
Technical Report

NREL/TP-6A20-78719

September 2021

National Renewable Energy Laboratory 15013 Denver West Parkway Golden, CO 80401 303-275-3000 • www.nrel.gov 


\section{NOTICE}

This work was authored by the National Renewable Energy Laboratory, operated by Alliance for Sustainable Energy, LLC, for the U.S. Department of Energy (DOE) under Contract No. DE-AC36-08GO28308. Funding provided by U.S. Department of Energy Office of Energy Efficiency and Renewable Energy Solar Energy Technologies Office. The views expressed herein do not necessarily represent the views of the DOE or the U.S. Government.

This report is available at no cost from the National Renewable Energy Laboratory (NREL) at www.nrel.gov/publications.

U.S. Department of Energy (DOE) reports produced after 1991 and a growing number of pre-1991 documents are available free via www.OSTI.gov.

Cover Photos by Dennis Schroeder: (clockwise, left to right) NREL 51934, NREL 45897, NREL 42160, NREL 45891, NREL 48097, NREL 46526.

NREL prints on paper that contains recycled content. 


\section{The Solar Futures Study and Supporting Reports}

The Solar Futures Study, initiated by the U.S. Department of Energy (DOE) Solar Energy Technologies Office and led by the National Renewable Energy Laboratory (NREL), envisions how, over the next few decades, solar could come to power $40 \%$ or more of U.S. electricity demand, dramatically accelerating the decarbonization of buildings, transportation, and industry.

Through state-of-the-art modeling, the Solar Futures Study is the most comprehensive review to date of the potential role of solar in decarbonizing the U.S. electric grid and broader energy system. However, not all the detailed analysis that informed the Solar Futures Study could be included within its pages. This further analysis is collected in additional National Renewable Energy Laboratory reports, each dedicated to a different technology or socioeconomic concern.

This report, The Potential for Electrons to Molecules Using Solar Energy, focuses on a particular technology area that could contribute to decarbonization.

\section{The Solar Futures Study Reports}

- Solar Futures Study (main report published by DOE)

- Research Priorities for Solar Photovoltaics in a Decarbonized U.S. Grid

- $\quad$ The Role of Concentrating Solar-Thermal Power Technologies in a Decarbonized U.S. Grid

- The Demand-Side Opportunity: The Roles of Distributed Solar and Building Energy Systems in a Decarbonized Grid

- Maximizing Solar and Transportation Synergies

- The Potential for Electrons to Molecules Using Solar Energy

- Affordable and Accessible Solar for All: Barriers, Solutions, and On-Site Adoption Potential

- Forthcoming Environment and Circular Economy Report

You can learn more about the project and reports on the NREL website at https://www.nrel.gov/analysis/solar-futures.html. 


\section{Acknowledgments}

The authors would like to thank the following individuals for their contributions and feedback on this report in the series of Solar Futures Study reports:

- Ron Kent, Southern California Gas Company

- Ellen Stechel, Arizona State University

- Joseph Powell, Shell

- Sean Simpson, LanzaTech

- Marc Melaina, U.S. Department of Energy Hydrogen Fuel Cell Technologies Office

- Neha Rustagi, U.S. Department of Energy Hydrogen Fuel Cell Technologies Office

- Gary Grim, National Renewable Energy Laboratory (NREL)

- Ling Tao, NREL

- $\quad$ Paige Jadun, NREL

- Trieu Mai, NREL

- Chad Hunter, NREL

- Kristen Ardani, NREL

- Colin McMillan, NREL

- Robert Margolis, NREL

- Randy Cortright, NREL

- Chad Augustine, NREL

- Mike Meshek, NREL

- Dan Bilello, NREL

This work was authored by the National Renewable Energy Laboratory, operated by Alliance for Sustainable Energy, LLC, for the U.S. Department of Energy (DOE) under Contract No. DEAC36-08GO28308. Funding provided by the Solar Energy Technologies Office. The views expressed in the article do not necessarily represent the views of the DOE or the U.S. Government. The U.S. Government retains and the publisher, by accepting the article for publication, acknowledges that the U.S. Government retains a nonexclusive, paid-up, irrevocable, worldwide license to publish or reproduce the published form of this work, or allow others to do so, for U.S. Government purposes. 


\section{List of Acronyms and Abbreviations}

\begin{tabular}{|c|c|}
\hline $\mathrm{A} / \mathrm{cm}^{2}$ & amperes/square centimeter \\
\hline $\mathrm{C}_{2} \mathrm{H}_{4}$ & ethylene \\
\hline $\mathrm{C}_{2} \mathrm{H}_{5} \mathrm{OH}$ & ethanol \\
\hline CCUS & carbon capture and storage \\
\hline $\mathrm{CH}_{3} \mathrm{OH}$ & methanol \\
\hline $\mathrm{CH}_{4}$ & methane \\
\hline $\mathrm{CO}$ & carbon monoxide \\
\hline $\mathrm{CO}_{2}$ & carbon dioxide \\
\hline $\mathrm{CO}_{2} \mathrm{R}$ & carbon dioxide reduction \\
\hline CSP & concentrating solar power \\
\hline $\mathrm{CT}$ & combustion turbine \\
\hline DOE & U.S. Department of Energy \\
\hline $\mathrm{E} 2 \mathrm{M}$ & electrons to molecules \\
\hline GJ & gigajoules \\
\hline $\mathrm{H}_{2}$ & hydrogen \\
\hline $\mathrm{HCOO}^{-}$ & formate \\
\hline $\mathrm{HCOOCH}_{3}$ & methyl formate \\
\hline $\mathrm{HCOOH}$ & formic acid \\
\hline $\mathrm{kg}$ & kilograms \\
\hline $\mathrm{kWh}$ & kilowatt-hours \\
\hline LDE & low-cost, dispatch-constrained electricity \\
\hline MJ & megajoules \\
\hline $\mathrm{MPa}$ & megapascal \\
\hline MTO & methanol-to-olefins \\
\hline $\mathrm{mV}$ & millivolts \\
\hline $\mathrm{N}_{2}$ & nitrogen \\
\hline NG & natural gas \\
\hline $\mathrm{NH}_{3}$ & ammonia \\
\hline NREL & National Renewable Energy Laboratory \\
\hline PV & photovoltaics \\
\hline R\&D & research and development \\
\hline RE & renewable energy \\
\hline RWGS & reverse water gas-shift \\
\hline SPS & southwestern public service \\
\hline $\mathrm{t}$ & tonnes \\
\hline TRL & technology readiness level \\
\hline TW & terawatts \\
\hline TWh & terawatt-hours \\
\hline
\end{tabular}




\section{Executive Summary}

Solar photovoltaics (PV) play an important role in the electric power sector and could potentially support other sectors that need low carbon energy sources. Molecules such as hydrogen, ammonia, and hydrocarbons, including ethylene are currently produced from natural gas and crude oil and are used in sectors other than the power sector. Processes to produce them emit carbon dioxide and other greenhouse gases both directly and in upstream feedstock recovery processes. Electrons-to-molecules (E2M) technologies are being developed to convert carbon dioxide, water, and atmospheric nitrogen to desired chemical products using electricity, and they represent large electricity loads. E2M technologies are thus emerging as a potential application for PV; essentially, they can act as electrochemical energy storage and thereby provide a means to use the energy generated from PV and store it in molecular form.

E2M systems offer an array of potential products and system designs that can be tailored to different end uses beyond energy storage applications in the power sector. E2M technology involves electrochemical conversion, which uses electricity to break molecular bonds and produce new molecules. Various electrochemical conversion technologies split water into hydrogen and oxygen, reduce carbon dioxide into other hydrocarbon molecules and several other possible combinations. Though we do not attempt to provide an exhaustive summary or analysis of the potential products from E2M systems, we do provide an initial overview that can be used to identify the potential opportunities and challenges for PV and E2M systems. In this report in the Solar Futures Study series of reports, we consider the potential for E2M to produce key chemicals and fuels that currently rely on hydrocarbons for production, either as a reactant or a source of high-grade heat.

E2M represents a key opportunity for PV systems, as its development could result in a significant increase in demand for electrical energy. Possible ranges of energy demand for several direct and indirect E2M pathways are shown in Figure ES-1 (page viii) in addition to the approximate technology readiness level for the pathway. In general, two electrochemical conversion options are possible for most products:

- Direct electrochemical conversion involves using an electrochemical reactor to make products from water, carbon dioxide, and/or nitrogen.

- Indirect electrochemical conversion involves water splitting electrolysis (an electrochemical route) to produce hydrogen and then traditional catalytic chemistry with hydrogen to produce the product.

The ranges shown in Figure ES-1 represent the energy demand if the entire supply chain for a particular molecule were to be shifted to E2M processes, with upper and lower bounds being determined by the current and best-case energy efficiency for the pathway. Though a complete and immediate shift to E2M-based supply chains is unlikely in the near term, the large market sizes and diversity of products indicate that numerous opportunities exist for PV to provide energy used in E2M. Smaller markets provide specialized opportunities for E2M systems. Hydrogen produced from E2M can serve as an intermediate for a variety of applications, from transport to ammonia production. Electrochemical ethylene production could leverage the large market size and infrastructure of existing petrochemical supply chains. E2M has many different opportunities to play a significant role in future energy and industrial systems, and thus PV has numerous opportunities to play a central role in this evolving system. 


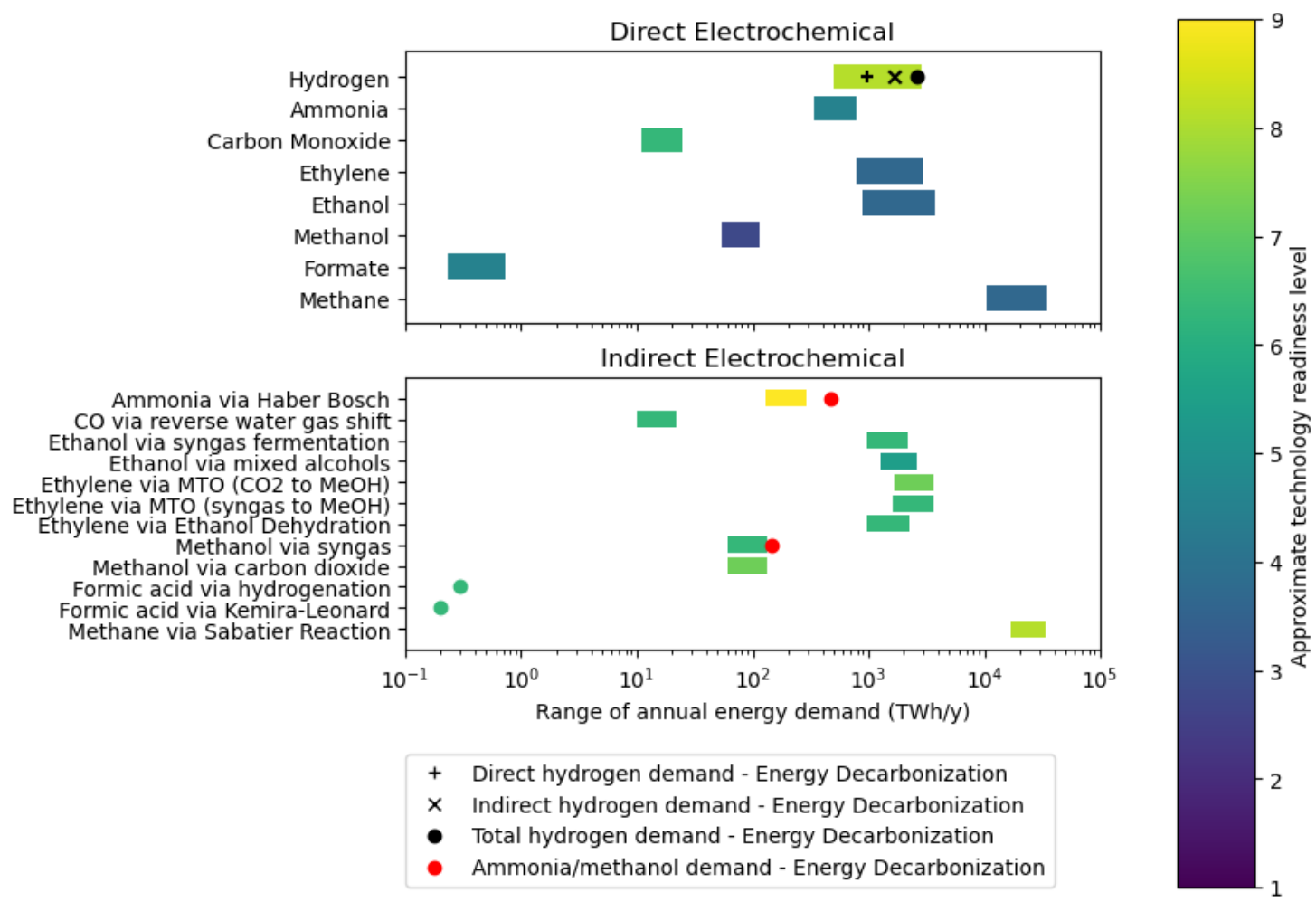

Figure ES-1. Possible ranges of annual energy demand for various E2M systems and products via both direct electrochemical (using an electrochemical reactor to produce the products from water, carbon dioxide, and/or nitrogen) and indirect electrochemical (water splitting electrolysis to produce hydrogen and then traditional catalytic chemistry with hydrogen to produce the product) pathways

Pathways with points instead of bar ranges did not have sufficient data to generate ranges of energy consumption. Key products from the Energy Decarbonization scenario are shown in black and red points, in contrast with bars charted for Base and Optimistic scenarios. For detailed descriptions of the assumptions used in these estimates, see the appendix.

This report in the Solar Futures Study series of reports identifies key challenges and opportunities to help enable further deployment of E2M, connecting these challenges to PV where possible. Though many research challenges are specific to E2M systems, overarching challenges and opportunities are summarized here:

- Reducing E2M system capital costs while realizing increases in system efficiency, lifetime, and durability while identifying opportunities for directly coupling E2M and PV

- Development of E2M systems so they can operate as dispatchable loads, actively cycling on and off or ramping up and down from base load operations to use energy from low-cost, dispatch-constrained electricity generation from wind and solar

- Identification of products and pathways for direct and indirect E2M systems

- Enabling E2M access to wholesale power markets, permitting systems to purchase power at location marginal prices, and compensating E2M systems for any grid services they provide while increasing demand for electricity from PV analysis and optimization of potential impacts of E2M technologies on grid and opportunities as dispatchable load to better use variable generation, ideally creating markets for every renewable kilowatt-hour of energy produced. 


\section{Table of Contents}

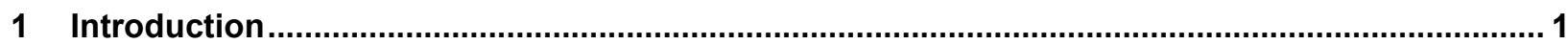

2 Electrons to Molecules as a Pathway for Electrification Across Sectors .................................. 3

3 Potential Electrons to Molecules Products and Pathways .......................................................... 6

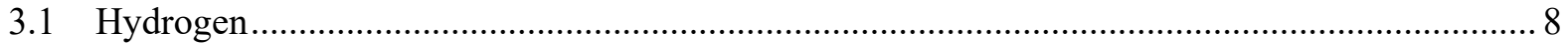

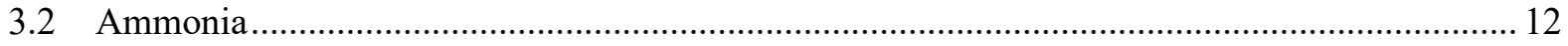

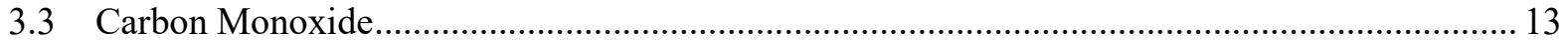

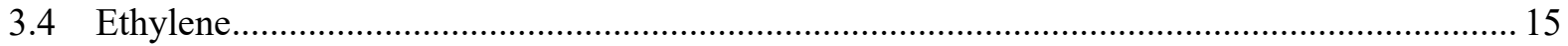

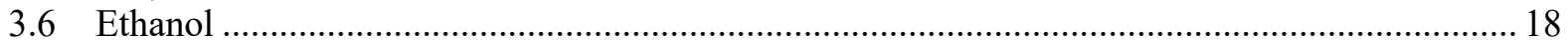

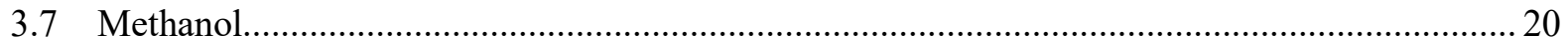

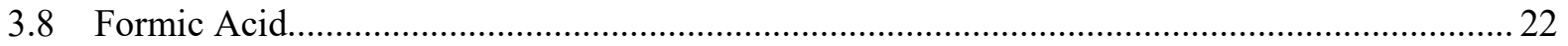

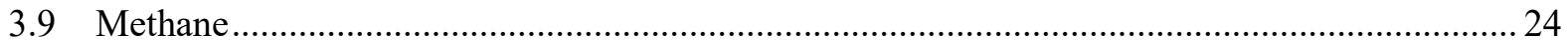

4 Electricity Prices and Direct Electrons to Molecules Pathways .............................................. 28

5 Social and Environmental Equity Implications for Electrons to Molecules ................................ 30

6 R\&D Challenges and Opportunities for Electrons to Molecules and PV ...................................31

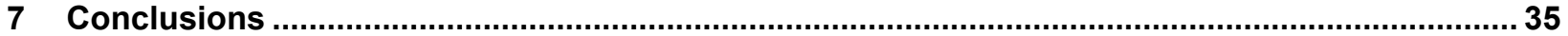

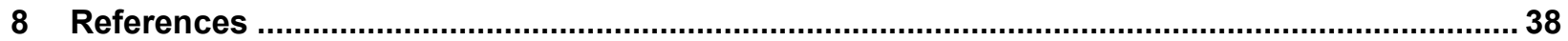

Appendix. Assumptions and Methodologies for E2M Energy Demands ....................................... 48

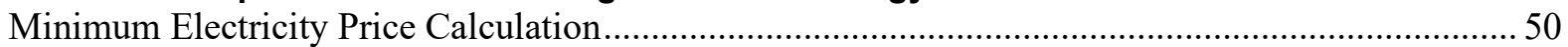

Energy Requirements for Direct Air Capture of Carbon Dioxide .................................................. 51

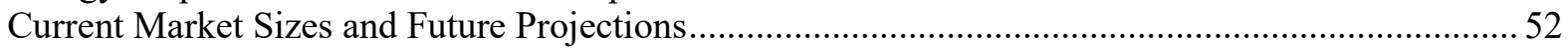

Block Flow Diagrams for Indirect E2M Pathways ..................................................................... 56 


\section{List of Figures}

Figure ES-1. Possible ranges of annual energy demand for various E2M systems and products via both direct electrochemical (using an electrochemical reactor to produce the products from water, carbon dioxide, and/or nitrogen) and indirect electrochemical (water splitting electrolysis to produce hydrogen and then traditional catalytic chemistry with hydrogen to produce the product) pathways viii

Figure 1. Projections for final energy consumed by sector in the United States, 2020-2050, with the divisions between electrical and nonelectrical energy demands shown across sectors ........... 1 Figure 2. Electrons to molecules initiative at the National Renewable Energy Laboratory ........... 3 Figure 3. Historical prices for fossil fuel feedstocks used in formation of fuels and chemicals ... 5 Figure 4. DOE H2@Scale concept ..................................................................................... 9 Figure 5. Natural gas consumed in the United States by sector, assuming 1,037 Btu/ $\mathrm{ft}^{3}$ of

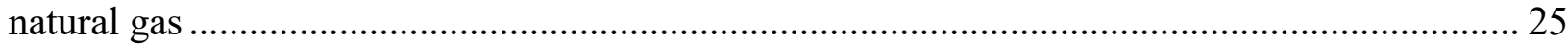

Figure 6. Ranges of electricity prices for selected E2M products for direct E2M pathways ....... 28

Figure 7. Price-duration curves for wholesale electricity at several locations .......................... 31 Figure 8. Cost of hydrogen produced via electrolysis at different capacity factors, using hourly

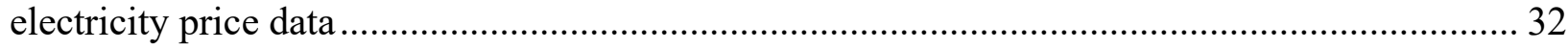

Figure 9. Modeled electricity generation for select electrolysis scenarios ............................. 34 Figure A-1. Block flow diagram for syngas production via RWGS and water electrolysis........ 56 Figure A-2. Block flow diagram for ethylene synthesis via methanol to olefins ...................... 57 Figure A-3. Block flow diagram for ethanol production via fermentation ............................... 57 Figure A-4. Block flow diagram for ethanol production via mixed alcohols synthesis .............. 58 Figure A-5. Block flow diagram for ethanol production via ethanol dehydration (Intratec 2013)

Figure A-6. Block flow diagram for methanol production via direct hydrogenation.................. 59

Figure A-7. Block flow diagram for methanol synthesis via syngas (Air Liquide 2021) ........... 59

Figure A-8. Block flow diagram for formic acid production via direct hydrogenation .............. 60

Figure A-9. Block flow diagram for formic acid production via Kemira-Leonard process ......... 60 Figure A-10. Block flow diagram for methane production via Sabatier and water electrolysis .. 61 


\section{List of Tables}

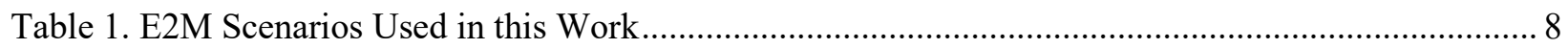

Table 2. E2M Hydrogen Market Metrics and PV Installed Capacity Required for Product Synthesis ...... 11

Table 3. Ammonia Market Metrics and PV Installed Capacity Required for Direct Electrochemical

Product Synthesis via Nitrogen Reduction Reaction ....................................................... 12

Table 4. Ammonia Market Metrics and PV Installed Capacity Required for Product Synthesis via Haber-

Bosch with Electrolytic Hydrogen .................................................................................... 13

Table 5. E2M CO Market Metrics and PV Installed Capacity Required for Direct Electrochemical Product

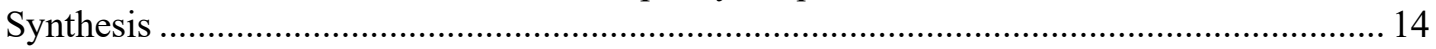

Table 6. E2M CO Market Metrics and PV Installed Capacity Required for Indirect E2M Product Synthesis .............................................................................................................. 15

Table 7. E2M Ethylene Market Metrics and PV Installed Capacity Required for Direct Electrochemical Product Synthesis ............................................................................................................. 16

Table 8. E2M Ethylene Market Metrics and PV Installed Capacity Required for Product Synthesis via Methanol Produced from Syngas .................................................................................... 17

Table 9. E2M Ethylene Market Metrics and PV Installed Capacity Required for Product Synthesis via Methanol Produced from CO2 .......................................................................................... 17

Table 10. E2M Ethylene Market Metrics and PV Installed Capacity Required for Product Synthesis via Ethanol Dehydration using Bioethanol ................................................................................ 18

Table 11. E2M Ethanol Market Metrics and PV Installed Capacity Required for Direct Electrochemical

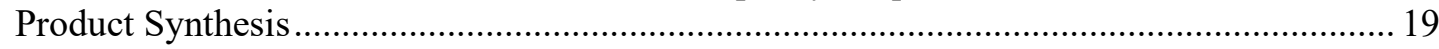

Table 12. E2M Ethanol Market Metrics and PV Installed Capacity Required for Product Synthesis via

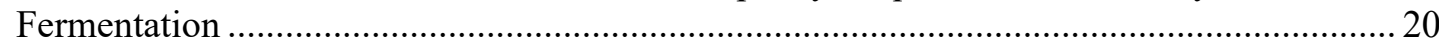

Table 13. E2M Ethanol Market Metrics and PV Installed Capacity Required for Product Synthesis via

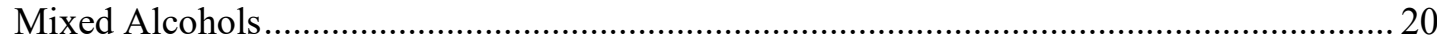

Table 15. E2M Methanol Market Metrics and PV Installed Capacity Required for Product Synthesis via

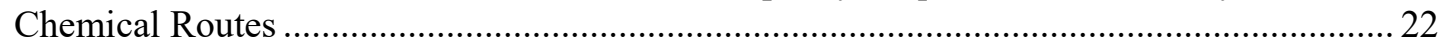

Table 16. E2M Formic Acid Market Metrics and PV Installed Capacity Required for Direct Electrochemical Product Synthesis ................................................................................... 23

Table 17. E2M Formic Acid Market Metrics and PV Installed Capacity Required for Product Synthesis via Direct Hydrogenation...................................................................................................... 24

Table 18. E2M Formic Acid Market Metrics and PV Installed Capacity Required for Product Synthesis

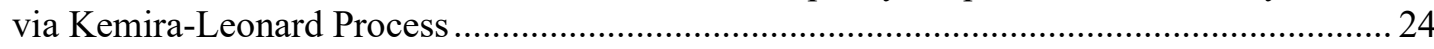

Table 19. E2M Methane Market Metrics and PV Installed Capacity Required for Direct Electrochemical Product Synthesis ....................................................................................................... 26

Table 20. E2M Methane Market Metrics and PV Installed Capacity Required for Product Synthesis via the Sabatier Reaction .............................................................................................. 27

Table 21. Summary of PV Generation and Capacity Required for E2M Synthesis of Key Chemicals and

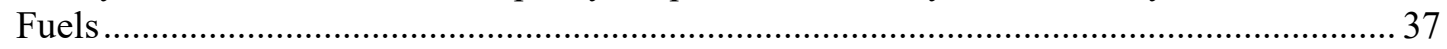

Table A-1. Performance Parameters for E2M Systems in Base and Future Cases .................................. 48

Table A-2. Performance Parameters for Conventional E2M Systems in Base and Future Cases .............. 49

Table A-3. Carbon Efficiencies for Conventional E2M Systems in Base and Future Cases..................... 52

Table A-4. Current and Projected Market Sizes for E2M Products .................................................... 52

Table A-5. Market Size Analysis for Hydrogen ............................................................................. 53

Table A-6. Market Size Analysis for Hydrogen Demands Identified in the Energy Decarbonization

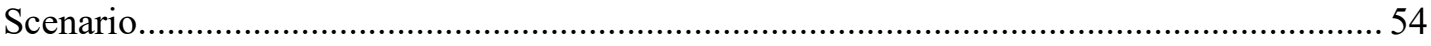

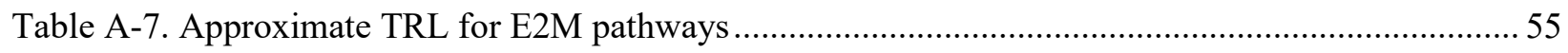




\section{Introduction}

Energy consumption takes on diverse forms among economic sectors, and electrical energy comprises a different portion of total energy used across the residential, commercial, industrial, and transportation sectors (EIA 2018). These sectors rely on electrical energy to meet lighting, heating, and cooling demands, which in turn comprise most of the final energy consumed among them. Electricity comprises smaller portions of energy consumed in the transportation and industrial sectors, where energy consumed is generally from hydrocarbon fuels and feedstocks in thermal and prime mover applications.

Final energy consumption scenarios from Regional Energy Deployment System modeling indicate that significant portions of total energy in 2020 and through 2050 will be consumed in the form of nonelectrical energy, even under scenarios with high electrification (Figure 1). Nonelectrical energy is used for applications that are difficult or expensive to electrify. These include aviation, marine, rail for shipping, and other long-drive cycle transportation needs. They also include installed space and water heating for buildings that do not turn over very often. Finally, the industrial sector is difficult to decarbonize because it both has heat requirements that are difficult to electrify economically (e.g., high temperatures, gas flow requirements for drying) and uses natural gas and oil as feedstocks for chemical products, including polymers, solvents, and other chemicals.
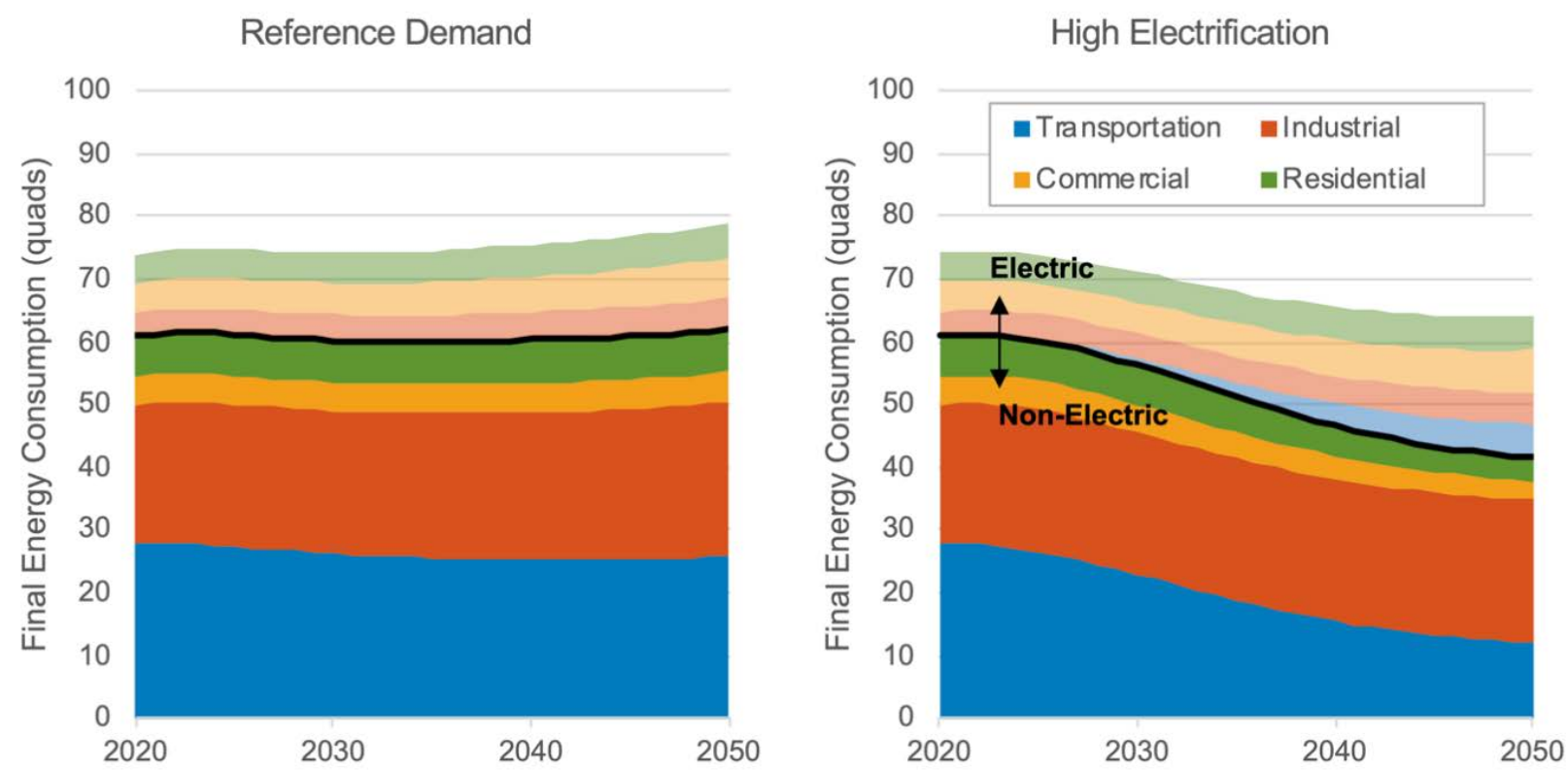

Figure 1. Projections for final energy consumed by sector in the United States, 2020-2050, with the divisions between electrical and nonelectrical energy demands shown across sectors

Results are shown for Reference and High-Electrification scenarios.

Source: Mai et al. 2021 
Evaluating the transportation and industrial sectors with respect to their contributions to annual greenhouse gas emission underscores the need for their decarbonization. For example, immediate and complete decarbonization of the electric power sector would yield an only $25 \%$ decrease in annual global emissions, as transportation, industry, and agriculture/land use comprise the remainder of greenhouse gases emitted worldwide annually (IPCC 2014). The development of pathways and technologies that enable decarbonization within these sectors is essential to meeting greenhouse gas reduction goals.

Several key areas in the industrial sector consume nonelectrical energy at high rates, including bulk chemicals, food, iron and steel, and petroleum refining (EIA 2020a). Therefore, development of systems that facilitate decarbonization of these areas remains a significant challenge (Davis et al. 2018; Kutscher, Logan, and Coburn 2020). In many cases these processes rely on natural gas for the production of high-grade heat or as a reactant in the formation of other molecules. Additionally, petroleum products and hydrocarbon gas liquids are used as chemical reactants in various processes (e.g., bulk chemicals). These energy needs cannot be directly met with electrons produced from solar photovoltaics (PV) or other renewables, which creates a unique challenge for decarbonization of these sectors that cannot be met with solar or wind power alone.

Moving toward a fully decarbonized economy requires significant investments in new and alternative infrastructure across multiple sectors of the economy. In this report in the Solar Futures Study series of reports, we focus on the potential interfaces between PV and the organic chemicals sector, and we analyze sustainable production pathways. Current supply chains for most of these products are linear rather than circular, and they rely primarily on fossil fuel feedstocks as the molecular basis for each product. Establishing sustainable supply chains for these processes is a twofold effort: circularity in feedstock supply is required and a decarbonized source of energy to power the process is needed. In nearly all the processes we consider, water is consumed either as a primary or secondary feedstock along with other molecules such as carbon dioxide. If these processes were to operate at widespread scale in the future, the water intensity of these process and how it compares to current supply chains should be analyzed in greater detail.

Here we identify products that can be produced via direct and indirect electrochemical conversion pathways that rely on electricity as a feedstock and thus can use energy from PV. We quantify electricity requirements to produce them at current market sizes and the resulting potential impact on the demand for solar energy. This review offers a systems level perspective - it focuses on using solar energy to increase the energy level of various molecules through electrochemical processing. It does not include an exhaustive review of the state of technology, advantages, and disadvantages of specific process designs; however, we acknowledge the degree to which reactor designs determine the scalability and manufactured costs of these systems. Additionally, siting considerations such as point-of-use applications and centralized systems are not considered here. 


\section{Electrons to Molecules as a Pathway for Electrification Across Sectors}

Electrons from PV can be transformed into other energy carriers, including hydrogen, methane, and other hydrocarbons (Haegel et al. 2019), which can in turn be used in the transportation and industrial sectors as chemicals and fuels. Here we analyze technologies that can transform solar electrons to molecules (E2M) that can then be used in sectors that conventionally consume nonelectrical energy. Numerous E2M technologies are emerging as potential pathways for transforming electrons from PV into useful fuels and chemicals, with most processes being able to use renewable electrons and basic molecular feedstocks to produce higher-value products (Figure 2) (NREL 2020b).
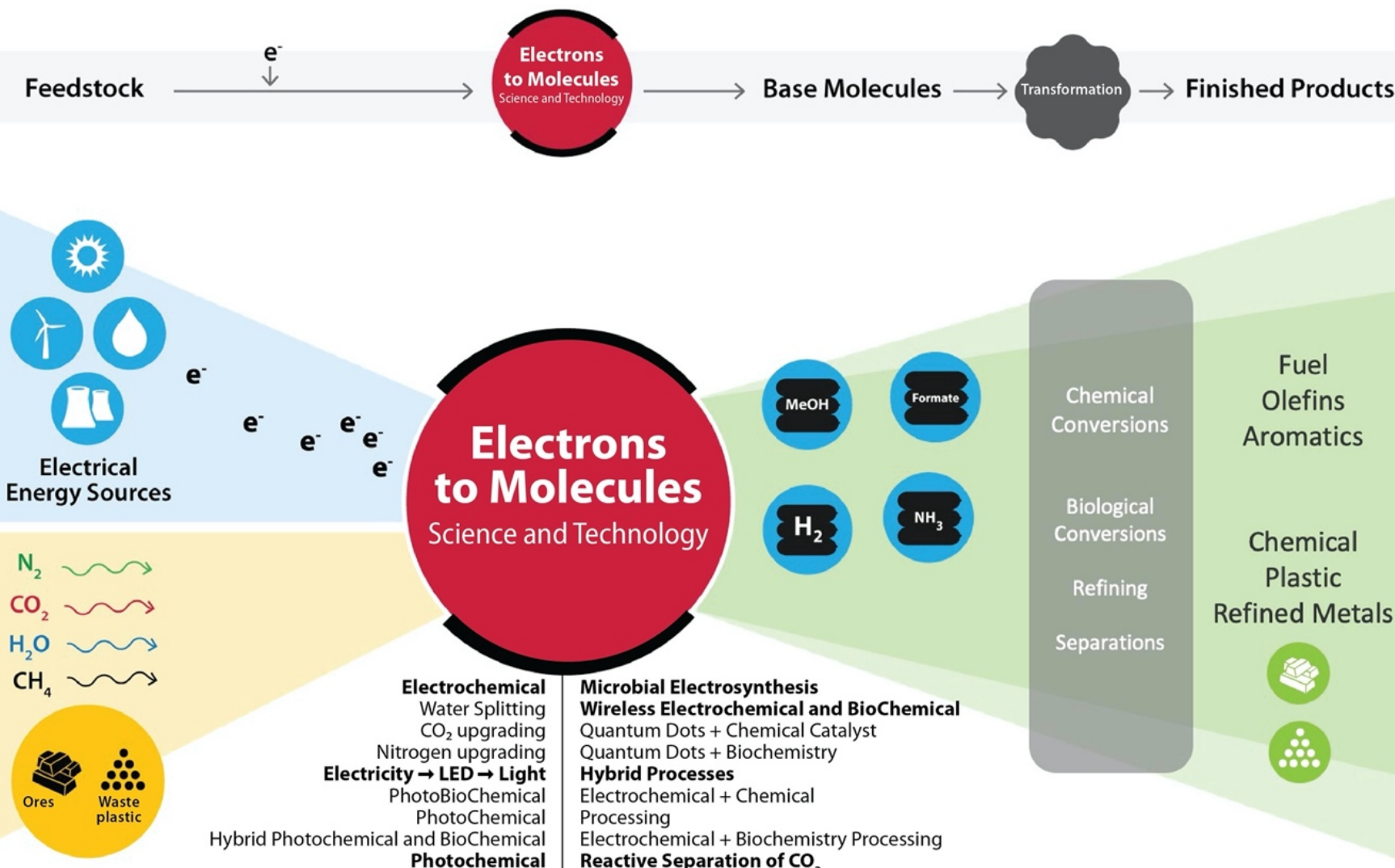

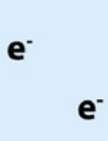

$\mathbf{e}^{-}$

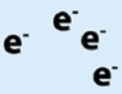

$\mathbf{e}^{-}$
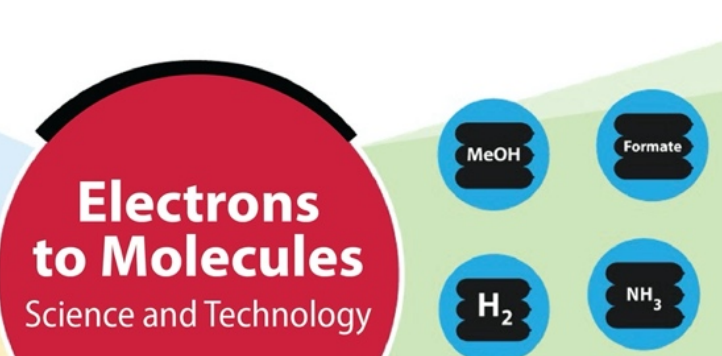

Conversions

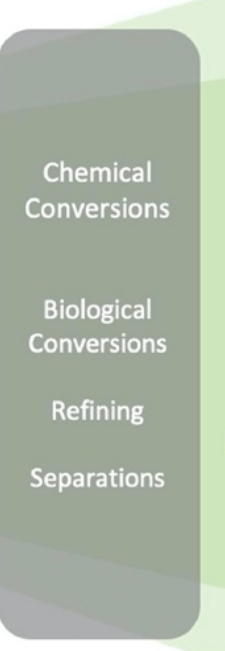

Fuel

Olefins

Aromatics

Chemical

Plastic Refined Metals

Figure 2. Electrons to molecules initiative at the National Renewable Energy Laboratory

Source: NREL 2020b

Possible conversion pathways include chemical, catalytic, biochemical, electrochemical, and other mechanisms. The ideal conversion process depends on the available feedstocks, energy supply, and desired products. Consequently, the carbon intensity of E2M products is affected by the carbon footprint of the technology supplying electricity to the process, which suggests renewable electricity is preferred for producing chemicals and fuels with lower lifecycle greenhouse gas emissions (Bhandari, Trudewind, and Zapp 2014; Khoo, Halim, and Handoko 2020). 
All the electrochemical processes in this work are assumed to operate at low temperatures $\left(<80^{\circ} \mathrm{C}\right)$. Several of the products reviewed here also can be produced by E2M pathways that operate at high temperatures. Hydrogen produced from high-temperature steam electrolysis consumes less electrical energy than low-temperature systems because of favorable thermodynamics and kinetics at high temperatures (Brisse, Schefold, and Zahid 2008). Carbon monoxide produced by high-temperature electrolysis of carbon dioxide $\left(\mathrm{CO}_{2}\right)$ is another emerging E2M platform that operates at temperatures greater than $80^{\circ} \mathrm{C}$ (Küngas 2020). These pathways show promise in economically competitive hydrogen and carbon monoxide synthesis. For the sake of consistency, we assume all electrochemical pathways operate at low temperatures; however, the emergence of high-temperature pathways is an important element of the emerging E2M sector.

Because electrochemical reactors directly consume electricity along with simple molecules like $\mathrm{CO}_{2}$ and $\mathrm{H}_{2} \mathrm{O}$, they have the potential to be suitable pathways for using energy from $\mathrm{PV}$ installations. Electrochemical reactors operate by applying an electrical potential to anode and cathode electrocatalysts, where reactants are supplied either in gaseous phase or in aqueous solution. Separate half reactions occur on the anode and cathode, with the net reaction reducing a reactant to the desired product. Electrocatalysts are separated by an ion exchange membrane, which allows either anions or cations to migrate from the anode to the cathode side of the reactor. Electrons flow between the electrodes and combine with ions and reactants to form the intended product.

The desired reaction determines the reactor architecture and catalytic materials, which in turn affect the capital cost of the reactor. Electrochemical reactors are operated with several different architectures, from small-scale experimental H-cell configurations to membrane electrode assemblies that are designed for sustained operation at high rates (Grim et al. 2019). The design of an electrochemical reactor depends on the desired reaction and scale of the system.

Historically, many of the products that can be produced from E2M technologies use fossil fuels and hydrocarbons as heat sources and chemical reactants. Feedstocks for these conventional processes have exhibited low market prices in recent years (EIA 2020h), which in turn has decreased the cost to produce chemicals and fuels in processes that use these feedstocks (Figure 3, page 5).

Low feedstock prices for conventional production pathways have created difficult market conditions for E2M technologies. In the absence of external market drivers, E2M technologies must generate products at prices comparable to those of existing production methods. The recent availability of low-cost natural gas and ethane, both common feedstocks for heat and chemical synthesis, has made this difficult. 


\section{Spot prices for hydrocarbon gas liquids, natural gas, and crude oil, January 2002-October 2020}

dollars per million British thermal units

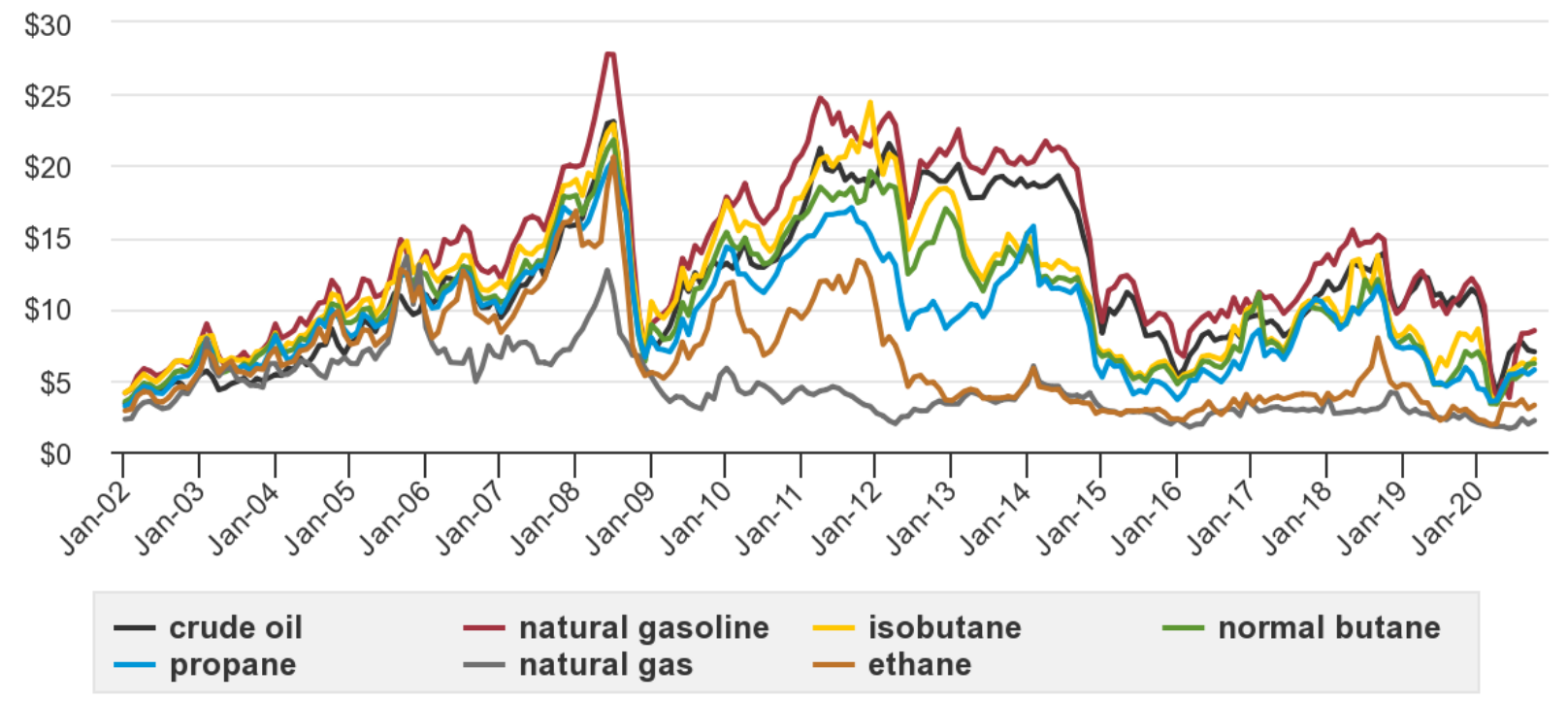

Note: Prices are monthly average of close-of-day spot prices; crude oil is Brent; natural gas is Henry Hub;

HGL products are at Mt. Belvieu non-LST (Lone Star Terminal).

Source: U.S. Energy Information Administration from Bloomberg

Figure 3. Historical prices for fossil fuel feedstocks used in formation of fuels and chemicals

Source: EIA 2020h 


\section{Potential Electrons to Molecules Products and Pathways}

In this section, we summarize the markets and conventional production methods for several key products that can be produced with E2M technologies. For each product, we summarize the direct single-step electrochemical pathways and any other indirect production pathways. Indirect pathways rely on electrochemical processes to supply an initial feedstock to the process (generally hydrogen, carbon monoxide, or syngas), coupling this step with catalytic processes to produce the desired molecule.

The potential E2M products presented here are an inexhaustive list of possible pathways for synthesis of fuels and chemicals using electricity. Though this report in the Solar Futures Study series of reports covers many of the key products with the largest market sizes, other products and opportunities do exist. As of 2019, the U.S. chemical industry shipped more than $\$ 550$ billion worth of products across multiple sectors (American Chemistry Council 2020); however the total market sizes and prices of the products discussed here is about $\$ 160$ billion, which suggests many more market opportunities for E2M exist than those discussed here. Other opportunities not captured here could include small market size, high-value products that are not currently targets for E2M synthesis.

The barriers to development of a particular E2M pathway are also related to the market size and performance of systems that are currently used to produce a target molecule. Products with extremely large existing markets will require a significant investment in E2M systems to meet the production rates of conventional processes. Existing production systems leverage economies of scale to offset the significant capital investment required to produce the chemicals or fuels. Though meeting these large market sizes represents a technical barrier to E2M, the existence of the large markets also provides more opportunities to exploit specialized markets for a product.

In each of the product-specific pathways we discuss in this report, we consider the current state of technology, barriers, and opportunities for the pathway. We conducted our pathway analyses independently of one another; however, it is important to note that the industrial sector is highly interconnected. A change in how a product is supplied in one sector could have downstream implications for other processes and products. For example, the ethylene supply chain is highly dependent on natural gas processing infrastructure to supply hydrocarbon gas liquid feedstocks. If ethylene production were to shift to an electrified process, demand for hydrocarbon gas liquids would be affected. Though we do not try to depict the complexities of this coupled system, such interactions are of important consideration for E2M deployment.

In addition to the barriers from performance of E2M systems, significant challenges exist with scaling experimental systems to industrially relevant throughputs. Understanding how materials, processes, and designs evolve as systems are scaled up is of notable interest in recent work (W. A. Smith et al. 2019; Endrödi et al. 2019), and further understanding of key challenges and opportunities will help enable development of E2M systems at scale.

Many sections of indirect electrochemical pathways are mature because they are currently in operation using natural gas feedstock instead of electrochemical hydrogen. Others (e.g., the 
Sabatier process for producing methane) were developed for commercial operations, but lowercost resources are available. Thus, barriers for the indirect electrochemical E2M pathways typically consist of efforts to intensify processes through improvements in energy efficiency and reductions in equipment size and cost. Innovation in catalyst performance and reactor design directly improve single pass conversions and thus result in reduced capital and operating costs. These efforts are especially relevant for $\mathrm{CO}_{2}$ hydrogenation pathways, which typically have lower levels of technical maturity than conventional routes. Process intensification efforts for reverse water gas shift (RWGS) systems that produce $\mathrm{CO}$ is also of significant importance for pathways that use syngas from $\mathrm{CO}_{2}$. The cost of producing syngas through RWGS is currently significantly higher than that of dry and steam methane reforming processes because of the high cost of hydrogen from water electrolysis. Efforts to reduce the RWGS system cost and electrolytic hydrogen costs will play an important role in the long-term adoption of low-carbon indirect E2M pathways.

Many different products and pathways exist within the E2M space. Technical maturity of the E2M technologies depicted here range from commercial to early stage research and development (R\&D), but the products and pathways discussed here are not intended to be an exhaustive list of either the products or pathways to products possible though E2M. In this analysis, we consider products that exhibit the largest market sizes and the E2M pathways that are nearest to commercial deployment. This list provides a high-level perspective of the noteworthy potential both for PV and E2M systems that exist in this space.

For most pathways, products are synthesized using $\mathrm{CO}_{2}$ as a carbon source. We acknowledge the barriers to securing a reliable and high-concentration source of $\mathrm{CO}_{2}$. For our analysis, we assume direct air capture is used to provide all $\mathrm{CO}_{2}$ used in the process. Direct air capture systems typically use solid sorbents or aqueous basic solutions to remove $\mathrm{CO}_{2}$ from air. The energy cost to capture $\mathrm{CO}_{2}$ via direct air capture are included in our electrical production efficiency estimates. Specifically, we use estimates from Carbon Engineering's aqueous-based industrial design that was developed based on their pilot plant facility (Keith et al. 2018). 0.1 megapascal (MPa) $\mathrm{CO}_{2}$ is produced using 5.25 gigajoules (GJ) of natural gas per ton $\mathrm{CO}_{2}$ and 77 kilowatthours $(\mathrm{kWh})$ of grid electricity per ton $\mathrm{CO}_{2}$. Natural gas is currently used for heating and fluidization in the calciner. Assuming electric heat is $95 \%$ efficient, $5.25 \mathrm{GJ} /$ ton- $\mathrm{CO}_{2}$ at $78 \%$ thermal efficiency is equivalent to $4.31 \mathrm{GJ} /$ ton- $\mathrm{CO}_{2}$ of electricity. Electrification of the calciner is feasible and is currently being researched by Carbon Engineering. The total electrical load to capture $\mathrm{CO}_{2}$ with the electrification of heat is $1,274 \mathrm{kWh} /$ ton- $\mathrm{CO}_{2}$.

For some pathways, we assume the product is synthesized in a single-step electrochemical process, while other pathways include multiple processes and a single E2M step. Though producing all the possible products via E2M is possible and is actively being researched, we acknowledge E2M processes at industrially relevant scales might not operate in the same way as is projected here. The estimates shown in Tables 2-20 should be considered order-of-magnitude estimates of the electrical energy and PV capacity needed to synthesize a given product via a particular pathway. Detailed analyses of specific technology pathways and products would be needed to develop estimates of the exact energy required.

The electrical energy and PV capacity requirements shown in this report are subject to numerous assumptions about the total demand for a product and the electrical efficiency of producing that 
product from a given E2M pathway. Several different scenarios reflect variation in these estimates for current, future, and decarbonized industrial systems (Table 1). Further information regarding assumptions and methodologies used in these scenarios can be found in each E2M product section (Sections 3.1-3.8) and the appendix.

For each combination of product and pathway we review in the following sections (e.g., hydrogen via water electrolysis in Section 3.1), we summarize key market characteristics in a table at the end of the section. Along with values on the market size and the current market prices in dollars per kilogram $(\$ / \mathrm{kg})$ for each product, the estimated electricity required to meet current market size with E2M production pathways is estimated (see the appendix). When data permit, a Base and an Optimistic scenario are presented (Table 1), where the Base scenario uses existing E2M performance parameters and the Optimistic scenario assumes advances in efficiency and selectivity of the E2M system, which would in turn lower the amount of electricity needed to produce the same amount of product.

Readers should note that not all E2M products and pathways have results for the Energy Decarbonization scenario. This scenario was developed to depict deep decarbonization in sectors beyond the core Solar Futures Study scenarios (Mai et al. 2021), but it does not consider products beyond those used for energy (e.g., it does not consider fossil use for polymers). Though E2M-based synthesis of those products could result in additional electrical loads, robust analysis of these pathways is beyond the scope of the Energy Decarbonization scenario. It estimates the use of biofuels, synthetic hydrocarbon fuels, hydrogen, methanol, and ammonia across different sectors of the economy. Though synthetic hydrocarbon fuels are based on methanol feedstocks, the methanol required to create these fuels is not considered in methanol demand estimates in this report. Biofuels are included in indirect hydrogen demand estimates.

Table 1. E2M Scenarios Used in this Work

\begin{tabular}{|l|l|}
\hline Scenario & Description \\
\hline Base & $\begin{array}{l}\text { - Uses current market sizes for each product molecule and current production } \\
\text { efficiency for each E2M pathway } \\
\text { - Uses current market price for each product }\end{array}$ \\
\hline Optimistic & $\begin{array}{l}\text { - Estimates potential future market sizes for products based on current market } \\
\text { sizes and annual growth rates from literature } \\
\text { - Optimistically increases E2M production efficiencies from those in the } \\
\text { Base scenario (see the appendix) }\end{array}$ \\
\hline Energy & $\begin{array}{l}\text { - Uses estimates for energy and transportation sector decarbonization as } \\
\text { discussed in the Solar Futures Study transportation (Ardani et al. 2021) and } \\
\text { scenarios (Mai et al. 2021) reports. } \\
\text { - Does not consider demand for products not directly used in the energy sector } \\
\text { (e.g., ethylene for plastics production or formate used in the organic chemicals } \\
\text { sector) }\end{array}$ \\
\hline
\end{tabular}

\subsection{Hydrogen}

Molecular hydrogen $\left(\mathrm{H}_{2}\right)$ is an energy carrier that can be produced from renewable energy through water electrolysis. Hydrogen is currently produced in significant quantities for use across multiple industries, including as a transportation fuel, long-duration energy storage, and in 
various industrial processes. The U.S. Department of Energy (DOE 2020) developed the H2@Scale concept to explore the full potential of hydrogen across sectors of the economy (Figure 4).

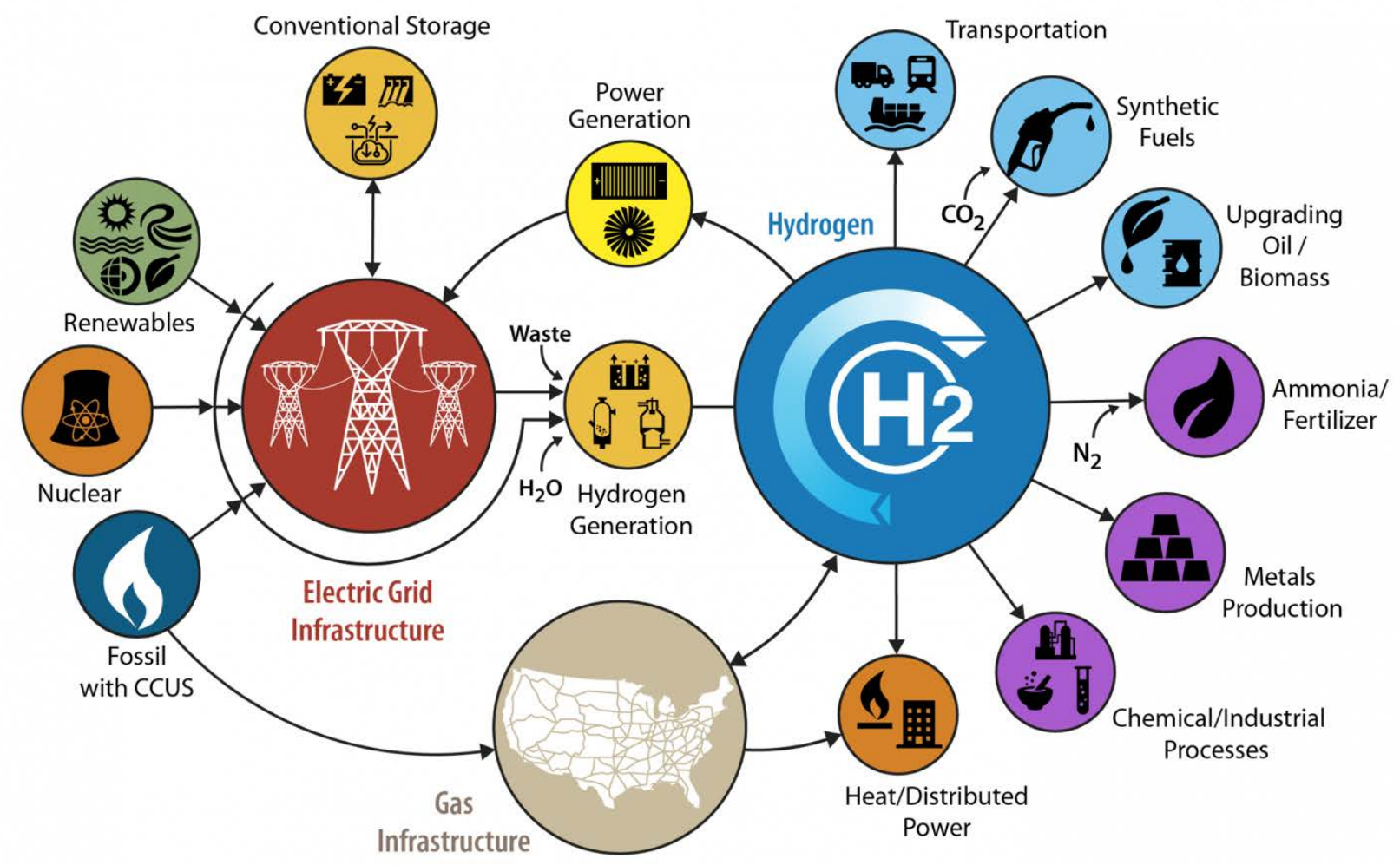

Figure 4. DOE H2@Scale concept

Source: “H2@Scale," DOE, https://www.energy.gov/eere/fuelcells/h2scale

CCUS $=$ carbon capture and storage

Hydrogen can be produced by multiple technologies, which have varying degrees of technical maturity. Today, most hydrogen is produced by steam methane reforming of natural gas, as it offers the most economic means of producing hydrogen at large scales. Steam methane reforming is a catalytic process that converts natural gas and steam to $\mathrm{CO}_{2}$ and hydrogen (Ruth et al. 2020). Centrally produced hydrogen could be integrated into existing downstream infrastructure for transportation and storage.

Electrolysis of water is an emerging production pathway to generate hydrogen using water and electricity and thus reduce reliance on natural gas. Water electrolysis is a direct electrochemical pathway that uses electricity to split water into hydrogen and oxygen (Equation 1). Hydrogen production from electrolysis could represent a significant source of demand for electricity, driven by the large market sizes and high amount of electricity required per kilogram of hydrogen (Table 2, page 11):

$$
\mathrm{H}_{2} \mathrm{O} \rightarrow \frac{1}{2} \mathrm{O}_{2}+\mathrm{H}_{2}
$$


Hydrogen can be produced via water electrolysis using renewable energy — and without using fossil fuels. Of potential hydrogen production technologies, water electrolysis powered by renewable energy is currently the preferred option from an environmental life cycle perspective (Bhandari, Trudewind, and Zapp 2014); however, hydrogen produced via water electrolysis exhibits higher costs than steam methane reforming in the United States because natural gas costs are low.

Costs for hydrogen from electrolysis are driven by high electrolyzer capital costs and electricity prices. Research efforts aim to decrease electricity costs by selective operation of water electrolyzers when renewable energy is low-cost (Ruth et al. 2019b). Capital costs have decreased in recent years, and they are expected to continue decreasing as market penetration increases and R\&D efforts result in performance gains (Schmidt, Gambhir, et al. 2017; Schmidt, Hawkes, et al. 2017). Cost decreases are generally expected to be driven by (1) reductions in material requirements, (2) achievement of manufacturing economies of scale in electrolyzer manufacturing (Mayyas et al. 2019), and (3) reductions in cost from learning-by-doing as facilities are constructed at scale (Badgett et al. 2021). Additionally, balance-of-plant costs such as those related to site engineering, switch gear, rectifiers, and chillers and cooling towers are significant, and these cost items need design development.

Significant market opportunities exist for hydrogen in both existing and emerging market applications. Existing applications, including oil refining and ammonia production comprise about 10 million tonnes per year ( $\mathrm{t} / \mathrm{yr}$ ) of on-purpose hydrogen production (Ruth et al. 2020). Expanding demand to emerging markets such as fuel cell electric vehicles, energy storage, and synthetic hydrocarbons has the potential to increase potential U.S. demand to over 100 million t/yr (Ruth et al. 2020).

Several different hydrogen market and technical scenarios were developed as part of the analysis for this report and the broader the Solar Futures Study to understand the potential applications and opportunities for hydrogen in the future energy system (Table 2). These scenarios are listed in Table 2 (page 11), depicting current and future potential for hydrogen market demands and technology efficiencies. The Base scenario depicts existing market demand for hydrogen (primarily from petroleum refining and other industrial processes) and the current state of technology for production efficiency.

For the Optimistic scenario, we use a hydrogen market size of 58 million $\mathrm{t} / \mathrm{yr}$. This estimate is adapted from a recent H2@Scale economic analysis (Ruth et al. 2020) where the hydrogen demand for the lowest-cost electrolysis scenario is 41 million $\mathrm{t} / \mathrm{yr}$ (see the appendix). The baseline involves specific assumptions on the adoption of hydrogen and electric vehicles and industry. The transportation report in the Solar Futures Study series of reports (Ardani et al. 2021) includes more aggressive assumptions for use of hydrogen in fuel cell vehicles and for synthetic fuels and ammonia that are produced using hydrogen. Modifications to hydrogen demand are reported in the appendix (Table A-3).

Potential hydrogen demand from the Solar Future Study's Energy Decarbonization scenario is also shown in Table 2, which represents additional demand across other sectors of the economy, including transportation, industry, and use of hydrogen in renewable energy combustion turbines in the electric power sector; see the appendix for detailed assumptions regarding hydrogen 
demand in these sectors and the companion Solar Futures Study scenarios report (Mai et al. 2021) for a summary of the Energy Decarbonization scenario methodology.

Included within the hydrogen market size estimate for the Energy Decarbonization scenario is hydrogen used for the production of synthetic hydrocarbon fuels, biofuels, ammonia, and methanol. In these use cases, hydrogen is produced from water electrolysis and used as an input to the production of the fuel or product. This hydrogen is segmented as indirect hydrogen demand in Table 2, while direct use hydrogen such as that used for transportation is also quantified. The total of direct and indirect hydrogen demand for the Energy Decarbonization scenario is shown in the last row of Table 2.

In the Energy Decarbonization scenario, hydrogen also provides dispatchable electricity generation using fuel cells or renewable energy combustion turbines as described in the companion Solar Futures Study scenarios report (Mai et al. 2021). Effectively, this option uses hydrogen as long-duration (seasonal) energy storage; hydrogen is produced when generation exceeds the load and battery storage charging availability and provides the necessary energy source when a dispatchable generation option is needed because of seasonal mismatches of renewable energy generation and demand and the potential to provide energy during occasional extreme weather events.

Potential demand for hydrogen estimated in the Energy Decarbonization scenario represents a significant increase from the Base scenario, illustrating the significant potential for hydrogen in a decarbonized energy system. Hydrogen can provide support across multiple economic sectors, including industry and transportation, thus offering pathways to decarbonizing end uses that cannot be easily electrified.

Table 2. E2M Hydrogen Market Metrics and PV Installed Capacity Required for Product Synthesis

\begin{tabular}{|c|c|c|c|c|c|}
\hline Scenario & $\begin{array}{l}\text { U.S. Market } \\
\text { Size } \\
\text { (million t/yr) }\end{array}$ & $\begin{array}{l}\text { Current } \\
\text { Market } \\
\text { Price } \\
(\$ / \mathbf{k g})^{\mathrm{a}, \mathrm{b}}\end{array}$ & $\begin{array}{l}\text { Electrical } \\
\text { Production } \\
\text { Efficiency } \\
\text { (kWh/kg) }^{\mathrm{c}}\end{array}$ & $\begin{array}{l}\text { Electricity } \\
\text { Demand to } \\
\text { Meet } 100 \% \\
\text { of Market } \\
\left(^{(T W h / y)^{c}}\right.\end{array}$ & $\begin{array}{l}\text { PV Capacity } \\
\text { Required to } \\
\text { Meet } \\
\text { Additional } \\
\text { Load (GW)c }\end{array}$ \\
\hline Base & $10^{d}$ & 1.40 & 51 & 505 & 230 \\
\hline Optimistic & $58^{e}$ & 1.40 & 41 & 2,360 & 1,073 \\
\hline $\begin{array}{l}\text { Direct Hydrogen Energy } \\
\text { Decarbonization }\end{array}$ & 24 & \multirow{3}{*}{$\mathrm{n} / \mathrm{a}$} & 41 & 960 & 437 \\
\hline $\begin{array}{l}\text { Indirect Hydrogen } \\
\text { Energy Decarbonization }\end{array}$ & 41 & & 41 & 1,654 & 752 \\
\hline $\begin{array}{l}\text { Total Energy } \\
\text { Decarbonization }\end{array}$ & 64 & & 41 & 2,614 & 1,189 \\
\hline
\end{tabular}

a Assumes gray hydrogen (from steam methane reforming with carbon capture and storage) price

b Recharge News 2020

c See the appendix for detailed calculations.

d Connelly, Elgowainy, and Ruth 2019

e See the appendix for detailed demand assumptions for this scenario. 


\subsection{Ammonia}

Ammonia $\left(\mathrm{NH}_{3}\right)$ is a gaseous molecule composed of nitrogen $\left(\mathrm{N}_{2}\right)$ and hydrogen. It is used across multiple industries, from fertilizer production to the production of chemicals, explosives, and plastics. Ammonia, which can store hydrogen and be transported from point of generation to the final consumer, also has potential applications as an energy carrier (Lan, Irvine, and Tao 2012). About 16 million $\mathrm{t} / \mathrm{yr}$ of ammonia is consumed annually in the United States, with $88 \%$ of that being consumed as a fertilizer (USGS 2020). Traditionally, ammonia is produced via the Haber-Bosch process, using $\mathrm{H}_{2}$ and $\mathrm{N}_{2}$ as chemical reactants in the presence of a metal catalyst under high pressure and temperature (Equation 2) (S. Chen et al. 2019).

$$
\mathrm{N}_{2}+3 \mathrm{H}_{2} \rightarrow 2 \mathrm{NH}_{3}
$$

Ammonia can be produced with less greenhouse gas emissions via several alternative processes. Hydrogen that is used in existing Haber-Bosch production processes can be supplied by water electrolysis, which is powered by solar energy (X. Liu, Elgowainy, and Wang 2020). Such a system would require minimal modification to existing ammonia supply chains. Ammonia can also be produced directly from the electrochemical nitrogen reduction reaction (Zhao et al. 2019) (Table 3). An electrochemical nitrogen reduction reaction avoids some of the significant heat and pressure demands of the Haber-Bosch process, which in turn reduces the environmental impacts of conventional ammonia synthesis (Zhao et al. 2019; Andersen et al. 2019).

Table 3. Ammonia Market Metrics and PV Installed Capacity Required for Direct Electrochemical Product Synthesis via Nitrogen Reduction Reaction

\begin{tabular}{|c|c|c|c|c|c|}
\hline Scenario & $\begin{array}{l}\text { U.S. Market } \\
\text { Size } \\
\text { (million t/yr) }\end{array}$ & $\begin{array}{l}\text { Current } \\
\text { Market } \\
\text { Price }(\$ / k g)^{a}\end{array}$ & $\begin{array}{l}\text { Electrical } \\
\text { Production } \\
\text { Efficiency } \\
(\mathbf{k W h} / \mathbf{k g})^{\mathbf{b}}\end{array}$ & $\begin{array}{l}\text { Electricity } \\
\text { Demand to } \\
\text { Meet } 100 \% \\
\text { of Market } \\
(\mathrm{TWh} / \mathrm{y})^{\mathrm{b}}\end{array}$ & $\begin{array}{l}\text { PV capacity } \\
\text { Required to } \\
\text { Meet } \\
\text { Additional } \\
\text { Load (GW) }\end{array}$ \\
\hline Base & $13^{a}$ & 0.25 & 35 & 433 & 197 \\
\hline Optimistic & $16^{b}$ & 0.25 & 22 & 343 & 156 \\
\hline Energy Decarbonization ${ }^{\mathrm{c}}$ & \multicolumn{5}{|c|}{$\mathrm{n} / \mathrm{a}$} \\
\hline
\end{tabular}

a IHS 2021; used with permission provided March 16, 2021

b See the appendix for detailed calculations.

c Ammonia included in the Energy Decarbonization scenario is assumed to be produced with electrolytic hydrogen in the Haber-Bosch process, which is not a direct electrochemical process.

Ammonia production from Haber-Bosch relies on hydrogen, and water electrolysis could supply that hydrogen. Water electrolysis, being more efficient than direct electrochemical ammonia production, decreases the electrical energy required for this pathway. Electrical energy for the separation of $\mathrm{N}_{2}$ from air and compression is estimated to be $0.75 \mathrm{kWh} / \mathrm{kg} \mathrm{NH}_{3}$ (C. Smith, Hill, and Torrente-Murciano 2020). The PV installed capacity for ammonia produced through the Haber-Bosch process is presented in Table 4. PV capacity is used solely for the electrolytic production of hydrogen and does not include any energy requirements from the Haber-Bosch process itself.

Ammonia produced in the Energy Decarbonization scenario is used for decarbonization of domestic and international shipping, in addition to other industrial applications. These additional 
demands result in a significant increase in market size and a corresponding increase in electricity demand and PV capacity to meet these demands. Ammonia produced in the Energy Decarbonization scenario is assumed to be produced using electrolytic hydrogen in the HaberBosch process.

Table 4. Ammonia Market Metrics and PV Installed Capacity Required for Product Synthesis via Haber-Bosch with Electrolytic Hydrogen

\begin{tabular}{|c|c|c|c|c|c|}
\hline Scenario & $\begin{array}{l}\text { U.S. Market } \\
\text { Size } \\
\text { (million t/yr) }\end{array}$ & $\begin{array}{l}\text { Current } \\
\text { Market } \\
\text { Price }(\$ / k g)^{a}\end{array}$ & $\begin{array}{l}\text { Electrical } \\
\text { Production } \\
\text { Efficiency } \\
(\mathbf{k W h} / \mathbf{k g})^{\mathbf{b}}\end{array}$ & $\begin{array}{l}\text { Electricity } \\
\text { Demand to } \\
\text { Meet } 100 \% \\
\text { of Market } \\
(\mathrm{TWh} / \mathrm{y})^{\mathrm{b}}\end{array}$ & $\begin{array}{l}\text { PV capacity } \\
\text { Required to } \\
\text { Meet } \\
\text { Additional } \\
\text { Load (GW) }^{\text {b }}\end{array}$ \\
\hline Base & $13^{a}$ & 0.25 & 10 & 130 & 59 \\
\hline Optimistic & $16^{b}$ & 0.25 & 10 & 160 & 73 \\
\hline Energy Decarbonization ${ }^{c}$ & 47 & $\mathrm{n} / \mathrm{a}$ & 10 & 470 & 214 \\
\hline
\end{tabular}

a IHS 2021; used with permission provided March 16, 2021

b See the appendix for detailed calculations.

c See the appendix for detailed demand assumptions for this scenario.

\subsection{Carbon Monoxide}

Carbon monoxide (CO) has numerous industrial applications. The most common are formation of acetic acid via methanol catalytic carbonylation and formic acid production via methyl formate hydrolysis (Küngas 2020). Carbon monoxide can be used in its pure form or as syngas, which is a mixture of $\mathrm{CO}$ and $\mathrm{H}_{2}$.

Carbon monoxide is conventionally produced by coal gasification, steam reforming of natural gas, or partial oxidation of hydrocarbons (Bierhals 2001). These processes generally produce gas mixtures containing $\mathrm{CO}$, and thus require downstream purification depending on the end use. In the U.S. market size estimates presented in Table 5 (page 14), we consider CO that is used as an input to the production of acetic acid via methanol carbonylation. Though other sources and production of CO exist, they are generally site-specific production with small market sizes and production data are not readily available. Given the varied and small applications for CO, it was not included in the Energy Decarbonization scenario.

Carbon monoxide can also be produced by electrochemical carbon dioxide reduction $\left(\mathrm{CO}_{2} \mathrm{R}\right)$. $\mathrm{CO}_{2} \mathrm{R}$ reactors are constructed and operated much like water electrolyzers; however, $\mathrm{a} \mathrm{CO}_{2}$ reduction reaction takes place on the cathode instead of the hydrogen evolution reaction. We assume the oxygen evolution reaction takes place on the anode, providing protons or hydroxide ions to complete the reaction. Water and electrons reduce $\mathrm{CO}_{2}$ into $\mathrm{CO}$ as shown in Equation 3, which assumes an alkaline $\mathrm{CO}_{2} \mathrm{R}$ reactor.

$$
\mathrm{CO}_{2}+\mathrm{H}_{2} \mathrm{O}+2 \mathrm{e}^{-} \rightarrow \mathrm{CO}+2 \mathrm{OH}^{-}
$$

In addition to evaluating direct $\mathrm{CO}_{2} \mathrm{R}$ to $\mathrm{CO}$, recent research has investigated the potential for two-stage electrochemical reactors, where $\mathrm{CO}_{2}$ is reduced to $\mathrm{CO}$, which is again reduced to other C-based molecules (Jouny, Luc, and Jiao 2018a; Luc et al. 2019). Using a two-stage system 
allows for the reduction of $\mathrm{CO}_{2}$ and $\mathrm{CO}$ to operate at higher current densities and selectivities, thus improving the performance of transforming $\mathrm{CO}_{2}$ into $\mathrm{C}_{2}+$ products (Jouny, Hutchings, and Jiao 2019).

Table 5. E2M CO Market Metrics and PV Installed Capacity Required for Direct Electrochemical Product Synthesis

\begin{tabular}{|c|c|c|c|c|c|}
\hline Scenario & $\begin{array}{l}\text { U.S. Market } \\
\text { Size } \\
\text { (million t/yr) }\end{array}$ & $\begin{array}{l}\text { Current } \\
\text { Market } \\
\text { Price }(\$ / k g)^{a}\end{array}$ & $\begin{array}{l}\text { Electrical } \\
\text { Production } \\
\text { Efficiency } \\
(\mathbf{k W h} / \mathbf{k g})^{\mathbf{b}}\end{array}$ & $\begin{array}{l}\text { Electricity } \\
\text { Demand to } \\
\text { Meet } 100 \% \\
\text { of Market } \\
(T W h / y)^{b}\end{array}$ & $\begin{array}{l}\text { PV Capacity } \\
\text { Required to } \\
\text { Meet } \\
\text { Additional } \\
\text { Load (GW) }^{\text {b }}\end{array}$ \\
\hline Base & $1.8^{\mathrm{c}}$ & 0.18 & 8 & 14 & 6 \\
\hline Optimistic & $2.1^{\mathrm{b}}$ & 0.18 & 5 & 11 & 5 \\
\hline Energy Decarbonization & \multicolumn{5}{|c|}{$\mathrm{n} / \mathrm{a}$} \\
\hline
\end{tabular}

a Grim et al. 2019

${ }^{b}$ Includes energy requirements for direct air capture of $\mathrm{CO}_{2}$; see the appendix for detailed calculations and assumptions.

${ }^{c}$ Market size estimate assumes $\mathrm{CO}$ is used in the methanol carbonylation reaction to form acetic acid, using the $\mathrm{CO}$ in the reaction.

Carbon monoxide can also be produced indirectly through the RWGS. This reaction typically takes place over iron and copper-based catalysts in a packed bed reactor (Pastor-Pérez et al. 2017; Saeidi, Amin, and Rahimpour 2014). The RWGS reaction is equilibrium-limited and endothermic and thus requires higher operating temperatures. RWGS is generally in competition with forward water gas-shift reaction (Equation 4) and $\mathrm{CO}_{2}$ methanation (Equation 5). Increasing the ratio of $\mathrm{H}_{2} / \mathrm{CO}_{2}$ feed has been shown to increase the $\mathrm{CO}_{2}$ conversion to $\mathrm{CO}$ (Loiland et al. 2016; Daza and Kuhn 2016). Thus, catalyst performance depends on catalyst composition, feed $\mathrm{H}_{2} / \mathrm{CO}_{2}$ ratio, space velocity, and operating temperature. Carbon monoxide selectivity typically reaches 99\% (Pastor-Pérez et al. 2017; Saeidi, Amin, and Rahimpour 2014; Loiland et al. 2016; Daza and Kuhn 2016; Abney et al. 2016), while single pass $\mathrm{CO}_{2}$ conversions range from $1 \%$ to $60 \%$ for various catalyst compositions and operating conditions. For many CO-based product pathways, downstream reactors typically operate at lower temperatures $\left(100^{\circ} \mathrm{C}-450^{\circ} \mathrm{C}\right)$, as in the case of methanol and Fisher-Tropsch products. Thus, it is ideal to select catalysts designed to operate at lower temperatures.

$$
\begin{aligned}
& \mathrm{CO}_{2}+\mathrm{H}_{2} \rightarrow \mathrm{CO}+\mathrm{H}_{2} \mathrm{O} \Delta \mathrm{H}^{\mathrm{o}}{ }_{298 \mathrm{k}}=+41 \mathrm{~kJ} \mathrm{~mol}^{-1} \\
& \mathrm{CO}_{2}+4 \mathrm{H}_{2} \rightarrow \mathrm{CH}_{4}+2 \mathrm{H}_{2} \mathrm{O} \Delta \mathrm{H}^{\mathrm{o}}{ }_{298 \mathrm{k}}=-165 \mathrm{~kJ} \mathrm{~mol}^{-1}
\end{aligned}
$$

Hydrogen used in RWGS reactions could be produced through water electrolysis powered by PV. Water in the RWGS product stream is typically removed through a condenser, and additional separation might be required for unconverted $\mathrm{CO}_{2}$, depending on the product. The $\mathrm{CO}$ product stream may also be mixed with additional hydrogen to produce syngas for different product pathways. The amount of hydrogen required to meet $\mathrm{CO}$ market demand is evaluated assuming sufficient $\mathrm{CO}_{2}$ is available, $\mathrm{CO}$ selectivity is $100 \%$, and the stoichiometric molar $\mathrm{H}_{2}$ to CO ratio is 1 (Whitlow 2003; C. M. Liu et al. 2020). Typically, the $\mathrm{H}_{2}$ to $\mathrm{CO}_{2}$ ratios required to promote the RWGS reaction or to produce a specific syngas composition range from 1 to 4 (Pastor-Pérez et al. 2017; Samimi, Hamedi, and Rahimpour 2019; Dzuryk and Rezaei 2020; 
Knighton et al. 2020; C. M. Liu et al. 2020). The Base scenario electric production efficiency for the indirect chemical pathway is significantly lower than the current state of art for the direct electrochemical pathway. With higher selectivity for $\mathrm{CO}$, the electrochemical production efficiency becomes lower (i.e., less energy is consumed per kilogram of product) than that of the chemical pathway (Table 6).

Table 6. E2M CO Market Metrics and PV Installed Capacity Required for Indirect E2M Product Synthesis

\begin{tabular}{|l|c|l|l|l|l|}
\hline Scenario & $\begin{array}{l}\text { U.S. Market } \\
\text { Size } \\
\text { (million t/yr) }\end{array}$ & $\begin{array}{l}\text { Current } \\
\text { Market } \\
\text { Price } \mathbf{( \$ / k g )})^{\mathbf{a}}\end{array}$ & $\begin{array}{l}\text { Electrical } \\
\text { Production } \\
\text { Efficiency } \\
(\mathbf{k W h} / \mathbf{k g})^{\mathbf{b}}\end{array}$ & $\begin{array}{l}\text { Electricity } \\
\text { Demand to } \\
\text { Meet 100\% } \\
\text { of Market } \\
\mathbf{( T W h / y ) ~}^{\mathbf{b}}\end{array}$ & $\begin{array}{l}\text { PV Capacity } \\
\text { Required to } \\
\text { Meet } \\
\text { Additional } \\
\text { Load (GW) }\end{array}$ \\
\hline Base & $1.8^{\mathrm{b}}$ & 0.18 & 6 & 10 & 5 \\
\hline Energy Decarbonization & \multicolumn{5}{|c|}{$\mathrm{n} / \mathrm{a}$} \\
\hline
\end{tabular}

a Grim et al. 2019

${ }^{b}$ Includes energy requirements for direct air capture of $\mathrm{CO}_{2}$; see the appendix for detailed calculations and assumptions.

In addition to considering advancements in RWGS catalyst performance, recent research has focused on intensifying the RWGS process because of its low equilibrium constant and poorer $\mathrm{CO}_{2}$ conversions at high space velocities. Packed bed membrane reactors have been investigated as the removal of produced water shifts the equilibrium to the right and removes the need for downstream water separation units (Samimi, Hamedi, and Rahimpour 2019; Dzuryk and Rezaei 2020). Also, NASA has investigated Precision Combustion Inc's RWGS reactor prototype based on patented Microlith technology to address issues such as reactor size and heat transfer associated with conventional RWGS reactors (Vilekar et al. 2012; Abney et al. 2016). There is also interest in reverse water gas-shift chemical looping, which is a high-temperature redox cycle comprised of the reduction of a metal oxide by hydrogen and the subsequent oxidation by $\mathrm{CO}_{2}$ to yield $\mathrm{CO}$. The main advantage of this technology is the reduced gas separation that is due to a higher $\mathrm{CO}-$ to- $\mathrm{CO}_{2}$ ratio and elimination of unwanted side reactions such as methanation.

\subsection{Ethylene}

Ethylene $\left(\mathrm{C}_{2} \mathrm{H}_{4}\right)$ is a chemical precursor to plastic products and is predominantly used to create polyethylene plastic. Conventionally, ethylene is produced by catalytic cracking of ethane, a hydrocarbon gas liquid. Recent increases in production of hydrocarbon gas liquids from shale gas formations has spurred renewed interest in expanding ethylene generation capacity in the United States (DOE 2018). United States ethylene capacity continues to grow significantly, with numerous capacity additions totaling about 13 million t planned for 2021-2022 (Lewandowski 2016). Ethylene demand has proven resistant to the effects of the COVID-19 pandemic, largely because of increased demand for plastic packaging (ICIS 2020).

Ethylene can be produced electrochemically through $\mathrm{CO}_{2} \mathrm{R}$, through either reduction of $\mathrm{CO}$ or direct reduction of $\mathrm{CO}_{2}$ (Equation 6). Research on electrochemical ethylene production is primarily focused on direct $\mathrm{CO}_{2} \mathrm{R}$, and driven by experimental research, notable advances have been made in the performance of these systems (García de Arquer et al. 2020; Nitopi et al. 2019). 
Electrochemical production of ethylene represents a significant long-term opportunity for utilization of low-cost solar energy.

$$
2 \mathrm{CO}_{2}+8 \mathrm{H}_{2} \mathrm{O}+12 \mathrm{e}^{-} \rightarrow \mathrm{C}_{2} \mathrm{H}_{4}+12 \mathrm{OH}^{-}
$$

Electrochemical production of ethylene requires significantly more electricity on a per-molecule basis than $\mathrm{CO}$. Twelve electrons are required to produce one ethylene molecule, and $\mathrm{CO}$ requires two electrons. As a result of the large market size and low production efficiency, the estimated installed solar capacity required to produce all the ethylene currently consumed in the United States nears 1 TW for the Base scenario (Table 7).

Ethylene, which is primarily used to produce plastics such as polyethylene, is not widely used as an energy source. For this reason, E2M ethylene production was not included in the Energy Decarbonization scenario. As shown in Tables 7-10, E2M ethylene synthesis could represent a significant demand for electricity from PV because of its large market size.

Table 7. E2M Ethylene Market Metrics and PV Installed Capacity Required for Direct Electrochemical Product Synthesis

\begin{tabular}{|c|c|c|c|c|c|}
\hline Scenario & $\begin{array}{l}\text { U.S. Market } \\
\text { Size } \\
\text { (million t/yr) }\end{array}$ & $\begin{array}{l}\text { Current } \\
\text { Market } \\
\text { Price }(\$ / k g)^{b}\end{array}$ & $\begin{array}{l}\text { Electrical } \\
\text { Production } \\
\text { Efficiency } \\
\text { (kWh/kg) }^{\mathrm{c}}\end{array}$ & $\begin{array}{l}\text { Electricity } \\
\text { Demand to } \\
\text { Meet } 100 \% \text { of } \\
\text { Market } \\
(\mathrm{TWh} / \mathrm{y})^{\mathrm{c}}\end{array}$ & $\begin{array}{l}\text { PV Capacity } \\
\text { Required to } \\
\text { Meet } \\
\text { Additional } \\
\text { Load (GW) }\end{array}$ \\
\hline Base & $27^{a}$ & 0.71 & 79 & 2,157 & 981 \\
\hline Optimistic & $37^{c}$ & 0.71 & 21 & 777 & 353 \\
\hline Energy Decarbonization & \multicolumn{5}{|c|}{$\mathrm{n} / \mathrm{a}$} \\
\hline
\end{tabular}

a IHS 2021; used with permission provided March 16, 2021

b Grim et al. 2019

c Includes energy requirements for direct air capture of $\mathrm{CO}_{2}$; see the appendix for detailed calculations and assumptions.

Ethylene can be produced indirectly from $\mathrm{CO}_{2}$ or syngas feedstocks through Fischer-Tropsch synthesis, methanol-to-olefins (MTO) pathways, or ethanol dehydration. Industry has not yet adopted Fisher-Tropsch synthesis for light olefins because of the wide product distribution and low selectivity of light olefins. MTO technology is commercialized and licensed by Honeywell UOP/Hydro with other competitors in Sinopec and Dalian Institute of Chemical Physics (Hongxing, Zaiku, and Guoliang 2013). Methanol feedstock is produced either from syngas or the direct conversion of $\mathrm{CO}_{2}$ to methanol, which is discussed in Section 3.6 (page 20). A MTO process model published by the Idaho National Laboratory (Knighton et al. 2020) is used to estimate the syngas needed to meet annual ethylene demand. The UOP/Hydro and Sinopec MTO processes also have the flexibility to produce ethylene to propylene product ratios of $0.5-1.5$ (Hongxing, Zaiku, and Guoliang 2013; J. Q. Chen et al. 2005; Gogate 2019). An ethylene to propylene ratio of 1.5 was selected for this analysis. Ethanol dehydration technology is currently implemented at an industrial scale by British Petroleum (BP), Braskem (Brazil), Chematur, and Axens (Mohsenzadeh, Zamani, and Taherzadeh 2017). Intratec released an in-depth analysis of BP's ethanol dehydration technology that considers the process in greater technical detail than that considered in this report (Intratec 2013). 
Here, we assume ethanol feedstock is produced via the ethanol fermentation pathway described in Section 3.5 (page 18). Ethanol conversion of 0.97-0.99 and a selectivity of 0.97 were selected based on the Syndol catalyst developed by American Halcon Scientific Design Inc. (Zhang and $\mathrm{Yu}$ 2013). The electrical efficiency of the MTO pathway is slightly better than that of the direct electrochemical Base scenario but significantly worse than that of the Optimistic scenario, which suggests direct electrochemical reactors could become the more efficient alternative if systems were developed that meet the Optimistic scenario assumptions. The ethanol dehydration pathway is significantly more efficient than the MTO pathway because less hydrogen is required to generate the feedstocks for ethanol fermentation than with methanol synthesis. Ethanol dehydration is competitive on an electrical production efficiency basis with the Optimistic direct electrochemical scenario.

Table 8. E2M Ethylene Market Metrics and PV Installed Capacity Required for Product Synthesis via Methanol Produced from Syngas

\begin{tabular}{|c|c|c|c|c|c|}
\hline Scenario & $\begin{array}{l}\text { U.S. Market } \\
\text { Size } \\
\text { (million t/yr) }\end{array}$ & $\begin{array}{l}\text { Current } \\
\text { Market } \\
\text { Price } \\
(\$ / k g)^{b}\end{array}$ & $\begin{array}{l}\text { Electrical } \\
\text { Production } \\
\text { Efficiency } \\
(\mathbf{k W h} / \mathbf{k g})^{\mathrm{c}}\end{array}$ & $\begin{array}{l}\text { Electricity } \\
\text { Demand to } \\
\text { Meet } 100 \% \text { of } \\
\text { Market } \\
\text { (TWh/y)c }\end{array}$ & $\begin{array}{l}\text { PV Capacity } \\
\text { Required to } \\
\text { Meet } \\
\text { Additional } \\
\text { Load (GW) }\end{array}$ \\
\hline Base & $27^{a}$ & 0.71 & 61 & 1,642 & 747 \\
\hline Optimistic & $37^{c}$ & 0.71 & 53 & 1,969 & 895 \\
\hline Energy Decarbonization & \multicolumn{5}{|c|}{$\mathrm{n} / \mathrm{a}$} \\
\hline
\end{tabular}

a IHS 2021; used with permission provided March 16, 2021

${ }^{b}$ Grim et al. 2019

${ }^{c}$ Includes energy requirements for direct air capture of $\mathrm{CO}_{2}$; see the appendix for detailed calculations and assumptions.

Table 9. E2M Ethylene Market Metrics and PV Installed Capacity Required for Product Synthesis via Methanol Produced from $\mathrm{CO}_{2}$

\begin{tabular}{|c|c|c|c|c|c|}
\hline Scenario & $\begin{array}{l}\text { U.S. Market } \\
\text { Size } \\
\text { (million t/yr) }\end{array}$ & $\begin{array}{l}\text { Current } \\
\text { Market } \\
\text { Price } \\
(\$ / k g)^{b}\end{array}$ & $\begin{array}{l}\text { Electrical } \\
\text { Production } \\
\text { Efficiency } \\
(\mathbf{k W h} / \mathbf{k g})^{\mathrm{c}}\end{array}$ & $\begin{array}{l}\text { Electricity } \\
\text { Demand to } \\
\text { Meet } 100 \% \text { of } \\
\text { Market } \\
(\mathrm{TWh} / \mathrm{y})^{\mathrm{c}}\end{array}$ & $\begin{array}{l}\text { PV Capacity } \\
\text { Required to } \\
\text { Meet } \\
\text { Additional } \\
\text { Load (GW)c }\end{array}$ \\
\hline Base & $27^{a}$ & 0.71 & 61 & 1,649 & 750 \\
\hline Optimistic & $37 c$ & 0.71 & 53 & 1,978 & 899 \\
\hline Energy Decarbonization & \multicolumn{5}{|c|}{$\mathrm{n} / \mathrm{a}$} \\
\hline
\end{tabular}

a IHS 2021; used with permission provided March 16, 2021

b Grim et al. 2019

${ }^{c}$ Includes energy requirements for direct air capture of $\mathrm{CO}_{2}$; see the appendix for detailed calculations and assumptions. 
Table 10. E2M Ethylene Market Metrics and PV Installed Capacity Required for Product Synthesis via Ethanol Dehydration using Bioethanol

\begin{tabular}{|c|c|c|c|c|c|}
\hline Scenario & $\begin{array}{l}\text { U.S. Market } \\
\text { Size } \\
\text { (million t/yr) }\end{array}$ & $\begin{array}{l}\text { Current } \\
\text { Market } \\
\text { Price }(\$ / k g)^{b}\end{array}$ & $\begin{array}{l}\text { Electrical } \\
\text { Production } \\
\text { Efficiency } \\
(\mathbf{k W h} / \mathbf{k g})^{\mathrm{c}}\end{array}$ & $\begin{array}{l}\text { Electricity } \\
\text { Demand to } \\
\text { Meet } 100 \% \\
\text { of Market } \\
(\mathrm{TWh} / \mathrm{y})^{\mathrm{c}}\end{array}$ & $\begin{array}{l}\text { PV Capacity } \\
\text { Required to } \\
\text { Meet } \\
\text { Additional } \\
\text { Load (GW) }\end{array}$ \\
\hline Base & $27^{a}$ & 0.71 & 36 & 959 & 436 \\
\hline Optimistic & $37^{c}$ & 0.71 & 35 & 1,287 & 585 \\
\hline Energy Decarbonization & \multicolumn{5}{|c|}{$\mathrm{n} / \mathrm{a}$} \\
\hline
\end{tabular}

a IHS 2021; used with permission provided March 16, 2021

${ }^{b}$ Grim et al. 2019

${ }^{c}$ Includes energy requirements for direct air capture of $\mathrm{CO}_{2}$; see the appendix for detailed calculations and assumptions.

\subsection{Ethanol}

Ethanol $\left(\mathrm{C}_{2} \mathrm{H}_{5} \mathrm{OH}\right)$ is a liquid fuel produced from various cellulosic and noncellulosic biomass feedstocks. It is conventionally produced through biobased feedstock fermentation, where starches are fermented into sugars and subsequently become alcohols. Ethanol production in the United States relies on corn as a primary feedstock, while other countries rely on sugar cane and sugar beets (EIA 2020f). Use of lignocellulosic feedstocks such as agricultural residues, energy crops or forest feedstocks has been a research target for decades, commercial penetration has been limited due to process complexity, costs, and yields.

As with ethylene, ethanol can be produced by $\mathrm{CO}_{2} \mathrm{R}$ via a 12-electron transfer reaction (Equation 7). $\mathrm{CO}_{2} \mathrm{R}$ to both ethylene and ethanol require the formation of molecules with two carbons (a C-C double bond in the case of ethylene). So, $\mathrm{CO}_{2} \mathrm{R}$ to these products can suffer from lower selectivity, with product formation often competing with other reactions on the cathode. These competing reactions lower the selectivity of $\mathrm{CO}_{2}$ to ethanol, which recent experimental work establishes at about 25\% (Grim et al. 2019).

$$
2 \mathrm{CO}_{2}+9 \mathrm{H}_{2} \mathrm{O}+12 \mathrm{e}^{-} \rightarrow \mathrm{C}_{2} \mathrm{H}_{5} \mathrm{OH}+12 \mathrm{OH}^{-}
$$

Given the low selectivity of $\mathrm{CO}_{2} \mathrm{R}$ to ethanol, the electrical energy required to produce one kilogram is among the highest of the potential products considered here (Table 11). Considering the large market size of ethanol, over $1 \mathrm{TW}$ of installed solar capacity would be required to offset ethanol production from conventional production methods for the base case. Ethanol production is not explicitly considered in the Energy Decarbonization scenario, but it could be a component of the biofuels included in that scenario. We report hydrogen requirements for biofuels in the appendix, but ethanol is not included as part of the Energy Decarbonization scenario. 
Table 11. E2M Ethanol Market Metrics and PV Installed Capacity Required for Direct Electrochemical Product Synthesis

\begin{tabular}{|c|c|c|c|c|c|}
\hline Scenario & $\begin{array}{l}\text { U.S. Market } \\
\text { Size } \\
\text { (million t/yr) }\end{array}$ & $\begin{array}{l}\text { Current } \\
\text { Market } \\
\text { Price }(\$ / k g)^{b}\end{array}$ & $\begin{array}{l}\text { Electrical } \\
\text { Production } \\
\text { Efficiency } \\
(\mathbf{k W h} / \mathbf{k g})^{\mathrm{c}}\end{array}$ & $\begin{array}{l}\text { Electricity } \\
\text { Demand to } \\
\text { Meet } 100 \% \\
\text { of Market } \\
(\mathrm{TWh} / \mathrm{y})^{\mathrm{c}}\end{array}$ & $\begin{array}{l}\text { PV Capacity } \\
\text { Required to } \\
\text { Meet } \\
\text { Additional } \\
\text { Load (GW) }\end{array}$ \\
\hline Base & $47^{a}$ & 0.52 & 62 & 2,916 & 1,326 \\
\hline Optimistic & $70^{c}$ & 0.52 & 13 & 880 & 400 \\
\hline Energy Decarbonization & \multicolumn{5}{|c|}{$\mathrm{n} / \mathrm{a}$} \\
\hline
\end{tabular}

a U.S. DOE 2017

b Grim et al. 2019

${ }^{c}$ Includes energy requirements for direct air capture of $\mathrm{CO}_{2}$; see the appendix for detailed calculations and assumptions

Ethanol can be produced indirectly by the fermentation of syngas to ethanol or the direct chemical conversion of syngas to ethanol (Tables 12 and 13 respectively, page 20). Syngas is assumed to be produced with $\mathrm{H}_{2}$ from water electrolysis and $\mathrm{CO}$ obtained through RWGS. The fermentation route is currently at commercial scale via a joint venture between LanzaTech and Shougang Group (LanzaTech 2018b). The hydration of ethylene to form ethanol is another major commercial pathway for ethanol production. However, producing ethanol from ethylene via MTO is complex and likely uneconomical.

We estimate the hydrogen demand for the fermentation route using data modeled after the LanzaTech commercial facility and technology. We assume the selectivity of ethanol and gas utilization to be 95\% (LanzaTech 2018a). Feed gas composition is based on LanzaTech's publicly reported feed gas molar ratio of 5:1:1 for $\mathrm{H}_{2}: \mathrm{CO}: \mathrm{CO}_{2}$ in ethanol fermentation (LanzaTech 2021; Lee et al. 2020; Huang et al. 2020). Half the mols of carbon in ethanol are assumed to be from $\mathrm{CO}$ and half are assumed to be from $\mathrm{CO}_{2}$ (Huang et al. 2020). The catalytic conversion of syngas to ethanol has not yet been commercialized because of low yield and poor selectivity (Spivey and Egbebi 2007; Choi and Liu 2009; Dieterich et al. 2020). The electrical production efficiency of ethanol via syngas is based on a syngas to mixed alcohols (primarily ethanol) route (Knighton et al. 2020) with a reported CO selectivity to ethanol of 0.63 . The methanol byproduct from this process can potentially reduce hydrogen and electricity demand numbers reported for direct methanol synthesis. We assume PV capacity is used to support the creation of syngas or CO via RWGS and any additional hydrogen demands through water electrolysis. The syngas production step was used to assign an approximate TRL of 6 , although it should be noted that the ethanol fermentation step is currently used in operating commercial plants and this step itself is likely at a higher TRL. If CO is supplied via a more mature pathway, then the overall TRL of the ethanol fermentation pathway is likely to be higher. Ethanol production through fermentation exhibits higher selectivities and carbon utilization, resulting in electrical production efficiency numbers comparable to the Optimistic direct scenario. 
Table 12. E2M Ethanol Market Metrics and PV Installed Capacity Required for Product Synthesis via Fermentation

\begin{tabular}{|c|c|c|c|c|c|}
\hline Scenario & $\begin{array}{l}\text { U.S. Market } \\
\text { Size } \\
\text { (million t/yr) }\end{array}$ & $\begin{array}{l}\text { Current } \\
\text { Market } \\
\text { Price }(\$ / k g)^{b}\end{array}$ & $\begin{array}{l}\text { Electrical } \\
\text { Production } \\
\text { Efficiency } \\
(\mathbf{k W h} / \mathbf{k g})^{\mathrm{c}}\end{array}$ & $\begin{array}{l}\text { Electricity } \\
\text { Demand to } \\
\text { Meet } 100 \% \\
\text { of Market } \\
(\mathrm{TWh} / \mathrm{y})^{\mathrm{c}}\end{array}$ & $\begin{array}{l}\text { PV Capacity } \\
\text { Required to } \\
\text { Meet } \\
\text { Additional } \\
\text { Load (GW) }\end{array}$ \\
\hline Base & $47^{a}$ & 0.52 & 20 & 958 & 436 \\
\hline Optimistic & $70^{c}$ & 0.52 & 18 & 1,257 & 572 \\
\hline Energy Decarbonization & \multicolumn{5}{|c|}{$\mathrm{n} / \mathrm{a}$} \\
\hline
\end{tabular}

a U.S. DOE 2017

b Grim et al. 2019

${ }^{c}$ Includes energy requirements for direct air capture of $\mathrm{CO}_{2}$; see the appendix for detailed calculations and assumptions.

Table 13. E2M Ethanol Market Metrics and PV Installed Capacity Required for Product Synthesis via Mixed Alcohols

\begin{tabular}{|c|c|c|c|c|c|}
\hline Scenario & $\begin{array}{l}\text { U.S. Market } \\
\text { Size } \\
\text { (million t/yr) }\end{array}$ & $\begin{array}{l}\text { Current } \\
\text { Market } \\
\text { Price }(\$ / k g)^{b}\end{array}$ & $\begin{array}{l}\text { Electrical } \\
\text { Production } \\
\text { Efficiency } \\
(\mathbf{k W h} / \mathrm{kg})^{\mathrm{c}}\end{array}$ & $\begin{array}{l}\text { Electricity } \\
\text { Demand to } \\
\text { Meet } 100 \% \\
\text { of Market } \\
(\text { TWh/y) }\end{array}$ & $\begin{array}{l}\text { PV Capacity } \\
\text { Required to } \\
\text { Meet } \\
\text { Additional } \\
\text { Load (GW)c }\end{array}$ \\
\hline Base & $47^{a}$ & 0.52 & 27 & 1,259 & 573 \\
\hline Optimistic & $70^{c}$ & 0.52 & 20 & 1,395 & 635 \\
\hline Energy Decarbonization & \multicolumn{5}{|c|}{$\mathrm{n} / \mathrm{a}$} \\
\hline
\end{tabular}

a U.S. DOE 2017

${ }^{b}$ Grim et al. 2019

${ }^{c}$ Includes energy requirements for direct air capture of $\mathrm{CO}_{2}$; see the appendix for detailed calculations and assumptions.

\subsection{Methanol}

Methanol $\left(\mathrm{CH}_{3} \mathrm{OH}\right)$ is produced at several facilities in the United States. Planned additions to existing capacity is expected to increase natural gas consumption for methanol production (EIA $2020 \mathrm{~g}$ ). Methanol can be used as a precursor to other chemical products, used an additive to gasoline, or directly used as a vehicle fuel (as is done in China) (EIA 2020b). Conventional methanol pathways rely on natural gas both as a chemical reactant and as a source of high-grade heat for the synthesis process (Marlin, Sarron, and Sigurbjörnsson 2018). Steam reforming and the water gas shift reaction are first used to create syngas from natural gas (Equations 8 and 9 respectively).

$$
\begin{gathered}
\mathrm{CH}_{4}+\mathrm{H}_{2} \mathrm{O} \rightarrow \mathrm{CO}+3 \mathrm{H}_{2} \\
\mathrm{CO}+\mathrm{H}_{2} \mathrm{O} \rightarrow \mathrm{CO}_{2}+\mathrm{H}_{2}
\end{gathered}
$$

Methanol is synthesized from the reaction of syngas and hydrogen in the presence of a catalyst, which is typically a mixture of copper, zinc-oxide, alumina, and magnesia (Equation 10) (NETL 2020). 


$$
\mathrm{CO}+2 \mathrm{H}_{2} \rightarrow \mathrm{CH}_{3} \mathrm{OH}
$$

Electrochemical synthesis of methanol from $\mathrm{CO}_{2} \mathrm{R}$ (Equation 11) tends to suffer from low selectivity. Increased selectivity and current density of $\mathrm{CO}_{2} \mathrm{R}$ to methanol have both been achieved using molecular catalysts (Wu et al. 2019).

$$
\mathrm{CO}_{2}+5 \mathrm{H}_{2} \mathrm{O}+6 \mathrm{e}^{-} \rightarrow \mathrm{CH}_{3} \mathrm{OH}+6 \mathrm{OH}^{-}
$$

Methanol produced via $\mathrm{CO}_{2} \mathrm{R}$ represents an opportunity for the storage of electricity and atmospheric $\mathrm{CO}_{2}$ in a molecule that could be used across multiple industries (Table 14). As the conventional production process for methanol relies on $\mathrm{CO}$ and $\mathrm{H}_{2}$, multiple pathways exist to integrate electrochemical technologies with existing processes for methanol synthesis. Rather than reducing $\mathrm{CO}_{2}$ directly to methanol via a single-step process, $\mathrm{CO}$ and $\mathrm{H}_{2}$ could be generated from $\mathrm{CO}_{2} \mathrm{R}$ and water electrolysis respectively (W. A. Smith et al. 2019). The resulting syngas could be used in existing downstream infrastructure and provides an opportunity to reduce the energy and heat demands of conventional production pathways.

Table 14. E2M Methanol Market Metrics and PV Installed Capacity Required for Direct

\begin{tabular}{|c|c|c|c|c|c|}
\hline Scenario & $\begin{array}{l}\text { U.S. Market } \\
\text { Size } \\
\text { (million t/yr) }\end{array}$ & $\begin{array}{l}\text { Current } \\
\text { Market } \\
\text { Price }(\$ / k g)^{b}\end{array}$ & $\begin{array}{l}\text { Electrical } \\
\text { Production } \\
\text { Efficiency } \\
(\mathbf{k W h} / \mathbf{k g})^{\mathrm{c}}\end{array}$ & $\begin{array}{l}\text { Electricity } \\
\text { Demand to } \\
\text { Meet } 100 \% \\
\text { of Market } \\
(\mathrm{TWh} / \mathrm{y})^{\mathrm{c}}\end{array}$ & $\begin{array}{l}\text { PV Capacity } \\
\text { Required to } \\
\text { Meet } \\
\text { Additional } \\
\text { Load (GW)c }\end{array}$ \\
\hline Base & $5^{a}$ & 0.35 & 10 & 54 & 25 \\
\hline Optimistic & $6^{c}$ & 0.35 & 9 & 60 & 27 \\
\hline Energy Decarbonization ${ }^{d}$ & \multicolumn{5}{|c|}{$\mathrm{n} / \mathrm{a}$} \\
\hline
\end{tabular}
Electrochemical Product Synthesis

a IHS 2021; used with permission provided March 16, 2021

b Grim et al. 2019

${ }^{c}$ Includes energy requirements for direct air capture of $\mathrm{CO}_{2}$; see the appendix for detailed calculations and assumptions.

${ }^{d}$ Methanol included in the Energy Decarbonization scenario is assumed to be produced via a chemical route-not a direct electrochemical process.

Methanol can be produced chemically from syngas (Equation 12) or the catalytic hydrogenation of $\mathrm{CO}_{2}$. Methanol is conventionally produced using syngas as a reactant in a series of adiabatic or quasi-isothermal gas-phase fixed-bed reactors.

$$
\mathrm{CO}+2 \mathrm{H}_{2} \rightarrow \mathrm{CH}_{3} \mathrm{OH}
$$

This technology is mature, as several industrial-scale processes have been demonstrated (Toyo 2020; Air Liquide 2021). There has also been recent interest in direct $\mathrm{CO}_{2}$-to-methanol systems as evidenced by various pilot plants, demonstration facilities, and planned commercial facilities (Shulenberger et al. 2007; Saito 1998; E.C. Heydorn, B.W. Diamond, and R.D. Lilly 2003; CEN 2008). Most notably, Carbon Recycling International is developing an industrial-scale methanol facility in Anyang, Henan Province, China, with an annual capacity of 110,000 t of low-carbon methanol (Carbon Recycling International 2020). 
An unconventional route that has not yet been commercialized is the liquid phase synthesis of methanol in slurry bubble column reactors (E.C. Heydorn, B.W. Diamond, and R.D. Lilly 2003). The commercial single pass conversion of syngas to methanol typically ranges from $30 \%$ to $80 \%$ (Dieterich et al. 2020; L. Chen et al. 2011) with methanol selectivities (except water) greater than 99\% (Dieterich et al. 2020). No indirect Optimistic scenario has been defined as improvements to methanol synthesis are usually related to improving the unit production cost and process energy efficiency. We assume PV capacity is used to support the creation of syngas via RWGS and any additional hydrogen demands through water electrolysis. The chemical production efficiency is lower than the current electrochemical efficiency.

Methanol production and associated energy requirements are included in the Energy Decarbonization scenario as a drop in fuel that is generated from chemical pathways using electrolytic hydrogen. These applications significantly increase the market size for methanol from current levels, more than doubling demand.

Table 15. E2M Methanol Market Metrics and PV Installed Capacity Required for Product Synthesis via Chemical Routes

\begin{tabular}{|c|c|c|c|c|c|}
\hline Scenario & $\begin{array}{l}\text { U.S. Market } \\
\text { Size } \\
\text { (million t/yr) }\end{array}$ & $\begin{array}{l}\text { Current } \\
\text { Market } \\
\text { Price } \\
(\$ / \mathbf{k g})^{\mathbf{b}}\end{array}$ & $\begin{array}{l}\text { Electrical } \\
\text { Production } \\
\text { Efficiency } \\
\text { (kWh/kg) }^{\mathrm{c}}\end{array}$ & $\begin{array}{l}\text { Electricity } \\
\text { Demand to } \\
\text { Meet } 100 \% \\
\text { of Market } \\
(T W h / y)^{c}\end{array}$ & $\begin{array}{l}\text { PV } \\
\text { Capacity } \\
\text { Required to } \\
\text { Meet } \\
\text { Additional } \\
\text { Load (GW) }\end{array}$ \\
\hline Syngas route & $5^{a}$ & 0.35 & 12 & 60 & 27 \\
\hline $\mathrm{CO}_{2}$ conversion route & $5^{\mathrm{a}}$ & 0.35 & 12 & 60 & 27 \\
\hline Energy decarbonization ${ }^{d}$ & 12 & $\mathrm{n} / \mathrm{a}$ & 12 & 146 & 66 \\
\hline
\end{tabular}

a IHS 2021; used with permission provided March 16, 2021

b Grim et al. 2019

${ }^{c}$ Includes only energy requirements for hydrogen production and direct air capture of $\mathrm{CO}_{2}$; see the appendix for detailed calculations and assumptions.

d See the appendix for detailed demand assumptions for this scenario.

\subsection{Formic Acid}

Formic acid $(\mathrm{HCOOH})$ is a common chemical intermediate and is conventionally produced from hydrolysis of methyl formate (Equations 13 and 14) (Rumayor, Dominguez-Ramos, and Irabien 2018).

$$
\begin{gathered}
\mathrm{CH}_{3} \mathrm{OH}+\mathrm{CO} \rightarrow \mathrm{HCOOCH}_{3} \\
\mathrm{HCOOCH}_{3}+\mathrm{H}_{2} \mathrm{O} \leftrightarrow \mathrm{CH}_{3} \mathrm{OH}+\mathrm{HCOOH}
\end{gathered}
$$

Formic acid has wide applications across many industries, including leather tanning, agriculture, and use as a deicer (BASF 2020). The first formic acid production plant in the United States began operating in 2015, and formate demand is expected to experience steady growth as new applications and uses emerge (Chemical Engineering News 2015; BASF 2012). Formic acid and its deprotonated form formate (HCOO-) can be produced from $\mathrm{CO}_{2} \mathrm{R}$ (Equations 15 and 16). Both formate and formic acid can be used to form products in various processes, including biomass conversion and biological synthesis pathways (Y. Chen et al. 2020). 


$$
\begin{gathered}
\mathrm{CO}_{2}+2 \mathrm{H}_{2} \mathrm{O}+2 \mathrm{e}^{-} \rightarrow \mathrm{HCOOH}+2 \mathrm{OH}^{-} \\
\mathrm{CO}_{2}+\mathrm{H}_{2} \mathrm{O}+2 \mathrm{e}^{-} \rightarrow \mathrm{HCOO}^{-}+\mathrm{OH}^{-}
\end{gathered}
$$

Formate and formic acid can be produced with high selectivity and current density in existing $\mathrm{CO}_{2} \mathrm{R}$ reactors, which makes them potential near-term products for hybridized solar and E2M systems (Fan et al. 2020; Y. Chen et al. 2020). Formic acid exhibits the highest minimum electricity price of the products we considered (Table 16), which suggests current $\mathrm{CO}_{2} \mathrm{R}$ technology could be an economically competitive opportunity for synthesis using electricity from PV. Though current market sizes for formate/formic acid are smaller than those for other E2M products considered here, the small amount of electricity required to synthesize this molecule and the cross-sector applications make it a possible near-term product for E2M synthesis. Remaining R\&D challenges for this pathway include scaling up E2M systems to industrially relevant levels and developing durable reactors that can operate at steady performance over long lifetimes.

Formic acid is not considered in the Energy Decarbonization scenario because of its small market size and lack of existing applications in the energy sector.

Table 16. E2M Formic Acid Market Metrics and PV Installed Capacity Required for Direct Electrochemical Product Synthesis

\begin{tabular}{|l|l|l|l|l|l|}
\hline Scenario & $\begin{array}{l}\text { U.S. Market } \\
\text { Size } \\
\text { (million t/yr) }\end{array}$ & $\begin{array}{l}\text { Current } \\
\text { Market } \\
\text { Price } \\
(\mathbf{\$} / \mathbf{k g})^{\mathbf{b}}\end{array}$ & $\begin{array}{l}\text { Electrical } \\
\text { Production } \\
\text { Efficiency } \\
(\mathbf{k W h} / \mathbf{k g})^{\mathbf{c}}\end{array}$ & $\begin{array}{l}\text { Electricity } \\
\text { Demand to } \\
\text { Meet 100\% of } \\
\text { Market } \\
\mathbf{( T W h / y )}^{\mathbf{c}}\end{array}$ & $\begin{array}{l}\text { PV Capacity } \\
\text { Required to } \\
\text { Meet } \\
\text { Additional } \\
\text { Load (GW)c }\end{array}$ \\
\hline Base & $0.06^{\mathrm{a}}$ & 0.66 & 9 & 0.5 & 0.2 \\
\hline Optimistic & $0.07^{\mathrm{c}}$ & 0.66 & 3 & 0.2 & 0.1 \\
\hline Energy Decarbonization & \multicolumn{5}{|c|}{$\mathrm{n} / \mathrm{a}$} \\
\hline
\end{tabular}

a Market size estimate based on a literature search of existing formic acid production facilities in the United States and annual imports of formic acid.

b Grim et al. 2019

${ }^{c}$ Includes energy requirements for direct air capture of $\mathrm{CO}_{2}$; see the appendix for detailed calculations and assumptions.

Two chemical pathways to produce formic acid using hydrogen are the conventional route (Equation 14) described by the equations above and the direct hydrogenation of $\mathrm{CO}_{2}$ to formic acid through homogeneous catalysis (Equation 17). The conventional route has been generally adopted by industry in the form of the Kemira-Leonard and BASF processes (Pérez-Fortes and Tzimas 2016). The direct hydrogenation of $\mathrm{CO}_{2}$ process currently has a European Union technology readiness level (TRL) of 3, 4, or 5 (Pérez-Fortes and Tzimas 2016). The direct hydrogenation pathway consists of two steps: the formation of a FA-amine adduct (Equation 17) under a ruthenium- and phosphino-based catalyst in a batch reactor followed by the dissociation of formic acid from the adduct (Equation 18) in a reactive distillation unit.

$$
\mathrm{CO}_{2}+\mathrm{H}_{2}+\mathrm{C}_{18} \mathrm{H}_{39} \mathrm{~N} \rightarrow \mathrm{C}_{18} \mathrm{H}_{39} \mathrm{~N}+\mathrm{HCOOH}
$$




$$
\mathrm{C}_{18} \mathrm{H}_{39} \mathrm{~N}-\mathrm{HCOOH} \rightarrow \mathrm{C}_{18} \mathrm{H}_{39} \mathrm{~N}+\mathrm{HCOOH}
$$

PV capacity could be used to support the creation of syngas via RWGS and any additional hydrogen demands through water electrolysis. Only formic acid produced via the conventional pathway achieves a production efficiency comparable to the direct Optimistic scenario.

Table 17. E2M Formic Acid Market Metrics and PV Installed Capacity Required for Product Synthesis via Direct Hydrogenation

\begin{tabular}{|l|c|c|l|l|c|}
\hline Scenario & $\begin{array}{l}\text { U.S. Market } \\
\text { Size } \\
\text { (million t/yr) }\end{array}$ & $\begin{array}{l}\text { Current } \\
\text { Market } \\
\text { Price } \mathbf{( \$ / k g )})^{\mathbf{b}}\end{array}$ & $\begin{array}{l}\text { Electrical } \\
\text { Production } \\
\text { Efficiency } \\
\mathbf{( k W h / k g}^{\mathbf{c}}\end{array}$ & $\begin{array}{l}\text { Electricity } \\
\text { Demand to } \\
\text { Meet 100\% } \\
\text { of Market } \\
\mathbf{( T W h / y ) ~}^{\mathbf{c}}\end{array}$ & $\begin{array}{l}\text { PV Capacity } \\
\text { Required to } \\
\text { Meet } \\
\text { Additional } \\
\text { Load (GW) }\end{array}$ \\
\hline Base & $0.06^{\mathbf{a}}$ & 0.66 & 5 & 0.3 & 0.1 \\
\hline Optimistic & $0.07^{\mathrm{c}}$ & 0.66 & 5 & 0.3 & 0.2 \\
\hline Energy Decarbonization & \multicolumn{5}{|c|}{$\mathrm{n} / \mathrm{a}$} \\
\hline
\end{tabular}

a Market size estimate based on a literature search of existing formic acid production facilities in the United States and annual imports of formic acid.

b Grim et al. 2019

${ }^{c}$ Includes energy requirements for direct air capture of $\mathrm{CO}_{2}$; see the appendix for detailed calculations and assumptions.

Table 18. E2M Formic Acid Market Metrics and PV Installed Capacity Required for Product Synthesis via Kemira-Leonard Process

\begin{tabular}{|l|c|c|l|l|c|}
\hline Scenario & $\begin{array}{l}\text { U.S. Market } \\
\text { Size } \\
\text { (million t/yr) }\end{array}$ & $\begin{array}{l}\text { Current } \\
\text { Market } \\
\text { Price (\$/kg) }\end{array}$ & $\begin{array}{l}\text { Electrical } \\
\text { Production } \\
\text { Efficiency } \\
(\mathbf{k W h} / \mathbf{k g})^{\mathbf{c}}\end{array}$ & $\begin{array}{l}\text { Electricity } \\
\text { Demand to } \\
\text { Meet 100\% } \\
\text { of Market } \\
\mathbf{( T W h / y ) ~}^{\mathbf{c}}\end{array}$ & $\begin{array}{l}\text { PV Capacity } \\
\text { Required to } \\
\text { Meet } \\
\text { Additional } \\
\text { Load (GW) }\end{array}$ \\
\hline Base & $0.06^{\mathrm{a}}$ & 0.66 & 4 & 0.2 & 0.1 \\
\hline Energy Decarbonization & \multicolumn{5}{|c|}{$\mathrm{n} / \mathrm{a}$} \\
\hline
\end{tabular}

a Market size estimate based on a literature search of existing formic acid production facilities in the United States and annual imports of formic acid.

b Grim et al. 2019

${ }^{c}$ Includes energy requirements for direct air capture of $\mathrm{CO}_{2}$; see the appendix for detailed calculations and assumptions.

\subsection{Methane}

Of the potential E2M products considered here, methane, or natural gas $\left(\mathrm{CH}_{4}\right)$ is currently consumed in the largest quantity in the U.S. Natural gas is used across multiple sectors, including for residential heating, in industry, and as a vehicle fuel (Figure 5) (EIA 2020i). It is consumed in different ways depending on the end use. Industrial natural gas can be used as a source of highgrade heat for steelmaking and as a chemical feedstock for hydrogen or methanol production. The large market and varied end uses for natural gas create significant opportunities for the development of alternative production processes. 


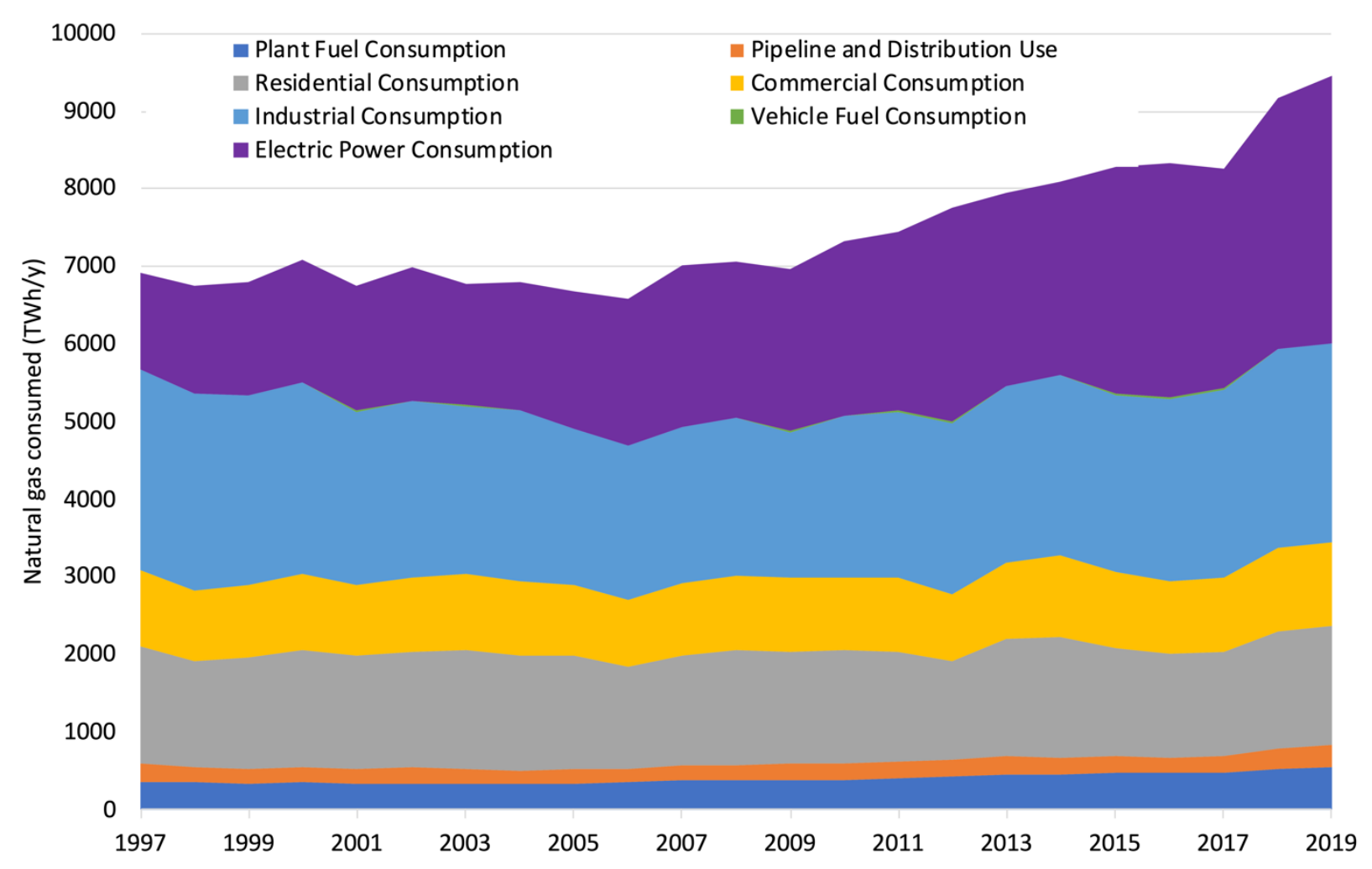

Figure 5. Natural gas consumed in the United States by sector, assuming 1,037 Btu/ft ${ }^{3}$ of natural gas

Electrochemical synthesis of natural gas using $\mathrm{CO}_{2}$ and electricity is a possibility for the development of supply chains that do not rely on fossil fuels; however, the current state of the technology exhibits low efficiencies and current densities (Grim et al. 2019). Also, given the low prices for natural gas produced from domestic shale gas formations (Figure 3), electrochemical synthesis of methane is likely a long-term opportunity. Considering the low efficiencies for direct electrochemical methane production and the large market size, installed PV capacity estimates exceed $10 \mathrm{TW}$ and $4 \mathrm{TW}$ for the Base and Optimistic scenarios, respectively (Table 19, page 26).

E2M-based synthesis of methane is not included in the Energy Decarbonization scenario estimates. Though methane has wide-ranging applications across the energy sector, assumptions in the Energy Decarbonization scenario replace existing methane consumption with electrification, efficiency, and alternative fuels, including hydrogen, ammonia, biofuels, and synthetic hydrocarbons. The high-level analysis conducted using the Energy Decarbonization scenario does not consider the numerous opportunities for generation and integration of renewable methane, including leveraging existing natural gas infrastructure, biogas, biomethanation, and E2M-based methane.

Methane produced biologically from $\mathrm{CO}_{2}$ and $\mathrm{H}_{2}$ is an emerging opportunity for the creation of hydrocarbon fuels from electricity. Renewable methane can be generated using hydrogen generated from water electrolysis, $\mathrm{CO}_{2}$, and specifically engineered microorganisms (NREL $2019 ; 2017)$. 
Table 19. E2M Methane Market Metrics and PV Installed Capacity Required for Direct Electrochemical Product Synthesis

\begin{tabular}{|c|c|c|c|c|c|}
\hline Scenario & $\begin{array}{l}\text { U.S. Market } \\
\text { Size } \\
\text { (million t/yr) }\end{array}$ & $\begin{array}{l}\text { Current } \\
\text { Market } \\
\text { Price }(\$ / \mathbf{k g})^{\text {b }}\end{array}$ & $\begin{array}{l}\text { Electrical } \\
\text { Production } \\
\text { Efficiency } \\
(\mathbf{k W h} / \mathbf{k g})^{\mathrm{c}}\end{array}$ & $\begin{array}{l}\text { Electricity } \\
\text { Demand to } \\
\text { Meet } 100 \% \\
\text { of Market } \\
(\mathrm{TWh} / \mathrm{y})^{\mathrm{c}}\end{array}$ & $\begin{array}{l}\text { PV Capacity } \\
\text { Required to } \\
\text { Meet } \\
\text { Additional } \\
\text { Load (GW) }\end{array}$ \\
\hline Base & $579^{a}$ & 0.15 & 41 & 24,011 & 10,920 \\
\hline Optimistic & $604^{c}$ & 0.15 & 17 & 10,350 & 4,707 \\
\hline Energy Decarbonization & \multicolumn{5}{|c|}{$\mathrm{n} / \mathrm{a}$} \\
\hline
\end{tabular}

${ }^{a}$ EIA 2020i

b Grim et al. 2019

${ }^{c}$ Includes energy requirements for direct air capture of $\mathrm{CO}_{2}$; see the appendix for detailed calculations and assumptions.

Methane can be formed thermochemically by the conversion of hydrogen and carbon dioxide in the presence of a catalyst (typically nickel-based). Adiabatic fixed-bed methanation is the most adopted method of thermochemical methanation and commercially available (Götz, Koch, and Graf 2014; Gahleitner 2013). For example, the Audi e-gas plant in Wertle, Germany, uses hydrogen produced from alkaline electrolysis and $\mathrm{CO}_{2}$ from a biogas plant to produce synthetic natural gas over a fixed-bed reactor (Held and Scholwin 2015). Several reactions that typically take place in a catalytic methanation reactor are in Equations 19-22:

$$
\begin{gathered}
\mathrm{CO}_{2}+4 \mathrm{H}_{2} \rightarrow \mathrm{CH}_{4}+2 \mathrm{H}_{2} \mathrm{O} \\
\mathrm{CO}+3 \mathrm{H}_{2} \rightarrow \mathrm{CH}_{4}+\mathrm{H}_{2} \mathrm{O} \\
\mathrm{CO}_{2}+\mathrm{H}_{2} \rightarrow \mathrm{CO}+\mathrm{H}_{2} \mathrm{O} \\
2 \mathrm{CO} \rightarrow \mathrm{C}(\mathrm{s})+\mathrm{CO}_{2}
\end{gathered}
$$

Methane selectivities for Ni-based catalysts are typically near 100\% (Götz, Koch, and Graf 2014). Also, the synthetic natural gas produced must have similar volumetric energy densities as natural gas found in current distribution networks. In the United States, natural gas typically has $2 \%$ more heat content than pure methane because of presence of $\mathrm{C}_{2+}$ fuels such as ethane and propane (Held and Scholwin 2015). Thus, for thermochemical methanation, achieving high conversions of $\mathrm{CO}_{2}$ to methane $(99 \%+)$ is needed to achieve natural gas specifications. We assume a stoichiometric $\mathrm{H}_{2}$ to $\mathrm{CO}_{2}$ ratio of $4: 1$ for the hydrogen demand estimation. The chemical route has electrical production efficiencies in between the electrochemical Base and Optimistic scenarios (Table 20). 
Table 20. E2M Methane Market Metrics and PV Installed Capacity Required for Product Synthesis via the Sabatier Reaction

\begin{tabular}{|c|c|c|c|c|c|}
\hline Scenario & $\begin{array}{l}\text { U.S. Market } \\
\text { Size } \\
\text { (million t/yr) }\end{array}$ & $\begin{array}{l}\text { Current } \\
\text { Market } \\
\text { Price }(\$ / k g)^{b}\end{array}$ & $\begin{array}{l}\text { Electrical } \\
\text { Production } \\
\text { Efficiency } \\
(\mathbf{k W h} / \mathbf{k g})^{\mathrm{c}}\end{array}$ & $\begin{array}{l}\text { Electricity } \\
\text { Demand to } \\
\text { Meet } 100 \% \\
\text { of Market } \\
(\mathrm{TWh} / \mathrm{y})^{\mathrm{c}}\end{array}$ & $\begin{array}{l}\text { PV Capacity } \\
\text { Required to } \\
\text { Meet } \\
\text { Additional } \\
\text { Load (GW)c }\end{array}$ \\
\hline Base & $579^{a}$ & 0.15 & 29 & 16,717 & 7,603 \\
\hline Energy Decarbonization & \multicolumn{5}{|c|}{$\mathrm{n} / \mathrm{a}$} \\
\hline
\end{tabular}

a EIA 2020i

b Grim et al. 2019

${ }^{c}$ Includes energy requirements for direct air capture of $\mathrm{CO}_{2}$; see the appendix for detailed calculations and assumptions. 


\section{Electricity Prices and Direct Electrons to Molecules Pathways}

Based on electrical efficiencies estimated for the Base and Optimistic scenarios, we estimate the maximum possible electricity price for different E2M products (Figure 6). These values represent the maximum possible electricity price that an E2M system could pay to produce the product at current market prices, assuming an electrolyzer capital cost of $\$ 400 / \mathrm{kW}$ and no other operational costs (see the appendix for detailed calculations). Higher maximum electricity prices are preferred, as they indicate that E2M production can be profitable even at higher electricity prices. Upper and lower bounds of maximum electricity prices represent the different in price ceilings between the base and optimistic case. Significant variability exists between the maximum prices, which depend on efficiency and market price for the product. The product pathways shown represent direct electrochemical pathways, although indirect pathways will be discussed in sections following as well.

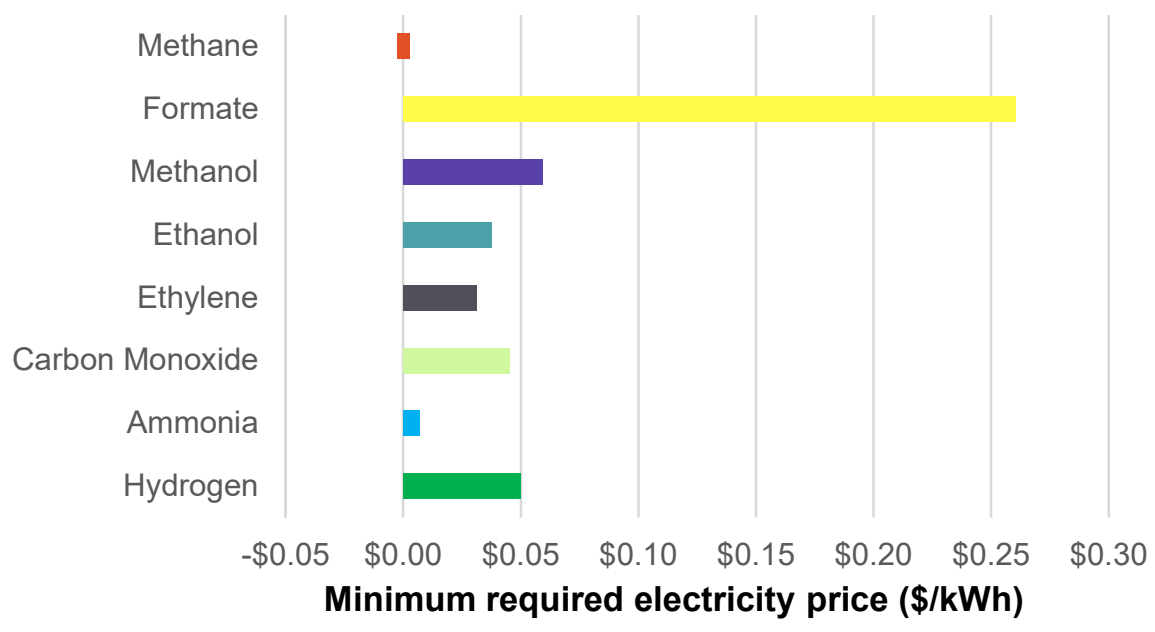

Figure 6. Ranges of electricity prices for selected E2M products for direct E2M pathways

Ranges are defined by the difference between required prices for the base and optimistic case. See the appendix for detailed calculations.

The electricity price ranges shown in Figure 6 are independent of the capacity factor of the E2M system and represent only the relationship between E2M efficiency and product market price. These prices assume any amount of electricity can be purchased at a given price, but in wholesale power markets, this is not the case. Wholesale electricity prices can become negative at certain times of the year, but these low-price periods might only exist for several hours. This limits the energy available at the given price, and subsequently the amount of product from an E2M system. Though we do not examine such considerations in detail here, they are important considerations for future E2M research.

Analysis results shown in Figure 6 should not be considered representative of a detailed technoeconomic analysis for any of the E2M pathways; however, they do help identify general opportunities to increase the economic competitiveness of E2M systems. In this case, the ranges of electricity prices depend on the electrical energy required per kilogram of product synthesized. The electrical efficiency of the process is driven by the thermodynamics of the reduction reaction 
taking place, which operates above the thermodynamic minimum because of inefficiencies in the system. Reductions in E2M system overpotentials could help decrease the electrical energy required per kilogram of product, and in turn increase the maximum electricity prices for these processes.

Maximum electricity prices increase in our Optimistic scenario, driven by advances in E2M efficiency that decrease the amount of electricity required per kilogram of product synthesized. This simplistic evaluation provides a high-level indication of how profitability might vary among the products we consider.

Of the pathways considered, formate exhibits the highest maximum electricity price, which indicates the single-step E2M process we consider could be a near-term opportunity for electrochemical synthesis. Formate could also serve as a potential precursor to new pathways such as direct formate fuel cells or as transport of syngas for chemical synthesis. Favorability for formate is driven by the low amount of electricity required per kilogram of product - an order of magnitude less than many other products (Table 16, page 23). Additionally, formic acid maintains all the initial mass of the input carbon dioxide. Carbon monoxide exhibits a similarly low energy requirement, but the current market price for $\mathrm{CO}$ is less than half that of formate, making the maximum electricity price slightly lower. Maximum electricity prices further illustrate the variation in economics among E2M processes. Though efficiency of the E2M plays a direct role, the current market prices for the products also determine the maximum electricity price.

Hydrogen exhibits a maximum electricity price range putting it within near-term opportunities. Hydrogen, with large scale commercial systems in operation around the world, also has the highest TRL of the direct electrochemical pathways we review (FuelCellsWorks 2020). More importantly, hydrogen from water electrolysis serves as an important intermediate in many of the indirect E2M processes described here. Enabling cost competitive hydrogen from electrolysis is an important step toward decarbonization of industry via E2M.

Except for methane, minimum electricity prices for all products are greater than zero. The slightly negative value for methane suggests a system would have to be paid to consume electricity to produce methane from $\mathrm{CO}_{2} \mathrm{R}$. This low economic favorability is driven by the low market prices for methane in the United States. Internationally, other more near-term opportunities may exist in regions with higher market prices for natural gas. Though a direct electrochemical path to methane might not be a near-term opportunity without policy support in the United States, several other pathways, such as biomethanation, are emerging as potential routes to produce renewable natural gas (NREL 2017).

A similar situation exists for ammonia, with the direct electrochemical synthesis pathway exhibiting a low electricity price ceiling. This suggests indirect E2M pathways for ammonia synthesis are more likely in the near term than the direct E2M one shown in Figure 6. The high electricity price ceiling shown for hydrogen suggests Haber-Bosch synthesis using electrolytic hydrogen could be a near-term opportunity for moving toward indirect E2M ammonia production (Section 3.2, page 12). 


\section{Social and Environmental Equity Implications for Electrons to Molecules}

Notable implications for environmental and social justice are associated with a shift to E2M-based supply chains. For example, widespread deployment of E2M technologies could have implications beyond the markets and supply chains for the products from these processes. And the significant amount of capital and infrastructure related to the products discussed here could impact local communities in terms of economic prosperity and public health. An exhaustive analysis of the social and environmental equity implications of E2M is beyond the scope of the work we report here, but we outline several key elements of this important area of research in this section.

Systems for production of organic chemicals are generally located where feedstocks for these processes are readily available. For example, ethylene production in the United States is highly concentrated on the Gulf Coast, where it is colocated with natural gas processing infrastructure. Because conventional ethylene synthesis relies on hydrocarbon gas liquids like ethane as a feedstock, it is advantageous to produce ethylene where hydrocarbon gas liquids (produced from oil and natural gas wells) are located. If ethylene is produced via $\mathrm{CO}_{2} \mathrm{R}$, feedstock requirements shift to sources of carbon dioxide and will likely drive a shift in where $\mathrm{CO}_{2} \mathrm{R}$ systems are located. This topic is the subject of recent work (Badgett, Feise, and Star 2021), which finds that a shift in the spatial location and scale of chemical processes is likely if production shifts to electrochemical synthesis technologies. And this shift could yield both costs and benefits to local communities where existing production systems are located. If existing supply chains are eliminated in favor of E2M, the localized health impacts from existing systems are reduced; however, if these systems are relocated, the community also loses a significant source of revenue and employment. Further research is needed to understand the specific tradeoffs of E2M system deployment and how such deployment might avoid negatively impacting communities.

At the global level, utilizing waste $\mathrm{CO}_{2}$ that would otherwise be emitted to the atmosphere and shifting production technologies to fully or partially electrified processes could reduce the carbon footprint of supply chains for the products discussed here. This shift could provide benefits on a global scale by reducing global greenhouse gas emissions. At a regional scale, E2M systems have significant potential to increase demand for renewable electricity that could be supplied to the system. Increased demand could drive higher deployment of wind, solar, and other renewable generation, and in turn produce downstream jobs and economic benefits from system manufacturing, installation, and operation. 


\section{R\&D Challenges and Opportunities for Electrons to Molecules and PV}

As penetration of PV and other sources of variable renewable power increases, the marginal economic value of energy generated from these sources is likely to change. High levels of PV penetration could reduce the marginal value of energy generated by lowering the value of the added capacity and energy (Mills and Wiser 2012). In other words, as total energy generated from variable renewable sources increases, the value of this energy could decrease if it is not always needed for the power sector. Such a situation could also result in low to negative wholesale electricity prices when supply exceeds demand, often during off-peak hours.

E2M systems capable of frequently cycling on and off during times of low electricity prices represent an emerging opportunity for increased deployment of these systems. E2M has been conventionally viewed as operating at high capacity factors with minimal system downtime; however, the increased prevalence of variable renewable generation creates opportunities for these systems to operate as dispatchable loads, using electricity when it is cheapest. The exact impact of variable operation on E2M systems is an emerging area of research that will likely gain momentum as low-cost dispatch-constrained electricity (LDE) from solar and other resources increases.

Figure 7 shows wholesale hourly location marginal prices (LMPs) of electricity for several locations across the United States, with hourly prices sorted from low to high. Though most hours fall in the range of $\$ 0-\$ 50 / \mathrm{MWh}$, notable numbers of hours exist where prices are below or above this range. An E2M system that selectively operates during low LMPs and cycles off for at times when LMPs are high could strategically reduce the average annual cost of supplying electricity to the system.

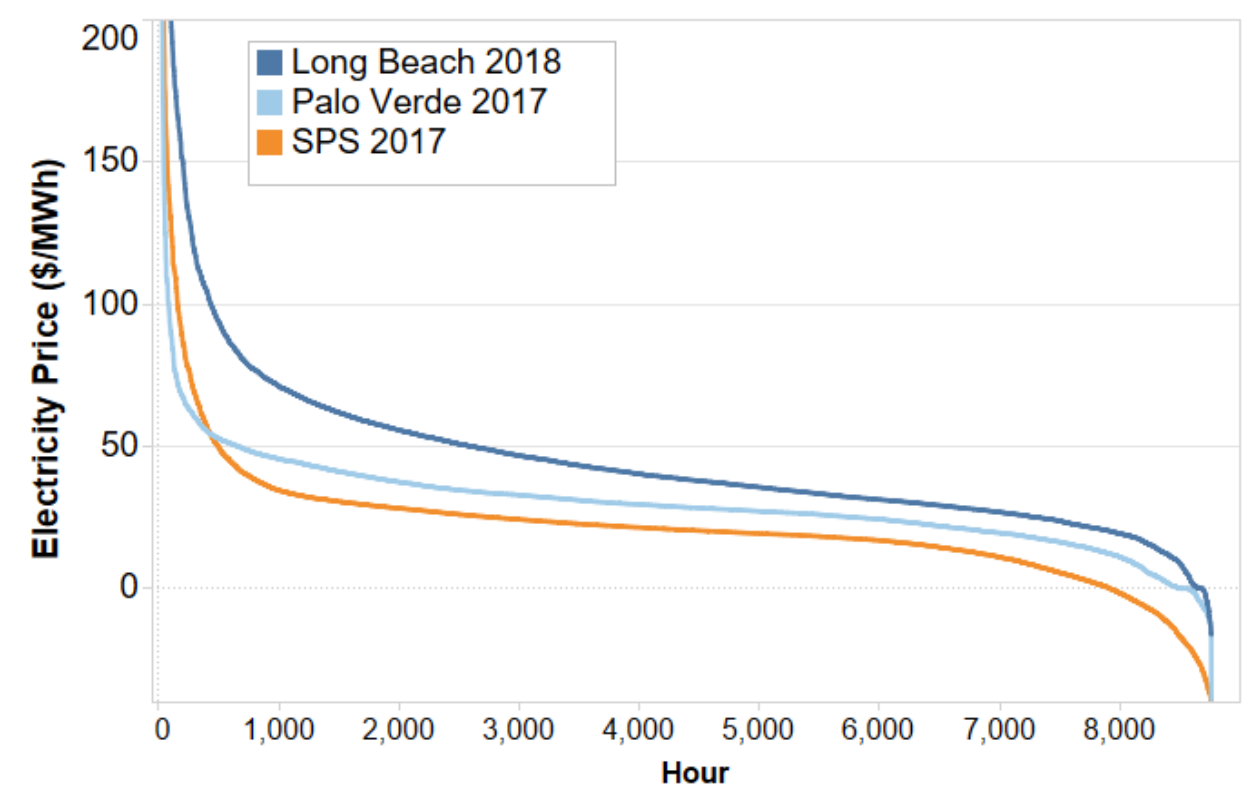

Figure 7. Price-duration curves for wholesale electricity at several locations

Source: Ruth et al. 2019

SPS $=$ Southwestern Public Service 
From the perspective of a flexible E2M load, LDE from power plants with low fuel costs (e.g., wind and solar) represents an opportunity to deploy E2M technologies that transform electrical energy into other products. For example, hydrogen could selectively be generated using electrolysis when LMPs are low, thus lowering the price of hydrogen produced by these systems. This selective operation at reduced capacity factors results in lower-cost electricity but increases the capital recovery costs; thus, there is a tradeoff between the two cost factors. An analysis of hydrogen produced from LDE is shown in Figure 8 for several electricity price schemes and electrolyzer capital costs (Ruth et al. 2019b). Wholesale electricity prices are preferrable, as they have the lowest markup of the retail alternatives shown.

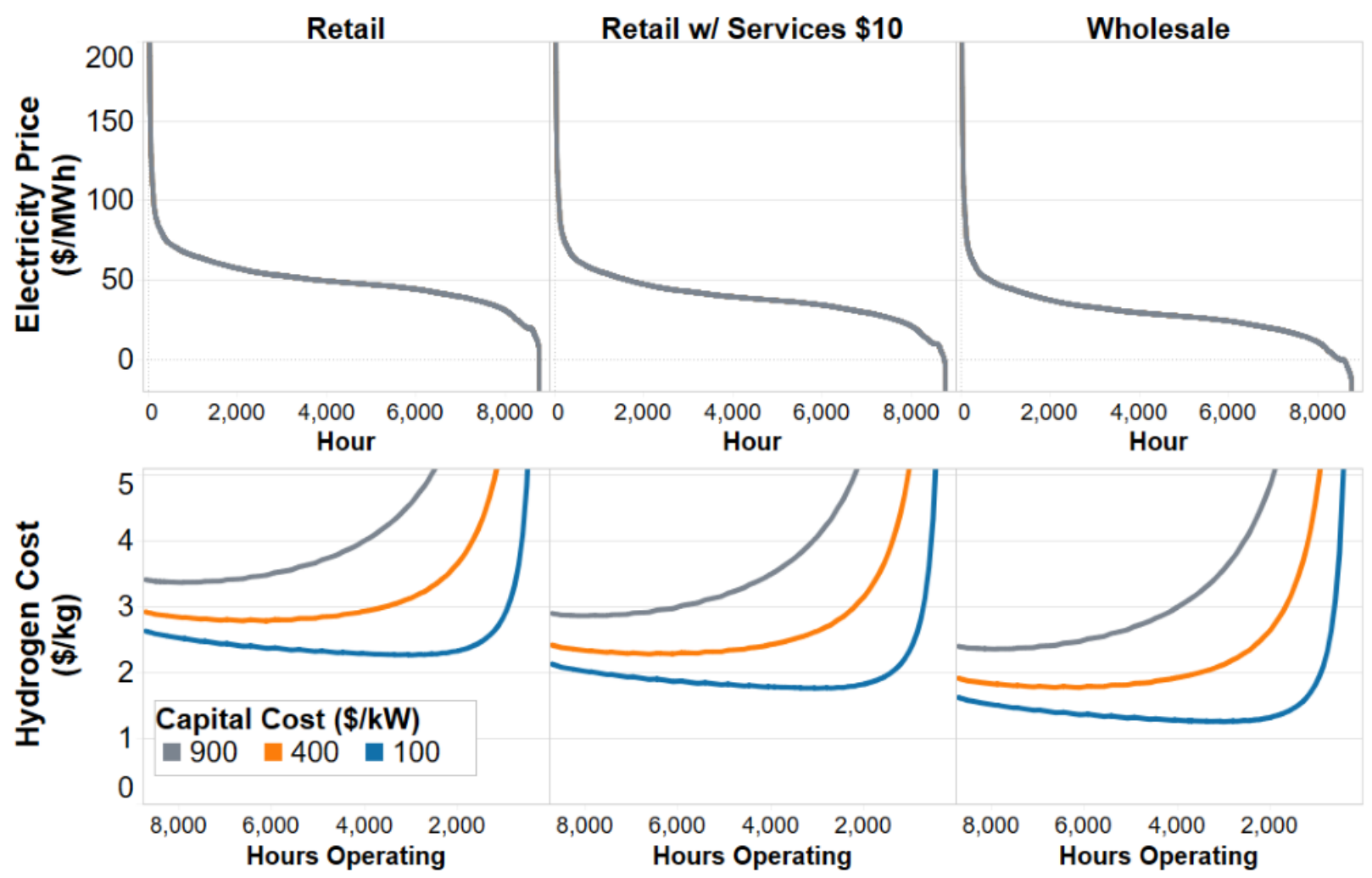

Figure 8. Cost of hydrogen produced via electrolysis at different capacity factors, using hourly electricity price data

Source: Ruth et al. 2019

Regardless of the type of electricity purchased by the electrolyzer, system capital costs play an important role in minimizing the costs of hydrogen produced, as indicated by different capital costs modeled in the second row of Figure 8. The capital cost also affects the shape of the cost curve and thus impacts the optimized costs of hydrogen produced. At low capacity factors (right side of the figure), capital cost recovery dominates; whereas, at high capacity factors (left side of the figure) average annual electricity costs increase, driving hydrogen production costs up for the system at higher operating hours. High capital cost systems experience minimized hydrogen costs at high capacity factors, and systems with low capital costs can minimize costs across a broader range of capacity factors. Figure 8 suggests hydrogen can be produced at or below the DOE target of $\$ 2 / \mathrm{kg}$ (Vickers, Peterson, and Randolph 2020) when the electrolyzer uses lowcost wholesale electricity and achieves low capital costs (Ruth et al. 2019a). 
Assuming E2M systems can operate as flexible loads across different time intervals, their operation is likely to be limited by the time and amount of total energy available. The capacity factor of an E2M system is constrained by the amount of LDE available, which has downstream effects on the economics of the E2M system. Operation at a low capacity factor increases the cost per kilogram of product produced, because the capital cost of the system is distributed over the smaller production rate. Reducing E2M capital costs is a key opportunity for enabling economic E2M operation at low capacity factors. In this work, we primarily discuss E2M potential in terms of energy (TWh) and not installed capacity (TW), but the influence of capacity factors on system costs is acknowledged.

Although we do not discuss curtailed energy in detail, it is another opportunity for E2M systems. Curtailed energy is often available at low costs, but its availability is variable and total curtailed energy available may or may not be sufficient for E2M operation. Regional Energy Deployment System modeling completed as part of the Solar Futures Study suggests over 400 TWh of curtailed energy could be produced across the United States by 2050 in the Decarbonization scenario. And at increased electrification in the Decarbonization + Electrification scenario, total annual curtailed energy could exceed 800 TWh (Mai et al. 2021). Though this amount of energy is certainly not negligible, energy consumption estimates reported here show that curtailed energy alone is insufficient to meet total energy demand from E2M-based supply chains for the subset of products considered here.

Though these factors can help E2M systems realize reductions in costs, such actions can also spur deployment of PV and other renewable generation. Recent work has investigated the potential for hydrogen production via water electrolysis to support the increased deployment of renewable power generation (Ruth et al. 2019b; 2020). Given its low system costs ( $\$ 100 / \mathrm{kW})$, electrolysis can serve as a flexible load that encourages capacity expansion of PV (Ruth et al. 2020). Adding electrolysis as a flexible load encourages deployment of variable renewable generation and the reduction of baseload generation, including coal and natural gas. In the Solar Futures Study, increased renewable generation and capacity modeled in the Decarbonization and Decarbonization + Electrification scenarios could result in similar opportunities for E2M systems (Figure 9) (Mai et al. 2021).

Electrolysis can support increased deployment of renewable electricity sources by serving as a flexible load that can use electricity generated from renewables that is available at low wholesale prices when grid electricity demand is low. The total amount of energy that can be dedicated to E2M systems depends on both the amount of renewable deployment on the grid and the grid generation mix, in addition to assumptions regarding cross-sectoral electrification. The additional renewable capacity shown in the Figure 9 scenarios (page 34) results in notable opportunities for E2M to both support a decarbonized grid and create pathways to decarbonization in other sectors. The increased deployment of wind and PV capacity shown in these scenarios is significant, and further potential for deployment exists if E2M technologies are deployed in conjunction with renewables.

To reduce the total cost of hydrogen produced from electrolysis that uses electricity from PV, recent work has explored the possibility of directly coupling wind, PV, and E2M systems (Jia et al. 2016; Clarke et al. 2009; Zhou and Liu 2013). Such a configuration allows for maximizing the solar-to-hydrogen efficiency and in turn lowering costs. Coupled systems minimize logistical 
constraints between systems and afford an opportunity to reduce some of the power electronics and balance-of-plant infrastructure required for the systems. This emerging field of research is likely to evolve as deployment of PV and E2M systems increases. And one can envision an electrolyzer coupled with a PV facility as a base electric supply that could ramp up when lowcost electricity is available. Such an approach could maximize the system duty cycle and revenues.

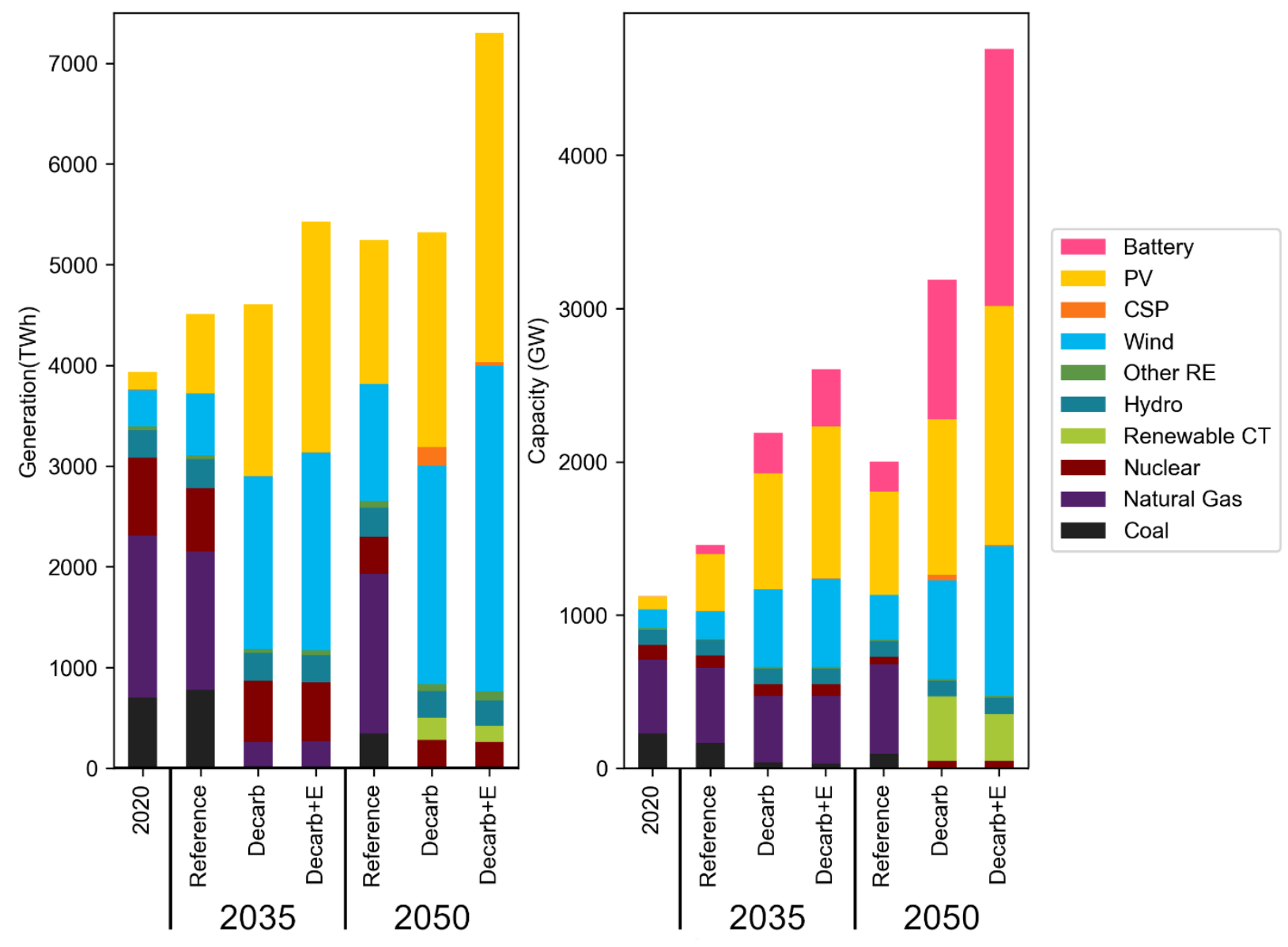

Figure 9. Modeled electricity generation for select electrolysis scenarios

Source: Solar Futures Study scenarios (Mai et al. 2021)

$\mathrm{CSP}=$ concentrating solar power; $\mathrm{CT}=$ combustion turbine; $\mathrm{RE}=$ renewable energy 


\section{Conclusions}

E2M can make products that are used across the transportation, industrial, and electric power sectors. E2M pathways for these products generally use electricity to drive an electrochemical reaction, transforming feedstock molecules into products. These production systems can be coupled with other processes, both upstream and downstream of the electrochemical reactor, to produce more-complex products. Current E2M technologies exhibit varying degrees of maturity, and recent $R \& D$ has focused on advances in efficiency and durability.

Realizing the potential for electrification across industry and transportation would likely significantly increase the demand for electricity beyond current levels. E2M and PV could serve as building blocks for economy-wide decarbonization by providing low-carbon molecules that can be used in various sectors, from transportation to industry. In this report, we provide an overview of emerging processes that rely on E2M either directly or indirectly. We also provide a highlevel quantification of the potential energy demands that supply chains dependent on E2M might experience. Here we summarize the four main potential opportunities for E2M and solar PV identified in this report. These opportunities could help increase deployment of economically competitive E2M and PV systems at industrially relevant scales.

Reducing E2M system capital costs while realizing increases in system efficiency, lifetime, and durability while identifying opportunities for directly coupling E2M and PV

PV and E2M systems have both experienced notable gains in performance from R\&D investments in recent years, yielding decreases in installed costs. PV currently represents a lowcost option for electricity supplied to the electric power sector, in turn making it a favorable source of electricity for reaction-driven E2M processes. Capital costs for electrochemical energy storage systems are expected to decrease, thus facilitating increases in their deployment. Realizing decreases in capital costs without sacrificing system performance, durability, or lifetime is crucial to making the fuels and chemicals they produce cost-competitive with existing processes, and for enabling variable operation of these systems with LDE at low capacity factors.

Solar PV has the potential to play a central role in the development of energy systems that produce both electricity and molecular products, where coupling PV and E2M systems represents a synergistic opportunity for both technologies. For example, the benefit of a PV installation could be maximized by adding a flexible load capable of using low-cost electricity. Excess energy could be used by E2M systems in the formation of fuels or chemicals, or the systems could be used to store electricity. Physically coupling these systems could provide opportunities to decrease the power electronics cost for a hybridized system.

Deploying E2M systems that can operate as dispatchable loads, actively cycling on and off to use energy from low-cost dispatch-constrained electricity such as wind and solar

Power generation technologies such as wind, solar PV, and nuclear exhibit low operating costs because of their low to zero fuel costs. These sources of LDE are incentivized to always produce as much power as possible. Conventional power generation for the grid is operated to follow load as much as possible; however, LDE generators do not have financial incentive to do so because of their lack of fuel costs. LDE penetration and other factors can result in many hours of the year with low-cost electricity; however, the total amount of such electricity varies by location and generation mix (Ruth et al. 2019b). 
For E2M systems to capitalize on the increased availability of LDE from sources of energy like PV, E2M must be able to operate as a dispatchable load, ramping up and down, or turning on and off at time intervals ranging from hours to minutes. This represents a challenge for system design and operation, as E2M has conventionally been viewed as operating at high capacity factors with minimal downtime. Reducing any detrimental effects that high levels of cycling have on system performance and durability is an emerging area of research that is important for enabling widespread deployment of E2M.

\section{Identification of products and pathways for direct and indirect E2M systems}

This report has demonstrated that multiple pathways exist to electrify supply chains for the products considered here and provided a cursory analysis into the feasibility of direct and indirect E2M pathways, quantifying their differences with electrical efficiencies for each pathway. Prioritization of near-term E2M products and pathways is a key opportunity that can help facilitate E2M deployment. Future work would be well suited to conduct economic, life cycle, and market assessments of various E2M pathways to provide a holistic perspective on opportunities. Such work could help facilitate the development of E2M systems, furthering economy-wide decarbonization efforts.

Enabling E2M access to wholesale power markets, compensating E2M systems for any grid services they provide while increasing demand for electricity generated from PV

Many E2M conversion pathways are at low technology readiness levels, and recent research on these pathways has focused on advances in their efficiency, reliability, and scalability. Additionally, techno-economic analyses of these technologies have identified electricity prices as a key driver of production costs (Colella et al. 2014; De Luna et al. 2019; Jouny, Luc, and Jiao 2018b), underscoring the need for supplying low-cost, renewable electricity to these processes.

Providing access to wholesale power markets reduces the cost of electricity supplied to the E2M system and enables the system to selectively operate during times of low location marginal prices (LMPs). Increased deployment of PV is likely to result in more LDE and in turn enable E2M to utilize some of this energy. Key market metrics for PV and E2M are summarized by product molecule in Table 21 (page 37). The electrical production efficiency for the Base scenario was determined assuming current state of technology for selectivity and whole-cell potential, while the Optimistic scenario assumed unity selectivity and standard reduction potentials with a small system overpotential (see the appendix). Table 21 suggests that producing one or several of the potential products using PV and E2M represents a significant opportunity for increased demand for electricity from PV, regardless of the scenario considered (i.e., Base or Optimistic scenario).

For reference, as of 2019, the United States generated about 103 TWh from just over $60 \mathrm{GW}$ of installed PV capacity (EIA 2020e; 2020c). These estimates demonstrate the significant size of potential markets for PV supporting E2M systems, and the many different product pathways emerging to meet the markets. As deployment of PV and E2M systems progress, realizing the opportunities for coupling these two systems is likely to increase deployment of both systems. 
Table 21. Summary of PV Generation and Capacity Required for E2M Synthesis of Key Chemicals and Fuels

\begin{tabular}{|c|c|c|c|c|c|c|}
\hline Product & $\begin{array}{l}\text { Electricity } \\
\text { Demand to } \\
\text { Meet } 100 \% \text { of } \\
\text { Market } \\
\text { (TWh/y) }\end{array}$ & $\begin{array}{l}\text { PV } \\
\text { Capacity } \\
\text { Required } \\
\text { to Meet } \\
\text { Additional } \\
\text { Load (GW) }\end{array}$ & $\begin{array}{l}\text { Electricity } \\
\text { Demand } \\
\text { to Meet } \\
100 \% \text { of } \\
\text { Market } \\
\text { (TWh/y) }\end{array}$ & $\begin{array}{l}\text { PV } \\
\text { Capacity } \\
\text { Required to } \\
\text { Meet } \\
\text { Additional } \\
\text { Load (GW) }\end{array}$ & $\begin{array}{l}\text { Electricity } \\
\text { Demand to } \\
\text { Meet } 100 \% \\
\text { of Market } \\
\text { (TWh/y) }\end{array}$ & $\begin{array}{l}\text { PV } \\
\text { Capacity } \\
\text { Required to } \\
\text { Meet } \\
\text { Additional } \\
\text { Load (GW) }\end{array}$ \\
\hline Scenario & \multicolumn{2}{|c|}{ Base } & \multicolumn{2}{|c|}{ Optimistic } & \multicolumn{2}{|c|}{ Energy Decarbonization } \\
\hline Hydrogen & 505 & 230 & 2,367 & 1,077 & $960^{\mathrm{a}}$ & $437^{a}$ \\
\hline Ammonia & 433 & 197 & 343 & 156 & 470 & 214 \\
\hline $\begin{array}{l}\text { Carbon } \\
\text { Monoxide }\end{array}$ & 14 & 6 & 11 & 5 & \multicolumn{2}{|c|}{$\mathrm{n} / \mathrm{a}$} \\
\hline Ethylene & 2,157 & 981 & 777 & 353 & \multicolumn{2}{|c|}{$\mathrm{n} / \mathrm{a}$} \\
\hline Ethanol & 2,916 & 1,326 & 880 & 400 & \multicolumn{2}{|c|}{$\mathrm{n} / \mathrm{a}$} \\
\hline Methanol & 54 & 25 & 60 & 27 & 146 & 66 \\
\hline Formate & 0.5 & 0.2 & 0.2 & 0.1 & \multicolumn{2}{|c|}{$\mathrm{n} / \mathrm{a}$} \\
\hline Methane & 24,011 & 10,920 & 10,350 & 4,707 & \multicolumn{2}{|c|}{$\mathrm{n} / \mathrm{a}$} \\
\hline
\end{tabular}

a Direct hydrogen values shown, indirect hydrogen energy demand is captured in ammonia and methanol rows 


\section{References}

Abney, Morgon B., Matthew Mansell, Bill Barnett, Christine M. Stanley, Christian Junaedi, Saurabh A. Vilekar, and Ryan Kent. 2016. "Demonstration of Robustness and Integrated Operation of a Series-Bosch System.” In 46th International Conference on Enviromental Systems.

Air Liquide. 2021. "Lurgi MegaMethanol ${ }^{\mathrm{TM}}$ | Air Liquide.” 2021. https://www.engineeringairliquide.com/lurgi-megamethanol.

American Chemistry Council. 2020. "Guide to the Business of Chemistry 2020."

Andersen, Suzanne Z., Viktor Čolić, Sungeun Yang, Jay A. Schwalbe, Adam C. Nielander, Joshua M. McEnaney, Kasper Enemark-Rasmussen, et al. 2019. "A Rigorous Electrochemical Ammonia Synthesis Protocol with Quantitative Isotope Measurements." Nature 570 (7762): 504-8. https://doi.org/10.1038/s41586-019-1260-x.

Ardani, Kristen, Chad Hunter, Caley Johnson, and Sam Koebrich. 2021. "Maximizing Solar and Transportation Synergies.” Golden, CO (United States).

Badgett, Alex, Alison Feise, and Andrew Star. 2021. "Optimal Utilization of Carbon Dioxide as a Feedstock in Electrochemical CO2 Reduction." In Progress.

Badgett, Alex, Mark Ruth, Brian James, and Bryan Pivovar. 2021. "Methods Identifying Cost Reduction Potential for Water Electrolysis Systems." Current Opinion in Chemical Engineering 33 (September): 100714. https://doi.org/10.1016/j.coche.2021.100714.

BASF. 2012. "BASF to Build New Formic Acid Plant in Geismar, Louisiana." 2012. https://www.basf.com/us/en/media/news-releases/2012/05/p-12-104.html.

_. 2020. "Formic Acid.” 2020. https://www.basf.com/us/en/products/General-BusinessTopics/formic-acid.html.

Bhandari, Ramchandra, Clemens A. Trudewind, and Petra Zapp. 2014. "Life Cycle Assessment of Hydrogen Production via Electrolysis - A Review." Journal of Cleaner Production 85: 15163. https://doi.org/10.1016/j.jclepro.2013.07.048.

Bierhals, Jürgen. 2001. “Carbon Monoxide.” In Ullmann's Encyclopedia of Industrial Chemistry, 619-28. Weinheim, Germany: Wiley-VCH Verlag GmbH \& Co. KGaA. https://doi.org/10.1002/14356007.a05_203.

Brisse, Annabelle, Josef Schefold, and Mohsine Zahid. 2008. "High Temperature Water Electrolysis in Solid Oxide Cells.” International Journal of Hydrogen Energy 33 (20): 5375-82. https://doi.org/10.1016/j.ijhydene.2008.07.120.

Carbon Recycling International. 2020. "Projects: Emissions-to-Liquids Technology - CRI Carbon Recycling International.” 2020. https://www.carbonrecycling.is/projects. 
CEN. 2008. "CO as Feedstock Mitsui Will Make Methanol from the Greenhouse Gas." Chemical \& Engineering News 86 (35): 13. https://doi.org/10.1021/cen-v086n035.p013a.

Chemical Engineering News. 2015. "Why Chemical Makers Have Their Eyes On Formic Acid." 2015. https://cen.acs.org/articles/93/i48/Chemical-Makers-Eyes-Formic-Acid.html.

Chen, John Q., Andrea Bozzano, Bryan Glover, Terje Fuglerud, and Steinar Kvisle. 2005. "Recent Advancements in Ethylene and Propylene Production Using the UOP/Hydro MTO Process." In Catalysis Today, 106:103-7. Elsevier. https://doi.org/10.1016/j.cattod.2005.07.178.

Chen, L., Q. Jiang, Z. Song, and D. Posarac. 2011. "Optimization of Methanol Yield from a Lurgi Reactor." Chemical Engineering and Technology 34 (5): 817-22.

https://doi.org/10.1002/ceat.201000282.

Chen, Shiming, Siglinda Perathoner, Claudio Ampelli, and Gabriele Centi. 2019.

Electrochemical Dinitrogen Activation: To Find a Sustainable Way to Produce Ammonia. Studies in Surface Science and Catalysis. 1st ed. Vol. 178. Elsevier B.V. https://doi.org/10.1016/B978-0-444-64127-4.00002-1.

Chen, Yingying, Ashlee Vise, W. Ellis Klein, Firat C. Cetinbas, Deborah J. Myers, Wilson A. Smith, Todd G. Deutsch, and K. C. Neyerlin. 2020. "A Robust, Scalable Platform for the Electrochemical Conversion of CO 2 to Formate: Identifying Pathways to Higher Energy Efficiencies." ACS Energy Letters 5 (6): 1825-33. https://doi.org/10.1021/acsenergylett.0c00860.

Choi, Yong Man, and Ping Liu. 2009. "Mechanism of Ethanol Synthesis from Syngas on $\mathrm{Rh}(111) . "$ Journal of the American Chemical Society 131 (36): 13054-61. https://doi.org/10.1021/ja903013x.

Chua, W. X., S. da Cunha, G. P. Rangaiah, and K. Hidajat. 2019. "Design and Optimization of Kemira-Leonard Process for Formic Acid Production." Chemical Engineering Science: X 2: 100021. https://doi.org/10.1016/j.cesx.2019.100021.

Clarke, R. E., S. Giddey, F. T. Ciacchi, S. P.S. Badwal, B. Paul, and J. Andrews. 2009. "Direct Coupling of an Electrolyser to a Solar PV System for Generating Hydrogen.” International Journal of Hydrogen Energy 34 (6): 2531-42. https://doi.org/10.1016/j.ijhydene.2009.01.053.

Colella, Whitney, Brian James, Jennie Moton, Genevieve Saur, and Todd Ramsden. 2014. "Techno-Economic Analysis of PEM Electrolysis for Hydrogen Production." Electrolytic Hydrogen Production Workshop.

https://www.energy.gov/sites/prod/files/2014/08/f18/fcto_2014_electrolytic_h2_wkshp_colella1. pdf.

Connelly, Elizabeth, Amgad Elgowainy, and Mark Ruth. 2019. "Current Hydrogen Market Size: Domestic and Global."

Davis, Steven J, Nathan S Lewis, Matthew Shaner, Sonia Aggarwal, Doug Arent, Inês L Azevedo, Sally M Benson, et al. 2018. "Net-Zero Emissions Energy Systems." Science 360 (6396). https://doi.org/10.1126/science.aas9793. 
Daza, Yolanda A, and John N Kuhn. 2016. "CO2 Conversion by Reverse Water Gas Shift Catalysis: Comparison of Catalysts $\{$,$\} Mechanisms and Their Consequences for CO2$ Conversion to Liquid Fuels." RSC Adv. 6 (55): 49675-91. https://doi.org/10.1039/C6RA05414E.

Dieterich, Vincent, Alexander Buttler, Andreas Hanel, Hartmut Spliethoff, and Sebastian Fendt. 2020. "Power-to-Liquid via Synthesis of Methanol, DME or Fischer-Tropsch-Fuels: A Review." Energy and Environmental Science 13 (10): 3207-52. https://doi.org/10.1039/d0ee01187h.

DOE. 2018. "Ethane Storage and Distribution Hub in the United States."

—. 2020. “H2@Scale.” 2020. https://www.energy.gov/eere/fuelcells/h2scale.

Dzuryk, Stephen, and Ebrahim Rezaei. 2020. "Intensification of the Reverse Water Gas Shift Reaction by Water-Permeable Packed-Bed Membrane Reactors." Industrial and Engineering Chemistry Research 59 (42): 18907-20. https://doi.org/10.1021/acs.iecr.0c02213.

E.C. Heydorn, B.W. Diamond, and R.D. Lilly. 2003. "Commercial-Scale Demonstration of the Liquid Phase Methanol (LPMEOH) Process." Undang-Undang Republik Indonesia Nomor 20 Tahun 2003 Tentang Sistem Pendidikan Nasional Dengan Rahmat Tuhan Yang Maha Esa Presiden Republik Indonesia. Vol. 2. Pittsburgh, PA, and Morgantown, WV. https://doi.org/10.2172/823132.

EIA. 2018. “Annual Energy Outlook 2018.” https://www.eia.gov/outlooks/aeo/data/browser/.

—. 2020a. “Annual Energy Outlook 2020.” 2020. https://www.eia.gov/outlooks/aeo/.

_. 2020b. "China's Use of Methanol in Liquid Fuels Has Grown Rapidly since 2000." 2020. https://www.eia.gov/todayinenergy/detail.php?id=30072.

—. 2020c. "Electric Power Monthly." 2020.

https://www.eia.gov/electricity/monthly/epm_table_grapher.php?t=epmt_1_01_a.

_. 2020d. "Electric Power Monthly." 2020.

https://www.eia.gov/electricity/monthly/epm_table_grapher.php?t=epmt_6_07_b.

—. 2020e. "Electricity Data." 2020. https://www.eia.gov/electricity/data.php\#gencapacity.

—. 2020f. "Ethanol Explained - U.S. Energy Information Administration (EIA)." 2020. https://www.eia.gov/energyexplained/biofuels/ethanol.php.

_. 2020g. "New Methanol Plants Expected to Increase Industrial Natural Gas Use through 2020.”2020. https://www.eia.gov/todayinenergy/detail.php?id=38412.

_.2020h. "Prices for Hydrocarbon Gas Liquids." 2020. https://www.eia.gov/energyexplained/hydrocarbon-gas-liquids/prices-for-hydrocarbon-gasliquids.php.

- 2020i. "U.S. Natural Gas Consumption by End Use.” 2020. https://www.eia.gov/dnav/ng/ng_cons_sum_dcu_nus_a.htm. 
Endrödi, B., E. Kecsenovity, A. Samu, F. Darvas, R. V. Jones, V. Török, A. Danyi, and C. Janáky. 2019. "Multilayer Electrolyzer Stack Converts Carbon Dioxide to Gas Products at High Pressure with High Efficiency.” ACS Energy Letters 4 (7): 1770-77. https://doi.org/10.1021/acsenergylett.9b01142.

Fan, Lei, Chuan Xia, Peng Zhu, Yingying Lu, and Haotian Wang. 2020. "Electrochemical CO2 Reduction to High-Concentration Pure Formic Acid Solutions in an All-Solid-State Reactor." Nature Communications 11 (1): 1-9. https://doi.org/10.1038/s41467-020-17403-1.

Freist, Roland. 2019. "Energy Solutions: Hamburg to Build World's Largest Hydrogen Electrolysis Plant.” 2019. https://www.hannovermesse.de/en/news/news-articles/hamburg-tobuild-worlds-largest-hydrogen-electrolysis-plant.

FuelCellsWorks. 2019. "Hamburg to Build the World's Largest Hydrogen Plant at Its Port." 2019. https://fuelcellsworks.com/news/hamburg-to-build-the-worlds-largest-hydrogen-plant-inits-port/.

2020. "World's Largest Hydrogen Plant Opens in Fukushima.” 2020.

https://fuelcellsworks.com/news/worlds-largest-hydrogen-plant-in-fukushima-opens/.

Gahleitner, Gerda. 2013. "Hydrogen from Renewable Electricity: An International Review of Power-to-Gas Pilot Plants for Stationary Applications." International Journal of Hydrogen Energy. Elsevier Ltd. https://doi.org/10.1016/j.ijhydene.2012.12.010.

García de Arquer, F. Pelayo, Cao-Thang Dinh, Adnan Ozden, Joshua Wicks, Christopher McCallum, Ahmad R. Kirmani, Dae-Hyun Nam, et al. 2020. "CO 2 Electrolysis to Multicarbon Products at Activities Greater than 1 A Cm -2.” Science 367 (6478): 661-66. https://doi.org/10.1126/science.aay4217.

Gogate, Makarand R. 2019. "Methanol-to-Olefins Process Technology: Current Status and Future Prospects." Petroleum Science and Technology 37 (5): 559-65.

https://doi.org/10.1080/10916466.2018.1555589.

Götz, Manuel, Amy Koch, and Frank Graf. 2014. "State of the Art and Perspectives of CO2 Methanation Process Concepts for Power-to-Gas Applications." In International Gas Research Conference Proceedings. Vol. 1.

Götz, Manuel, Jonathan Lefebvre, Friedemann Mörs, Amy McDaniel Koch, Frank Graf, Siegfried Bajohr, Rainer Reimert, and Thomas Kolb. 2016. "Renewable Power-to-Gas: A Technological and Economic Review." Renewable Energy 85: 1371-90. https://doi.org/10.1016/j.renene.2015.07.066.

Grand View Research. 2020. "U.S. Industrial Ethanol Market Size Trends Report, 2019-2025." 2020. https://www.grandviewresearch.com/industry-analysis/us-industrial-ethanol-market.

Grim, R. Gary, Zhe Huang, Michael T. Guarnieri, Jack R. Ferrell, Ling Tao, and Joshua A. Schaidle. 2019. "Transforming the Carbon Economy: Challenges and Opportunities in the Convergence of Low-Cost Electricity and Reductive CO2 Utilization." Energy \& Environmental Science. https://doi.org/10.1039/C9EE02410G. 
Haegel, Nancy M., Harry Atwater, Teresa Barnes, Christian Breyer, Anthony Burrell, Yet-Ming Chiang, Stefaan De Wolf, et al. 2019. "Terawatt-Scale Photovoltaics: Transform Global Energy." Science 364 (6443): 836-38. https://doi.org/10.1126/science.aaw1845.

Held, Jorgen, and Frank Scholwin, eds. 2015. "The Role of Biogas in the Global Energy Transition." In 2nd International Conference on Renewable Energy Gas Technology, 1-4. Barcelona, Spain: REGATEC 2015.

Hongxing, Liu, Xie Zaiku, and Zhao Guoliang. 2013. "The Progress of SINOPEC Methanol-toOlefins (S-MTO) Technology.” In DGMK Tagungsbericht, 89-92. DGMK Conference.

https://www.osti.gov/etdeweb/servlets/purl/22176038.

Huang, Zhe, Gary Grim, Joshua Schaidle, and Ling Tao. 2020. "Using Waste CO2 to Increase Ethanol Production from Corn Ethanol Biorefineries: Techno-Economic Analysis." Applied Energy 280 (April): 115964. https://doi.org/10.1016/j.apenergy.2020.115964.

ICIS. 2020. "Ethylene Prices, Markets \& Analysis." 2020.

https://www.icis.com/explore/commodities/chemicals/ethylene/.

IHS. 2021. "IHS Markit.” 2021. https://ihsmarkit.com/index.html.

Intratec. 2013. Technology Economics: Ethylene Production Via Ethanol Dehydration. CreateSpace Independent Publishing Platform. https://books.google.com/books?id=MRsTaP5z1fYC.

IPCC. 2014. Climate Change 2014 Mitigation of Climate Change. Climate Change 2014 Mitigation of Climate Change. https://doi.org/10.1017/cbo9781107415416.

Jadhav, Suhas G., Prakash D. Vaidya, Bhalchandra M. Bhanage, and Jyeshtharaj B. Joshi. 2014. "Catalytic Carbon Dioxide Hydrogenation to Methanol: A Review of Recent Studies." Chemical Engineering Research and Design 92 (11): 2557-67. https://doi.org/10.1016/j.cherd.2014.03.005.

Jarvis, Sean M., and Sheila Samsatli. 2018. "Technologies and Infrastructures Underpinning Future CO2 Value Chains: A Comprehensive Review and Comparative Analysis." Renewable and Sustainable Energy Reviews 85 (January): 46-68. https://doi.org/10.1016/j.rser.2018.01.007.

Jia, Jieyang, Linsey C. Seitz, Jesse D. Benck, Yijie Huo, Yusi Chen, Jia Wei Desmond Ng, Taner Bilir, James S. Harris, and Thomas F. Jaramillo. 2016. "Solar Water Splitting by Photovoltaic-Electrolysis with a Solar-to-Hydrogen Efficiency over 30\%." Nature Communications 7 (May): 1-6. https://doi.org/10.1038/ncomms13237.

Jouny, Matthew, Gregory S. Hutchings, and Feng Jiao. 2019. "Carbon Monoxide Electroreduction as an Emerging Platform for Carbon Utilization." Nature Catalysis 2 (12): 1062-70. https://doi.org/10.1038/s41929-019-0388-2.

Jouny, Matthew, Wesley Luc, and Feng Jiao. 2018a. "High-Rate Electroreduction of Carbon Monoxide to Multi-Carbon Products." Nature Catalysis 1 (10): 748-55.

https://doi.org/10.1038/s41929-018-0133-2. 
_. 2018b. "General Techno-Economic Analysis of CO 2 Electrolysis Systems." Industrial \& Engineering Chemistry Research 57 (6): 2165-77. https://doi.org/10.1021/acs.iecr.7b03514.

Junaedi, Christian, Kyle Hawley, Dennis Walsh, Subir Roychoudhury, Morgan Abney, and Jay L. Perry. 2011. "Compact and Lightweight Sabatier Reactor for Carbon Dioxide Reduction." NASA. https://ntrs.nasa.gov/api/citations/20120016419/downloads/20120016419.pdf.

Keith, David W., Geoffrey Holmes, David St. Angelo, and Kenton Heidel. 2018. "A Process for Capturing CO2 from the Atmosphere." Joule 2 (8): 1573-94. https://doi.org/10.1016/j.joule.2018.05.006.

Khoo, Hsien H., Iskandar Halim, and Albertus D. Handoko. 2020. "LCA of Electrochemical Reduction of CO2to Ethylene." Journal of CO2 Utilization 41 (May): 101229. https://doi.org/10.1016/j.jcou.2020.101229.

Knighton, Lane T, Lesley Snowden-Swan, Daniel S Wendt, Jeromy Jenks, Charles Freeman, and Jalal Askander. 2020. "Techno-Economic Analysis of Synthetic Fuels Pathways Integrated with Light Water Reactors.” https://inldigitallibrary.inl.gov/sites/sti/sti/Sort_26721.pdf.

Küngas, Rainer. 2020. “ Review_-Electrochemical CO 2 Reduction for CO Production: Comparison of Low- and High-Temperature Electrolysis Technologies ." Journal of The Electrochemical Society 167 (4): 044508. https://doi.org/10.1149/1945-7111/ab7099.

Kutscher, Charles F, Jeffrey S Logan, and Timothy C Coburn. 2020. "Accelerating the US Clean Energy Transformation Challenges and Solutions by Sector Challenges and Solutions by Sector." Boulder, Colorado. https://www.colorado.edu/rasei/sites/default/files/attachedfiles/accelerating_the_us_clean_energy_transformation_final.2.pdf.

Lan, Rong, John T.S. Irvine, and Shanwen Tao. 2012. "Ammonia and Related Chemicals as Potential Indirect Hydrogen Storage Materials.” International Journal of Hydrogen Energy 37 (2): 1482-94. https://doi.org/10.1016/j.ijhydene.2011.10.004.

LanzaTech. 2018a. "LanzaTech - No Such Thing as Waste." https://ccnet-nibb.co.uk/wpcontent/uploads/2018/04/simpson.pdf.

- 2018b. "World's First Commercial Waste Gas to Ethanol Plant Starts Up | LanzaTech." 2018. https://www.lanzatech.com/2018/06/08/worlds-first-commercial-waste-gas-ethanol-plantstarts/.

—. 2021. "LanzaTech | Capturing Carbon. Fueling Growth.” 2021. https://www.lanzatech.com/.

Lee, Uisung, Troy R Hawkins, Eunji Yoo, Michael Wang, Zhe Huang, and Ling Tao. 2020. "Using Waste CO2 from Corn Ethanol Biorefineries for Additional Ethanol Production: LifeCycle Analysis." Biofuels, Bioproducts and Biorefining, 1-13. https://doi.org/10.1002/bbb.2175.

Lewandowski, Steve. 2016. "Ethylene - Global." 2016. http://cdn.ihs.com/www/pdf/SteveLewandowski-Big-Changes-Ahead-for-Ethylene-Implications-for-Asia.pdf. 
Liu, Caroline M., Navjot K. Sandhu, Sean T. McCoy, and Joule A. Bergerson. 2020. "A Life Cycle Assessment of Greenhouse Gas Emissions from Direct Air Capture and Fischer-Tropsch Fuel Production.” Sustainable Energy and Fuels 4 (6): 3129-42.

https://doi.org/10.1039/c9se00479c.

Liu, Xinyu, Amgad Elgowainy, and Michael Wang. 2020. "Life Cycle Energy Use and Greenhouse Gas Emissions of Ammonia Production from Renewable Resources and Industrial By-Products.” Green Chemistry 22 (17): 5751-61. https://doi.org/10.1039/d0gc02301a.

Loiland, Jason A, Matthew J Wulfers, Nebojsa S Marinkovic, and Raul F Lobo. 2016. "Fe/ $\gamma$ $\mathrm{A} 12 \mathrm{O} 3$ and $\mathrm{Fe}-\mathrm{K} / \gamma-\mathrm{Al} 2 \mathrm{O} 3$ as Reverse Water-Gas Shift Catalysts." Catal. Sci. Technol. 6 (14): 5267-79. https://doi.org/10.1039/C5CY02111A.

Luc, Wesley, Xianbiao Fu, Jianjian Shi, Jing Jing Lv, Matthew Jouny, Byung Hee Ko, Yaobin $\mathrm{Xu}$, et al. 2019. "Two-Dimensional Copper Nanosheets for Electrochemical Reduction of Carbon Monoxide to Acetate." Nature Catalysis 2 (5): 423-30. https://doi.org/10.1038/s41929-0190269-8.

Luna, Phil De, Christopher Hahn, Drew Higgins, Shaffiq A. Jaffer, Thomas F. Jaramillo, and Edward H. Sargent. 2019. "What Would It Take for Renewably Powered Electrosynthesis to Displace Petrochemical Processes?” Science 364 (6438): eaav3506. https://doi.org/10.1126/science.aav3506.

Ma, Sichao, Raymond Luo, Jake I. Gold, Aaron Z. Yu, Byoungsu Kim, and Paul J. A. Kenis. 2016. "Carbon Nanotube Containing Ag Catalyst Layers for Efficient and Selective Reduction of Carbon Dioxide." Journal of Materials Chemistry A 4 (22): 8573-78.

https://doi.org/10.1039/C6TA00427J.

Mai, Trieu, Johnathan Ho, Brady Cowiestoll, Wesley Cole, and Paul Denholm. 2021. "The Solar Futures Scenarios." Golden, CO (United States).

Marlin, Dana S., Emeric Sarron, and Ómar Sigurbjörnsson. 2018. "Process Advantages of Direct CO2 to Methanol Synthesis." Frontiers in Chemistry 6 (September): 1-8.

https://doi.org/10.3389/fchem.2018.00446.

Mayyas, Ahmad, Mark Ruth, Bryan Pivovar, Guido Bender, and Keith Wipke. 2019.

"Manufacturing Cost Analysis for Proton Exchange Membrane Water Electrolyzers."

Mills, Andrew D., and Ryan H. Wiser. 2012. "Changes in the Economic Value of Photovoltaic Generation at High Penetration Levels: A Pilot Case Study of California." Lawrence Berkeley National Laboratory. https://doi.org/10.1109/PVSC-Vol2.2013.6656763.

Mohsenzadeh, Abas, Akram Zamani, and Mohammad J. Taherzadeh. 2017. "Bioethylene Production from Ethanol: A Review and Techno-Economical Evaluation." ChemBioEng Reviews 4 (2): 75-91. https://doi.org/10.1002/cben.201600025.

NETL. 2020. "Syngas Conversion to Methanol.” 2020. https://netl.doe.gov/research/coal/energysystems/gasification/gasifipedia/methanol. 
Nitopi, Stephanie, Erlend Bertheussen, Soren B. Scott, Xinyan Liu, Albert K. Engstfeld, Sebastian Horch, Brian Seger, et al. 2019. "Progress and Perspectives of Electrochemical CO2 Reduction on Copper in Aqueous Electrolyte." Chemical Reviews 119 (12): 7610-72. https://doi.org/10.1021/acs.chemrev.8b00705.

NREL. 2017. "Undersea Microbes Provide Path to Energy Storage.” 2017. https://www.nrel.gov/news/features/2017/undersea-microbes-provide-path-to-energystorage.html.

—. 2019. "NREL Marks Partner Forum With Dedication of Bioreactor." 2019. https://www.nrel.gov/news/program/2019/nrel-marks-partner-forum-with-dedication-ofbioreactor.html.

—. 2020a. "H2A: Hydrogen Analysis Production Case Studies." 2020. https://www.nrel.gov/hydrogen/h2a-production-case-studies.html.

- 2020b. "Today's Energy Challenges, Tomorrow's Solutions: Electrons to Molecules: Building a New Foundation for Industrial Processes.” https://www.nrel.gov/docs/fy20osti/76320.pdf.

Pastor-Pérez, L., F. Baibars, E. Le Sache, H. Arellano-García, S. Gu, and T. R. Reina. 2017. "CO2 Valorisation via Reverse Water-Gas Shift Reaction Using Advanced Cs Doped Fe$\mathrm{Cu} / \mathrm{A} 12 \mathrm{O} 3$ Catalysts." Journal of CO2 Utilization 21 (August): 423-28. https://doi.org/10.1016/j.jcou.2017.08.009.

Pérez-Fortes, M., and Evangelos Tzimas. 2016. "Techno-Economic and Environmental Evaluation of CO2 Utilisation for Fuel Production." Scientific and Technical Research Series. https://doi.org/10.2790/89238.

Recharge News. 2020. "A Wake-up Call on Green Hydrogen: The Amount of Wind and Solar Needed Is Immense | Recharge." 2020. https://www.rechargenews.com/transition/a-wake-upcall-on-green-hydrogen-the-amount-of-wind-and-solar-needed-is-immense/2-1-776481.

Rumayor, Marta, Antonio Dominguez-Ramos, and Angel Irabien. 2018. "Formic Acid Manufacture: Carbon Dioxide Utilization Alternatives." Applied Sciences (Switzerland) 8 (6): 112. https://doi.org/10.3390/app8060914.

Ruth, Mark F, Paige Jadun, Nicholas Gilroy, Elizabeth Connelly, Richard Boardman, A J Simon, Amgad Elgowainy, and Jarett Zuboy. 2020. "The Technical and Economic Potential of the H2@Scale Hydrogen Concept within the United States."

https://www.nrel.gov/docs/fy21osti/77610.pdf.

Ruth, Mark F, Paige N Jadun, Daniel Levie, and Bethany Frew. 2019a. "Electrolysis' Potential Value for Supporting the Electrical Grid." National Renewable Energy Laboratory. https://www.nrel.gov/docs/fy20osti/75373.pdf.

- 2019b. "Electrolysis ' Potential Value for Supporting the Electrical Grid." https://www.nrel.gov/docs/fy20osti/75373.pdf. 
Saeidi, Samrand, Nor Aishah Saidina Amin, and Mohammad Reza Rahimpour. 2014. "Hydrogenation of CO2 to Value-Added Products - A Review and Potential Future Developments." Journal of CO2 Utilization. Elsevier Ltd. https://doi.org/10.1016/j.jcou.2013.12.005.

Saito, Masahiro. 1998. "R\&D Activities in Japan on Methanol Synthesis from CO2 and H2." Catalysis Surveys from Japan 2 (2): 175-84. https://doi.org/10.1023/A:1019082525994.

Samimi, Fereshteh, Nazanin Hamedi, and Mohammad Reza Rahimpour. 2019. "Green Methanol Production Process from Indirect CO2 Conversion: RWGS Reactor versus RWGS Membrane Reactor." Journal of Environmental Chemical Engineering 7 (1): 102813. https://doi.org/10.1016/j.jece.2018.102813.

Schmidt, O., A. Gambhir, I. Staffell, A. Hawkes, J. Nelson, and S. Few. 2017. "Future Cost and Performance of Water Electrolysis: An Expert Elicitation Study." International Journal of Hydrogen Energy 42 (52): 30470-92. https://doi.org/10.1016/j.ijhydene.2017.10.045.

Schmidt, O., A. Hawkes, A. Gambhir, and I. Staffell. 2017. "The Future Cost of Electrical Energy Storage Based on Experience Rates.” Nature Energy 2 (8): 17110. https://doi.org/10.1038/nenergy.2017.110.

Shulenberger, Arthur, Fridrik Ragnar Jonsson, Oddur Ingolfsson, and Kim-Chinh Tran. 2007. Process for Producing Liquid Fuel from Carbon Dioxide and Water. US 2007/0244208A1, issued 2007.

Smith, Collin, Alfred K. Hill, and Laura Torrente-Murciano. 2020. "Current and Future Role of Haber-Bosch Ammonia in a Carbon-Free Energy Landscape.” Energy and Environmental Science 13 (2): 331-44. https://doi.org/10.1039/c9ee02873k.

Smith, Wilson A., Thomas Burdyny, David A. Vermaas, and Hans Geerlings. 2019. "Pathways to Industrial-Scale Fuel Out of Thin Air from CO2 Electrolysis.” Joule 3 (8): 1822-34. https://doi.org/10.1016/j.joule.2019.07.009.

Soloveichik, Grigorii. 2019. "Electrochemical Synthesis of Ammonia as a Potential Alternative to the Haber-Bosch Process." Nature Catalysis 2 (5): 377-80. https://doi.org/10.1038/s41929019-0280-0.

Spivey, James J., and Adefemi Egbebi. 2007. "Heterogeneous Catalytic Synthesis of Ethanol from Biomass-Derived Syngas.” Chemical Society Reviews 36 (9): 1514-28. https://doi.org/10.1039/b414039g.

Toyo. 2020. "Methanol/MRF-Z | Toyo Engineering Corporation.” 2020. https://www.toyoeng.com/jp/en/products/petrochmical/methanol/index.php.

U.S. DOE. 2017. “Alternative Fuels Data Center.” 2017. https://www.afdc.energy.gov/fuels/prices.html. 
United States Geological Survey (USGS). 2020. Mineral Commodity Summaries 2020. U.S Departtment OF The Interior, U.S Geological Survey.

https://pubs.usgs.gov/periodicals/mcs2020/mcs2020.pdf.

Vickers, James, David Peterson, and Katie Randolph. 2020. "DOE Hydrogen and Fuel Cells Program Record: Cost of Electrolytic Hydrogen Production with Existing Technology."

Hydrogen and Fuel Cell Technologies Office. https://www.hydrogen.energy.gov/pdfs/20004cost-electrolytic-hydrogen-production.pdf.

Vilekar, Saurabh, Kyle Hawley, Christian Junaedi, Dennis Walsh, Subir Roychoudhury, Morgan Abney, and James Mansell. 2012. "Performance Evaluation of Staged Bosch Process for CO2 Reduction to Produce Life Support Consumables." In 42nd International Conference on Environmental Systems. Reston, Virigina: American Institute of Aeronautics and Astronautics. https://doi.org/10.2514/6.2012-3555.

Whitlow, Jonathan E. 2003. "Operation, Modeling and Analysis of the Reverse Water Gas Shift Process.” In AIP Conference Proceedings, 654:1116-23. AIP.

https://doi.org/10.1063/1.1541409.

Wu, Yueshen, Zhan Jiang, Xu Lu, Yongye Liang, and Hailiang Wang. 2019. "Domino Electroreduction of CO2 to Methanol on a Molecular Catalyst." Nature 575 (7784): 639-42. https://doi.org/10.1038/s41586-019-1760-8.

Zapp, Karl-Heinz, Karl-Heinz Wostbrock, Manfred Schäfer, Kimihiko Sato, Herbert Seiter, Werner Zwick, Ruthild Creutziger, and Herbert Leiter. 2000. "Ammonium Compounds.” In Ullmann's Encyclopedia of Industrial Chemistry. Weinheim, Germany: Wiley-VCH Verlag GmbH \& Co. KGaA. https://doi.org/10.1002/14356007.a02_243.

Zhang, Minhua, and Yingzhe Yu. 2013. "Dehydration of Ethanol to Ethylene." Industrial and Engineering Chemistry Research 52 (28): 9505-14. https://doi.org/10.1021/ie401157c.

Zhao, Runbo, Hongtao Xie, Le Chang, Xiaoxue Zhang, Xiaojuan Zhu, Xin Tong, Ting Wang, et al. 2019. "Recent Progress in the Electrochemical Ammonia Synthesis under Ambient Conditions." EnergyChem 1 (2): 100011. https://doi.org/10.1016/j.enchem.2019.100011.

Zhou, Mingjie, and Yefeng Liu. 2013. "Theoretical Study on Direct Coupling of a PV Array to a PEM Electrolyser." ICMREE 2013 - Proceedings: 2013 International Conference on Materials for Renewable Energy and Environment 1 (20113120120006): 52-56.

https://doi.org/10.1109/ICMREE.2013.6893613. 


\section{Appendix. Assumptions and Methodologies for E2M Energy Demands}

The electrical efficiency (in $\mathrm{kWh} / \mathrm{kg}$ ) of a given E2M product $p$ is estimated by Equation $\mathrm{A} 1$ :

$$
\eta_{e l e c, p}=\frac{m_{P} z_{p} V_{p} F}{M M_{p} \delta_{p}}+E_{D A C, p}
$$

where:

$m_{P}(\mathrm{~kg})=$ mass of product $p$

$z_{p}\left(\frac{e^{-}}{\text {product }}\right)=$ electrons per molecule of product $p$

$V_{p}(V)=$ whole cell potential for electrochemical cell producing product $p$

$F\left(\frac{A * s}{m o l e^{-}}\right)=$Faraday constant $(96,485)$

$M M_{p}\left(\frac{\mathrm{kg}}{\mathrm{mol}}\right)=$ molar mass of product $p$

$\delta_{p}(\%)=$ selectivity (Faraday efficiency) of electrochemical cell producing product $p$

$E_{D A C, p}\left(\frac{k W h}{k g \text { product }}\right)=$ energy required for direct air capture of $\mathrm{CO}_{2}$ per kilogram of product $p$ (Equation A9).

Performance parameters used for each product for base and optimistic cases are given in Table A-1.

Table A-1. Performance Parameters for E2M Systems in Base and Future Cases

\begin{tabular}{|l|c|c|c|c|}
\hline & \multicolumn{2}{|c|}{ Base Case } & \multicolumn{2}{c|}{ Optimistic Case } \\
\hline Product & Selectivity & Whole Cell Potential & Selectivity $^{\mathbf{a}}$ & Whole Cell Potential $^{\mathbf{b}}$ \\
\hline Hydrogen & 1.00 & $1.90^{\mathrm{c}}$ & 1.00 & 1.53 \\
\hline Ammonia & $0.90^{\mathrm{d}}$ & $3.30^{\mathrm{d}}$ & 1.00 & 2.30 \\
\hline Carbon monoxide & $0.95^{\mathrm{e}}$ & $3.00^{\mathrm{e}}$ & 1.00 & 1.64 \\
\hline Ethylene & $0.60^{\mathrm{f}}$ & $3.90^{\mathrm{f}}$ & 1.00 & 1.47 \\
\hline Ethanol & $0.26^{\mathrm{g}}$ & $2.21^{\mathrm{g}}$ & 1.00 & 1.45 \\
\hline Methanol & $0.98^{\mathrm{g}}$ & $1.66^{\mathrm{g}}$ & 1.00 & 1.51 \\
\hline Formate & $0.93^{\mathrm{h}}$ & $5.80^{\mathrm{h}}$ & 1.00 & 1.78 \\
\hline Methane & $0.76^{\mathrm{g}}$ & $2.88^{\mathrm{g}}$ & 1.00 & 1.36 \\
\hline
\end{tabular}

a Unity selectivity is assumed for all reactions in optimistic case. 
${ }^{\mathrm{b}}$ Whole cell potential in the optimistic case is equal to the standard reduction potential for the product, assuming oxygen evolution reaction as the other half-cell reaction. A 300 -millivolt $(\mathrm{mV})$ cell overpotential is added to the standard reduction potential.

${ }^{c}$ NREL 2020b, ${ }^{d}$ Zhao et al. 2019, e Ma et al. 2016, ${ }^{f}$ García de Arquer et al. 2020, g Grim et al. 2019,

h Y. Chen et al. 2020

The electrical efficiency (in $\mathrm{kWh} / \mathrm{kg}_{\mathrm{p}}$ ) for given E2M products produced via the conventional pathway is determined by electrical energy used to produce $\mathrm{H}_{2}$ for the conventional pathway. Every pathway uses hydrogen either through direct hydrogenation of $\mathrm{CO}_{2}$, RWGS to produce $\mathrm{CO}$, or syngas hydrogen requirements. Thus, the electrical efficiency for a given product $p$ is estimated by Equation A2:

$$
\eta_{\text {elec }, p}=\eta_{\text {elec }, \mathrm{H} 2} R_{H 2, p}
$$

where:

$$
\eta_{e l e c, H 2}\left(\frac{k w h}{k g_{H 2}}\right)=\text { electrical efficiency of } \mathrm{H}_{2}
$$

$R_{H 2, p}\left(\frac{k g_{H 2}}{k g_{p}}\right)=\mathrm{kg} \mathrm{H}_{2}$ required to produce $\mathrm{kg}$ of product $p$.

The equation of $\mathrm{R}_{\mathrm{H} 2, \mathrm{p}}$ depends on the reaction pathway (syngas or direct $\mathrm{CO}_{2}$ ) and the performance parameters available (carbon efficiencies, selectivities, overall conversions, separation recoveries). Generally, performance parameters or published stream tables are used to estimate the mols of $\mathrm{CO}$ or $\mathrm{CO}_{2}$ required for a mol of product. The total hydrogen demand for a mol of product is then calculated by summing the hydrogen used to produce CO via RWGS and any additional hydrogen used in either the syngas to $\mathrm{X}$ or $\mathrm{CO}_{2}$ to $\mathrm{X}$ feedstock. The performance parameters used for each product are combined into a carbon-hydrogen efficiency (mols $\mathrm{C}_{\text {product }} / \mathrm{mols}_{2}$,reactant). In the case of ammonia, mols of nitrogen in the product are used instead as there is no carbon. These efficiencies are given in Table A-2.

Table A-2. Performance Parameters for Conventional E2M Systems in Base and Future Cases

\begin{tabular}{|l|c|c|}
\hline \multirow{2}{*}{ Product } & Base Case & Optimistic Case \\
\cline { 2 - 3 } Ammonia & $\mathbf{C : \mathbf { H } _ { \mathbf { 2 } } \text { Efficiency }}$ & $\mathbf{C}: \mathbf{H}_{\mathbf{2}}$ Efficiency \\
\hline Carbon monoxide & $0.65^{\mathrm{a}}$ & 0.65 \\
\hline Ethylene via CO2 & $1^{\mathrm{b}}$ & 1 \\
\hline Ethylene via syngas (MTO) & $0.14^{\mathrm{c}, \mathrm{d}, \mathrm{e}, \mathrm{f}}$ & 0.16 \\
\hline Ethylene via EtOH & $0.14^{\mathrm{f}, \mathrm{g}}$ & 0.16 \\
\hline Ethanol via fermentation & $0.24^{\mathrm{n}}$ & 0.24 \\
\hline Ethanol via mixed alcohols & $0.25^{\mathrm{h}}$ & 0.29 \\
\hline Methanol via syngas & $0.21^{\mathrm{f}}$ & 0.26 \\
\hline Methanol via CO 2 & $0.31^{\mathrm{f}, \mathrm{i}}$ & 0.31 \\
\hline Formic Acid via Kemira Leonard & $0.31^{\mathrm{g}, \mathrm{i}}$ & 0.31 \\
\hline
\end{tabular}




\begin{tabular}{|l|c|c|}
\hline \multirow{2}{*}{ Product } & Base Case & Optimistic Case \\
\cline { 2 - 3 } & C:H $\mathbf{H}_{\mathbf{2}}$ Efficiency & C: $\mathbf{H}_{\mathbf{2}}$ Efficiency \\
\hline Formic Acid via $\mathrm{CO}_{2}$ hydrogenation & $0.39^{\mathrm{j}}$ & 0.39 \\
\hline Methane & $0.25^{1, \mathrm{~m}}$ & 0.25 \\
\hline
\end{tabular}

a Zapp et al. 2000

${ }^{b}$ See conversion, selectivity and $\mathrm{H}_{2}$ : $\mathrm{CO}$ stoichiometric ratio cited in the carbon monoxide section

c Shulenberger et al. 2007

d Jadhav et al. 2014

e Dieterich et al. 2020

${ }^{f}$ Knighton et al. 2020

g J. Q. Chen et al. 2005

h LanzaTech 2021; 2018b; Huang et al. 2020; Lee et al. 2020

'Dieterich et al. 2020

j Pérez-Fortes and Tzimas 2016

${ }^{k}$ Chua et al. 2019

' Götz et al. 2016

m Junaedi et al. 2011

nZhang and Yu 2013

The amount of energy from PV needed to meet the existing market size for a product $p$ is estimated by Equation $\mathrm{A} 3$ :

$$
E_{\text {energy,p }}=\eta_{\text {elec }, p} \gamma_{p}
$$

where:

$\gamma_{p}\left(\frac{k g}{y}\right)=$ existing market size for product $p$

The total installed PV capacity for a product $p$ is estimated with Equation A4:

$$
E_{\text {capacity, } p}=\frac{E_{\text {energy,p }}}{C_{f} h}
$$

where:

$$
\begin{aligned}
& h\left(\frac{h}{y}\right)=\text { hours per year }(8,760) \\
& C_{f}(\%)=25.1 \% \text { solar capacity factor (EIA 2020d). }
\end{aligned}
$$

\section{Minimum Electricity Price Calculation}

The minimum electricity price for each product is estimated by considering the efficiency at which the product can be created by an electrochemical process and the current market price for 
the product. We assume a simple system capital cost $C_{S}$ of $\$ 400 / \mathrm{kW}$, amortized into a series of annual payments using Equation A5:

$$
C R F=\frac{i(1+i)^{n}}{(1+i)^{n}-1}
$$

where:

$$
\begin{aligned}
& i(\%)=\text { effective interest rate }(10 \%) \\
& n(y)=\text { facility lifetime }(30 \mathrm{yr}) .
\end{aligned}
$$

The total capital cost of a system to produce is the capital cost $C_{c}(\$ 400 / \mathrm{kW})$ multiplied by the energy required $E_{\text {energy,p }}$, divided by 8,760 hours per year $h$ and an assumed capacity factor $C_{f}$ of $80 \%$ (Equation A6):

$$
C_{\text {capital }}=\frac{C_{c} E_{\text {energy, } p}(C R F)}{C_{f} h}
$$

The cost of capital is converted from $\$ / \mathrm{y}$ to $\$ / \mathrm{kg}$ by dividing by the existing market size for a given product using Equation A7:

$$
P_{\text {capex }}=\frac{C_{\text {capital }}}{\gamma_{p}}
$$

The minimum electricity price $E_{m}$ is a function of the current market price $P_{\text {market }}$ and the cost of capital $P_{\text {capex }}$ (Equation A8), divided by the electrical efficiency estimated in Equation A1:

$$
E_{m}=\frac{P_{\text {market }}-P_{\text {capex }}}{\eta_{\text {elec }, p}}
$$

\section{Energy Requirements for Direct Air Capture of Carbon Dioxide}

The energy requirement for direct air capture of $\mathrm{CO}_{2}$ to be used in $\mathrm{CO}_{2} \mathrm{R}$ and conventional pathways is included, with energy consumption ratios based on work by Keith et al. (2018). A carbon efficiency is applied to the conventional pathways based on carbon losses in the system. The energy requirement for direct air capture per kilogram of product $p$ is a function of the stoichiometric ratios of the product and $\mathrm{CO}_{2}$ (Equation $\mathrm{A} 9$ ).

$$
E_{D A C, p}=\frac{\mathrm{MM}_{C O_{2} Z_{C, p}}}{M M_{p}} \eta_{D A C}
$$

where:

$$
M M_{p}\left(\frac{k g}{m o l}\right)=\text { molar mass of product } p
$$


$\mathrm{MM}_{\mathrm{CO}_{2}}\left(\frac{\mathrm{kg}}{\mathrm{mol}}\right)=$ molar mass of carbon dioxide

$z_{c, p}\left(\frac{\text { carbons }}{\text { molecule }}\right)=$ carbon atoms per molecule $p$

$\eta_{D A C}\left(\frac{k W h}{k g C O_{2}}\right)=$ energy requirement per kilogram $\mathrm{CO}_{2}$ for direct air capture $=1.274$

(Keith et al. 2018).

Table A-3 shows carbon efficiencies for conventional thermochemical processes used in indirect E2M pathways. Carbon efficiencies vary between the Base and Optimistic scenarios.

Table A-3. Carbon Efficiencies for Conventional E2M Systems in Base and Future Cases

\begin{tabular}{|l|c|c|}
\hline \multirow{2}{*}{ Product } & Base Case & Optimistic Case \\
\cline { 2 - 3 } & $\mathbf{C}_{\text {product }} / \mathbf{C}_{\text {co2 }}$ & $\mathbf{C}_{\text {product }} / \mathbf{C}_{\mathbf{c o 2}}$ \\
\hline Carbon monoxide & 1 & 1 \\
\hline Ethylene via $\mathrm{CO}_{2}$ (MTO) & 0.42 & 0.48 \\
\hline Ethylene via syngas (MTO) & 0.42 & 0.49 \\
\hline Ethylene via EtOH & 0.83 & 0.96 \\
\hline Ethanol via fermentation & 0.88 & 1 \\
\hline Ethanol via mixed alcohols & 0.45 & 0.79 \\
\hline Methanol via syngas & 0.94 & 0.94 \\
\hline Methanol via $\mathrm{CO}_{2}$ & 0.94 & 0.94 \\
\hline Formic Acid via $\mathrm{Kemira}_{2}$ Leonard & 0.97 & 0.97 \\
\hline Formic Acid via $\mathrm{CO}_{2}$ hydrogenation & 0.97 & 0.97 \\
\hline Methane & 1 & 1 \\
\hline
\end{tabular}

\section{Current Market Sizes and Future Projections}

The increases in market size for the optimistic case are projections based on the expected growth rate for each product over a 10-year period (Table A-4, page 53).

Table A-4. Current and Projected Market Sizes for E2M Products

\begin{tabular}{|l|c|c|c|}
\hline Product & $\begin{array}{c}\text { Base Market Size } \\
\text { (million t/yr) }\end{array}$ & $\begin{array}{c}\text { Growth Rate } \\
\mathbf{( \% )}\end{array}$ & $\begin{array}{c}\text { Optimistic Market Size } \\
\text { (million t/yr) }\end{array}$ \\
\hline Hydrogen & 10 & $\mathrm{n}^{\mathrm{a}}$ & 58 \\
\hline Ammonia & 13 & $2.6 \%^{\mathrm{b}}$ & 16 \\
\hline Carbon monoxide & 2 & $2.0 \%^{\mathrm{c}}$ & 2 \\
\hline Ethylene & 27 & $3.6 \%^{\mathrm{b}}$ & 37 \\
\hline Ethanol & 47 & $4.9 \%^{\mathrm{d}}$ & 70 \\
\hline Methanol & 5 & $2.0 \%^{\mathrm{c}}$ & 6 \\
\hline
\end{tabular}




\begin{tabular}{|l|c|c|c|}
\hline Product & $\begin{array}{c}\text { Base Market Size } \\
\text { (million t/yr) }\end{array}$ & $\begin{array}{c}\text { Growth Rate } \\
\text { (\%) }\end{array}$ & $\begin{array}{c}\text { Optimistic Market Size } \\
\text { (million t/yr) }\end{array}$ \\
\hline Formate & 0.06 & $2.0 \%^{\mathrm{c}}$ & 0.07 \\
\hline Methane & 579 & $0.4 \%^{\mathrm{e}}$ & 604 \\
\hline
\end{tabular}

a The optimistic hydrogen market size is a function of adoption of growth in demand within transportation sector and other industrial applications.

b IHS 2021; used with permission provided March 16, 2021

${ }^{c}$ For products with market growth rates unavailable, a $2 \%$ market growth is assumed.

d Grand View Research 2020

e EIA 2020a

Table A-5 shows assumptions for hydrogen market size in the optimistic case, which are adapted from a technical and economic analysis of hydrogen potential in the United States as part of the Department of Energy H2@Scale initiative (Ruth et al. 2020). Market sizes for different sectors are adopted from the lowest cost electrolysis scenario in Ruth et al. (2020), and total hydrogen potential is estimated to be 41 million t/yr. Though potential hydrogen demand is largely consistent, it varies for several sectors for this work; most of the variation stems from different assumptions about the evolution of the transportation sector. This work assumes slightly lower rates of adoption of light-duty fuel cell electric vehicles and greater adoption of electric vehicles in the light-duty sector. Additionally, higher rates of adoption of fuel cell electric vehicles in the medium- and heavy-duty sectors is assumed, which results in a doubling of hydrogen demand in this sector. Increased demand for ammonia, synthetic hydrocarbons, and hydrogen for the rail sector are also driven by assumptions about electrification in the transportation sector. These demands result from higher rates of electrification in the air, shipping, and other heavy-duty transportation sectors.

Table A-5. Market Size Analysis for Hydrogen in Optimistic Scenario

\begin{tabular}{|l|c|c|}
\hline Product & $\begin{array}{c}\text { H2@Scale Lowest Cost } \\
\text { Electrolysis Scenario } \\
\text { (Ruth et al. 2020) } \\
\text { (million t/yr) }\end{array}$ & $\begin{array}{c}\text { E2M Optimistic } \\
\text { Case } \\
\text { (million t/yr) }\end{array}$ \\
\hline Oil refining & 7 & 7 \\
\hline Metals refining & 4 & 4 \\
\hline Ammonia production & 4 & 7 \\
\hline Biofuels production & 9 & 7 \\
\hline Synthetic hydrocarbons & 0 & 12 \\
\hline Light-duty fuel cell electric vehicles & 12 & 10 \\
\hline Medium- and heavy-duty fuel cell electric vehicles & 5 & 10 \\
\hline Rail & 0 & 1 \\
\hline Total & $\mathbf{4 1}$ & $\mathbf{5 8}$ \\
\hline
\end{tabular}


Table A-6 shows assumptions for hydrogen market size in the Solar Futures Study Energy Decarbonization scenario. Market sizes for different sectors are based on the energy consumption within each subsector to estimate the mass of hydrogen required on a higher heating value basis of 142 megajoules $(\mathrm{MJ}) / \mathrm{kg}$. Hydrogen demands for each economic sector range from direct to indirect. Direct use cases stem from hydrogen used as a transportation fuel in heavy- or medium-duty fuel cell electric vehicles to hydrogen used in the power sector in renewable energy combustion turbines. Hydrogen is also used indirectly across industry and transportation as an intermediate for production of other low-carbon fuels, such as ammonia, biofuels, and synthetic hydrocarbons.

Total annual hydrogen demand in the Energy Decarbonization scenario, which exceeds 60 million $\mathrm{t} / \mathrm{yr}$, is driven largely by direct and indirect applications in the transportation sector, but uses in industry and the power sector also result in notable demand.

Table A-6. Market Size Analysis for Hydrogen Demands Identified in the Energy Decarbonization Scenario

\begin{tabular}{|c|c|c|c|}
\hline Sector & $\begin{array}{l}\text { Direct Hydrogen } \\
\text { Demand, Solar } \\
\text { Futures Energy } \\
\text { Decarbonization } \\
\text { Scenario } \\
\text { (quads/y) }\end{array}$ & $\begin{array}{l}\text { Indirect Hydrogen } \\
\text { Demand, Solar } \\
\text { Futures Energy } \\
\text { Decarbonization } \\
\text { Scenario } \\
\text { (quads/y) }\end{array}$ & $\begin{array}{l}\text { Total Direct and } \\
\text { Indirect Annual } \\
\text { Hydrogen Demand, } \\
\text { Higher Heating } \\
\text { Value Basis } \\
\text { (million t/yr) }\end{array}$ \\
\hline Agriculture & 0.00 & 0.03 & 0.2 \\
\hline Construction & 0.00 & 0.20 & 1.5 \\
\hline Glass industry & 0.00 & 0.15 & 1.1 \\
\hline Oil refining & 0.00 & 0.00 & $0.00^{\mathrm{a}}$ \\
\hline Metals refining & 0.00 & 0.54 & $4.0^{\mathrm{b}}$ \\
\hline Ammonia production & 0.00 & 0.94 & $7.0^{\mathrm{c}}$ \\
\hline Industry demand subtotal & 0 & 1.9 & 13.8 \\
\hline Air transportation & 0.41 & 1.00 & 10.5 \\
\hline Bus transportation & 0.04 & 0.02 & 0.4 \\
\hline Domestic shipping & 0.00 & 0.03 & 0.2 \\
\hline Freight rail & 0.09 & 0.40 & 3.6 \\
\hline Heavy-duty trucks & 0.66 & 0.25 & 6.8 \\
\hline International shipping & 0.00 & 0.60 & 4.4 \\
\hline Light-duty vehicles & 0.00 & 0.00 & 0.0 \\
\hline Lubricants & 0.00 & 0.19 & 1.4 \\
\hline Medium-duty trucks & 0.17 & 0.00 & 1.2 \\
\hline Military & 0.00 & 0.83 & 6.1 \\
\hline Motorcycles & 0.00 & 0.00 & 0.00 \\
\hline
\end{tabular}




\begin{tabular}{|l|c|c|c|}
\hline Sector & $\begin{array}{c}\text { Direct Hydrogen } \\
\text { Demand, Solar } \\
\text { Futures Energy } \\
\text { Decarbonization } \\
\text { Scenario } \\
\text { (quads/y) }\end{array}$ & $\begin{array}{c}\text { Indirect Hydrogen } \\
\text { Demand, Solar } \\
\text { Futures Energy } \\
\text { Decarbonization } \\
\text { Scenario } \\
\text { (quads/y) }\end{array}$ & $\begin{array}{c}\text { Total Direct and } \\
\text { Indirect Annual } \\
\text { Hydrogen Demand, } \\
\text { Higher Heating } \\
\text { Value Basis } \\
\text { (million t/yr) }\end{array}$ \\
\hline Passenger rail & 0.01 & 0.02 & 0.2 \\
\hline Recreational boats & 0.00 & 0.28 & 2.1 \\
\hline Transportation demand subtotal & 1.37 & 3.62 & 37.08 \\
\hline RE-CT demand & 1.80 & 0.00 & 13.4 \\
\hline Power sector demand subtotal & 1.80 & $\mathbf{0 . 0 0}$ & $\mathbf{1 3 . 4 0}$ \\
\hline Total & 3.18 & 5.47 & $\mathbf{6 4 . 2 5}$ \\
\hline
\end{tabular}

${ }^{a}$ Hydrogen demand in oil refining is assumed to equal zero because of low hydrocarbon fuel demand in the transportation sector.

${ }^{b}$ Demand from Ruth et al. 2020 is assumed.

${ }^{c}$ Demand from Ruth et al. 2020 is assumed. The value includes only ammonia used as fertilizer. Other ammonia demands in the transportation sector are included in the respective transportation subsectors.

${ }^{\mathrm{d}} \mathrm{RE}-\mathrm{CT}=$ renewable energy-combustion turbine

Technology readiness levels (TRLs) for direct and indirect E2M processes are shown in Table A7. The pathway TRLs shown are approximate, as the current state of technology for many of these pathways is rapidly evolving and TRL is a subjective metric for the maturity of the technology. For indirect pathways that couple mature processes with E2M systems, the lowest TRL for a given component process is chosen to represent the TRL for the entire pathway.

Table A-7. Approximate TRL for E2M pathways

\begin{tabular}{|c|c|c|c|}
\hline Product & TRL & Pathway Type & Reference \\
\hline Hydrogen & 8 & Direct electrochemical & a \\
\hline Ammonia & 4 & Direct electrochemical & $\mathrm{b}$ \\
\hline Carbon monoxide & 6 & Direct electrochemical & c \\
\hline Ethylene & 3 & Direct electrochemical & c \\
\hline Ethanol & 3 & Direct electrochemical & c \\
\hline Methanol & 2 & Direct electrochemical & c \\
\hline Formate & 4 & Direct electrochemical & c \\
\hline Methane & 3 & Direct electrochemical & c \\
\hline Ammonia via Haber Bosch & 9 & Indirect electrochemical & $\mathrm{n} / \mathrm{a}$ \\
\hline $\mathrm{CO}$ via reverse water gas shift & 6 & Indirect electrochemical & $d$ \\
\hline Ethanol via syngas fermentation & 6 & Indirect electrochemical & $d$ \\
\hline Ethanol via mixed alcohols & 5 & Indirect electrochemical & e \\
\hline Ethylene via $\mathrm{MTO}\left(\mathrm{CO}_{2}\right.$ to $\left.\mathrm{MeOH}\right)$ & 7 & Indirect electrochemical & $d, f$ \\
\hline Ethylene via MTO (syngas to $\mathrm{MeOH}$ ) & 6 & Indirect electrochemical & $d$ \\
\hline
\end{tabular}




\begin{tabular}{|l|c|l|c|}
\hline Product & TRL & Pathway Type & Reference \\
\hline Ethylene via ethanol dehydration & 6 & Indirect electrochemical & $\mathrm{g}$ \\
\hline Methanol via syngas & 6 & Indirect electrochemical & $\mathrm{d}$ \\
\hline Methanol via carbon dioxide & 7 & Indirect electrochemical & $\mathrm{d}, \mathrm{f}$ \\
\hline Formic acid via hydrogenation & 6 & Indirect electrochemical & $\mathrm{d}$ \\
\hline Formic acid via Kemira-Leonard & 6 & Indirect electrochemical & $\mathrm{d}$ \\
\hline Methane via Sabatier Reaction & 8 & Indirect electrochemical & $\mathrm{d}$ \\
\hline
\end{tabular}

a Multiple large-scale water electrolysis systems are currently in operation (FuelCellsWorks 2020; Freist 2019; FuelCellsWorks 2019).

b The TRL is approximated based on current density, selectivity, and efficiency of E2M ammonia production relative to other electrochemical pathways (Zhao et al. 2019; Soloveichik 2019).

c The TRL is approximated based on findings from Grim et al. (2019), where TRLs for pathways are roughly categorized for TRL 1-3 for $\mathrm{C}_{2+}$ products and TRL 4-6 for $\mathrm{C}_{1}$ products. The TRLs are further distinguished within these ranges based on current energy efficiency of the pathway and the development of commercial applications of the pathway, if any.

d Jarvis and Samsatli 2018

e Knighton et al. 2020

${ }^{f}$ Pérez-Fortes and Tzimas 2016

g Intratec 2013

\section{Block Flow Diagrams for Indirect E2M Pathways}

Figures A-1 through A-10 show the block flow diagrams for the various indirect E2M pathways analyzed for this report.

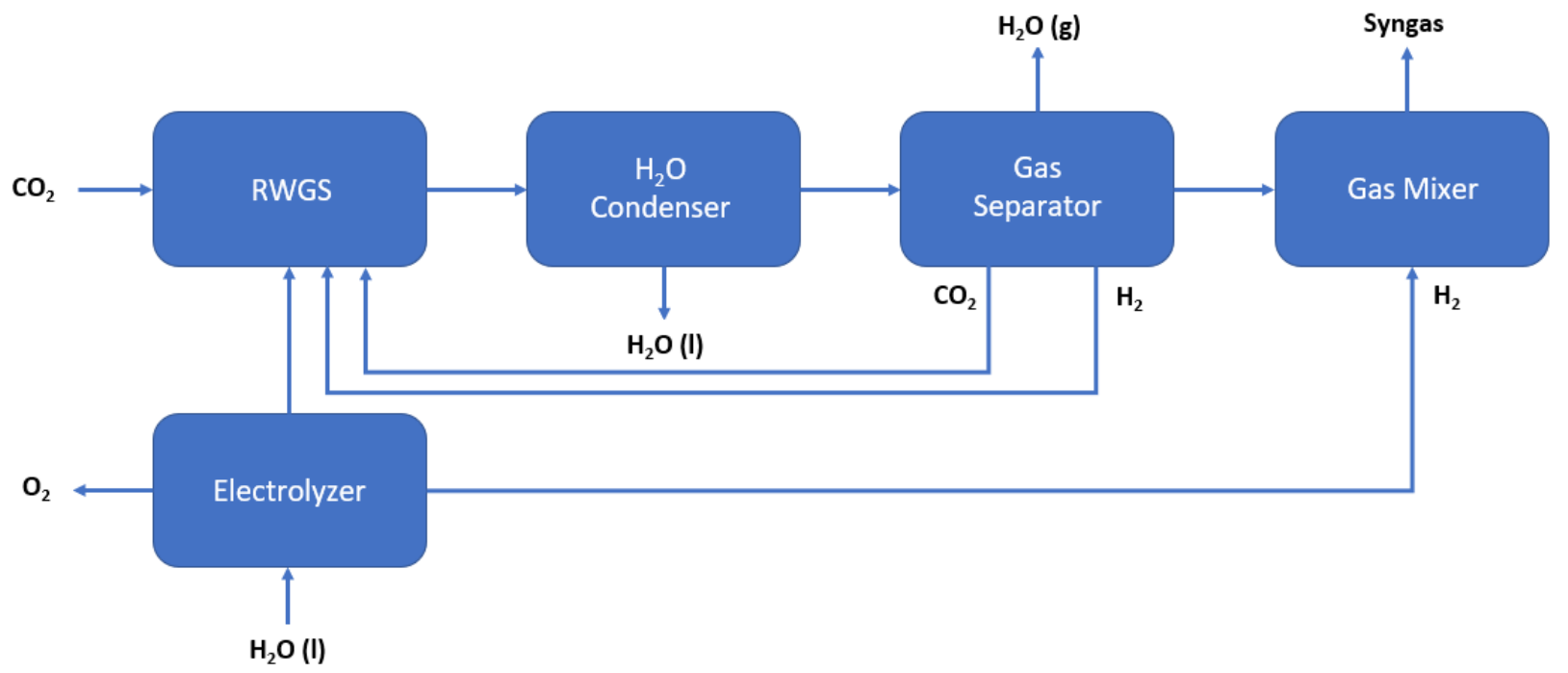

Figure A-1. Block flow diagram for syngas production via RWGS and water electrolysis 


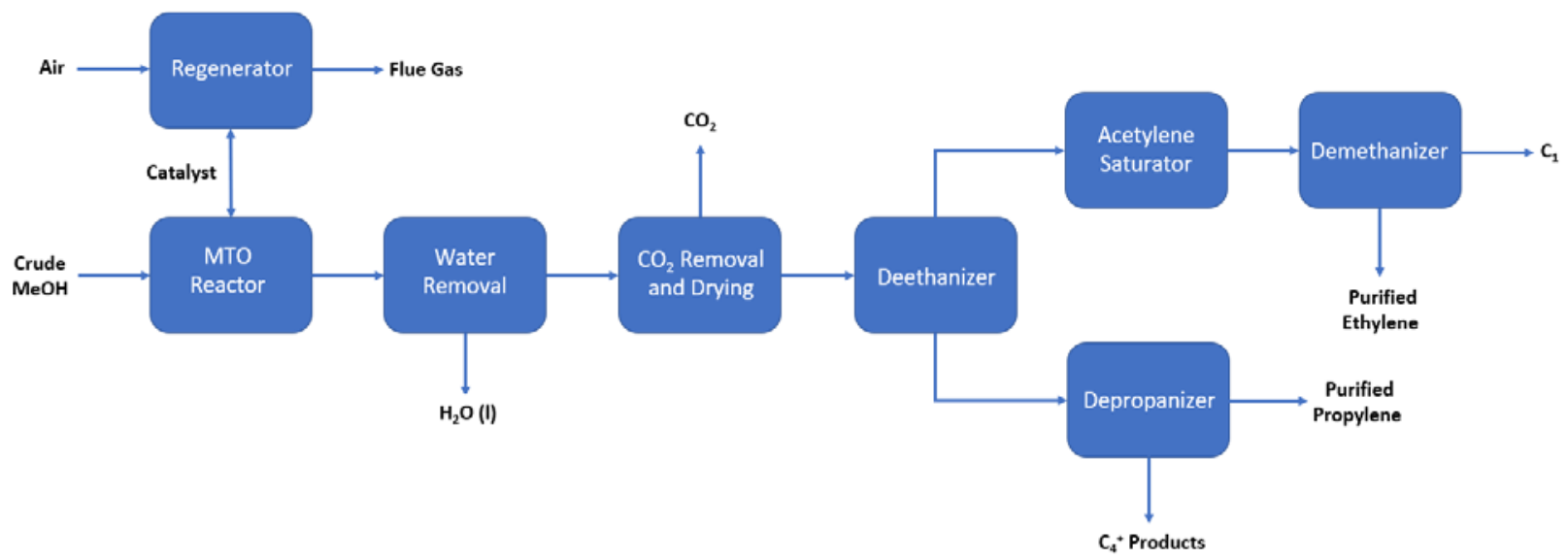

Figure A-2. Block flow diagram for ethylene synthesis via methanol to olefins

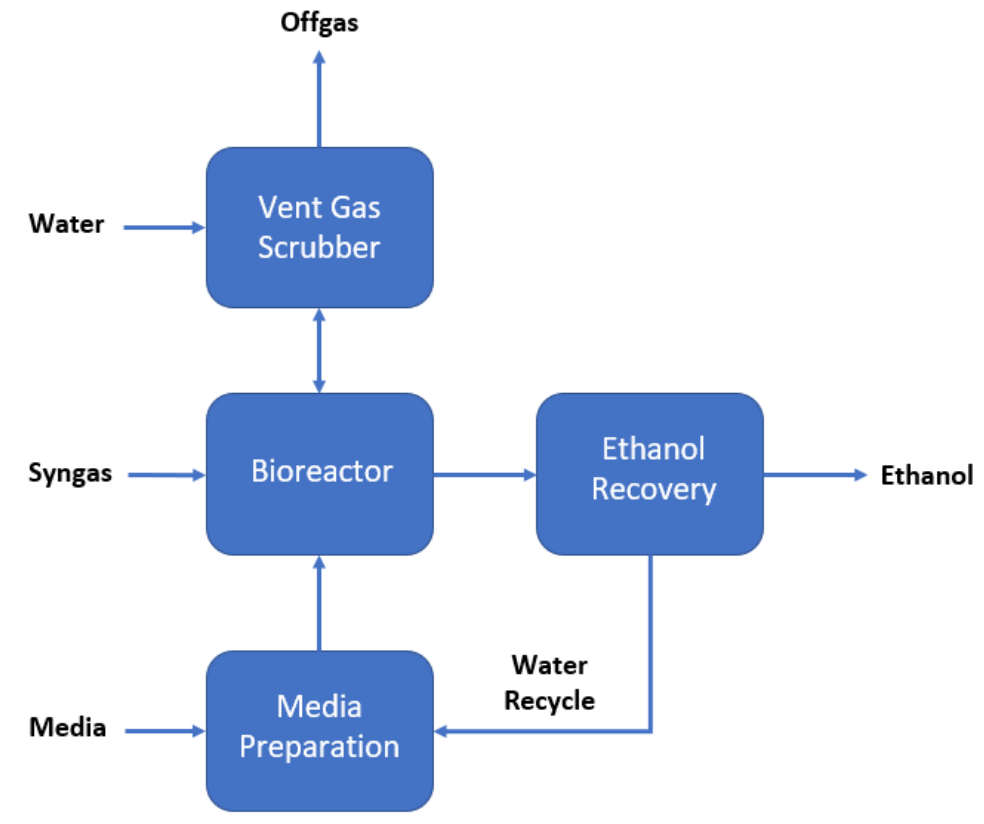

Figure A-3. Block flow diagram for ethanol production via fermentation 


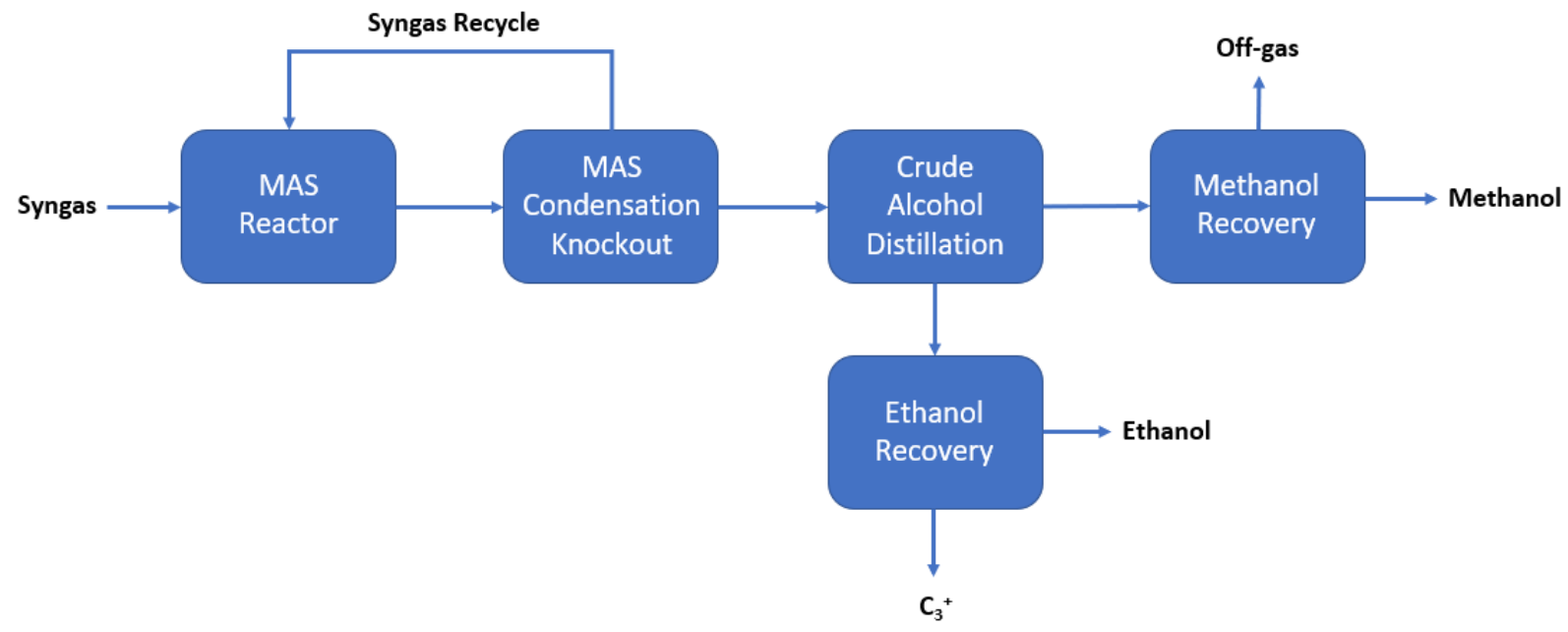

Figure A-4. Block flow diagram for ethanol production via mixed alcohols synthesis

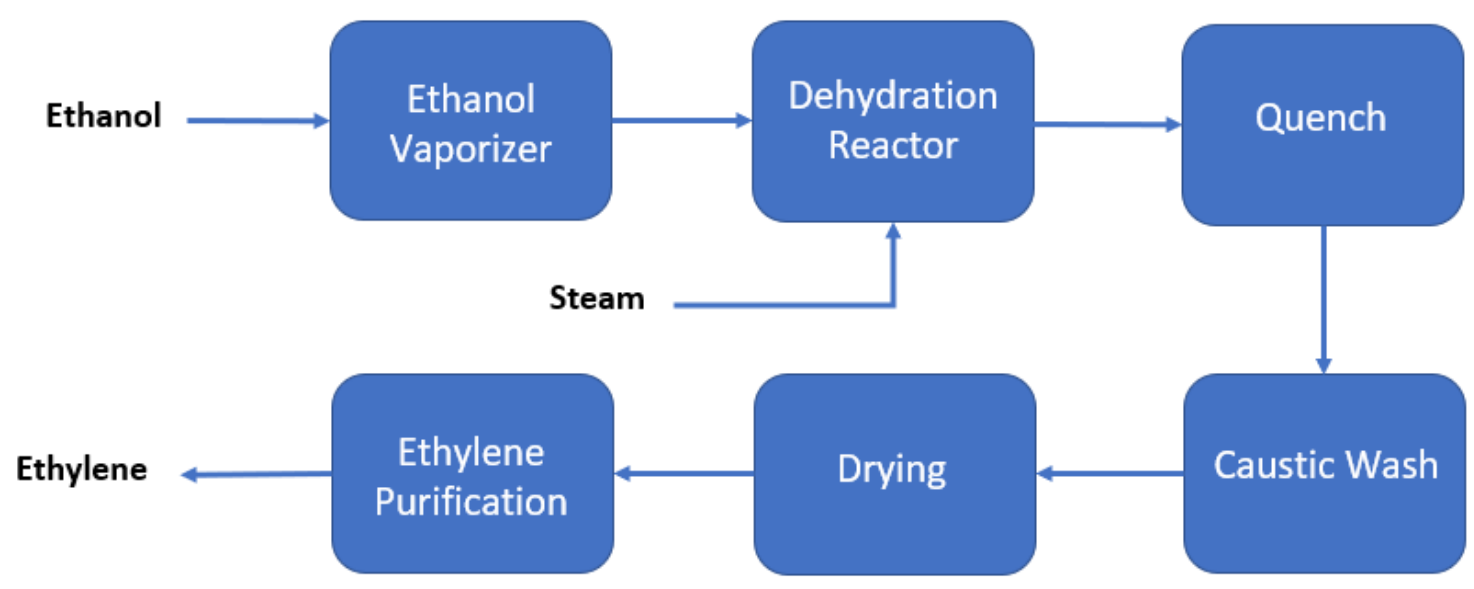

Figure A-5. Block flow diagram for ethanol production via ethanol dehydration (Intratec 2013) 


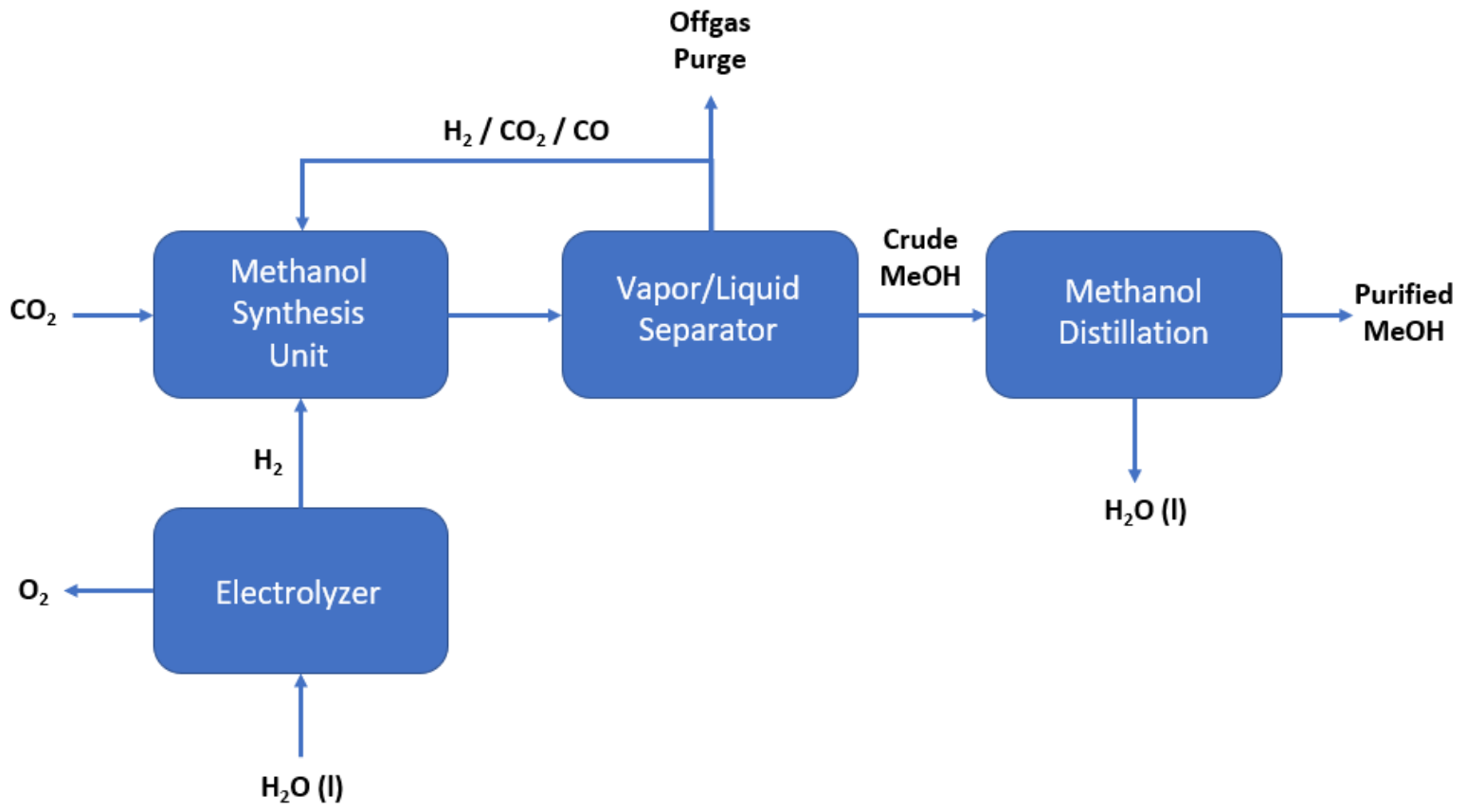

Figure A-6. Block flow diagram for methanol production via direct hydrogenation

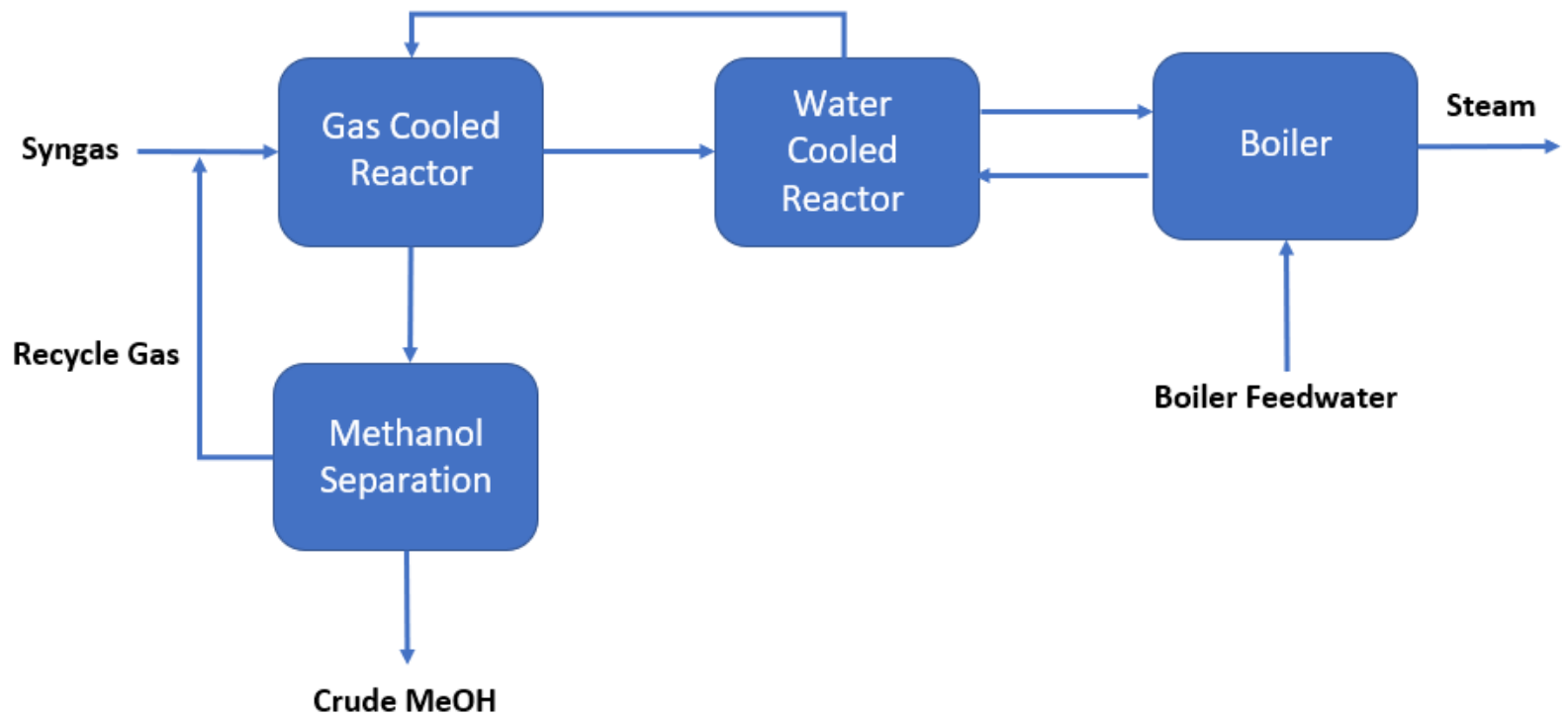

Figure A-7. Block flow diagram for methanol synthesis via syngas (Air Liquide 2021) 


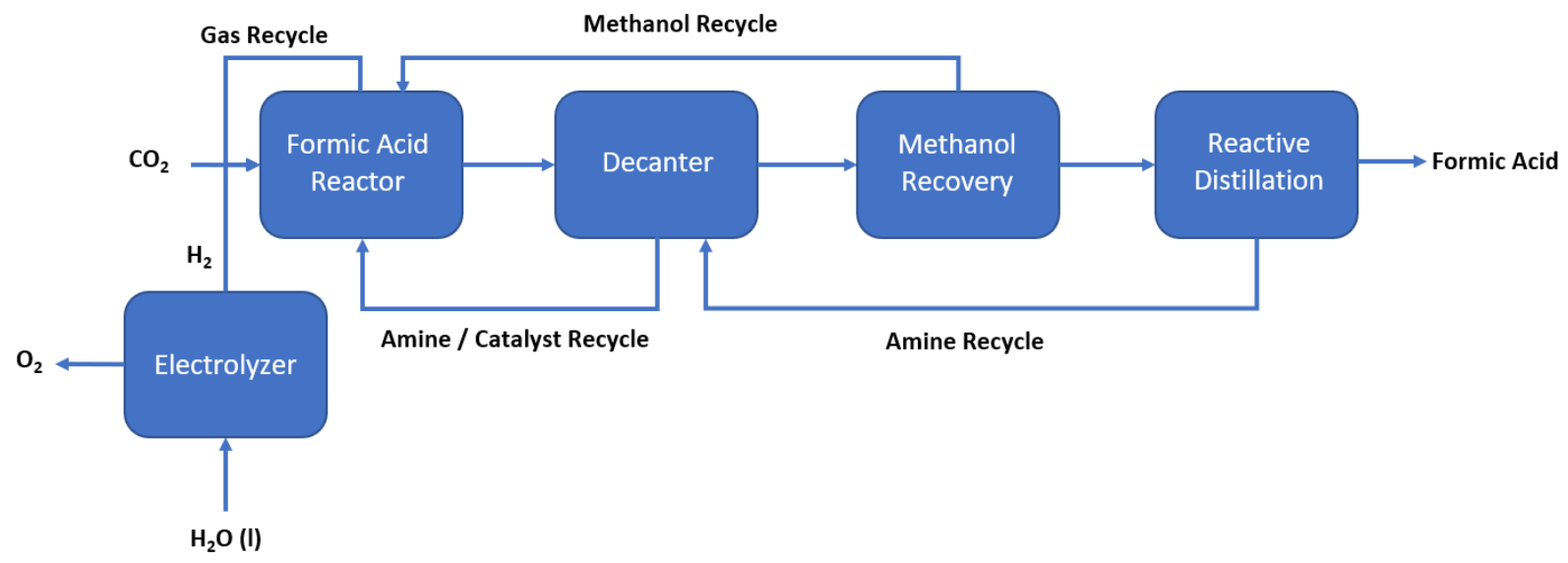

Figure A-8. Block flow diagram for formic acid production via direct hydrogenation

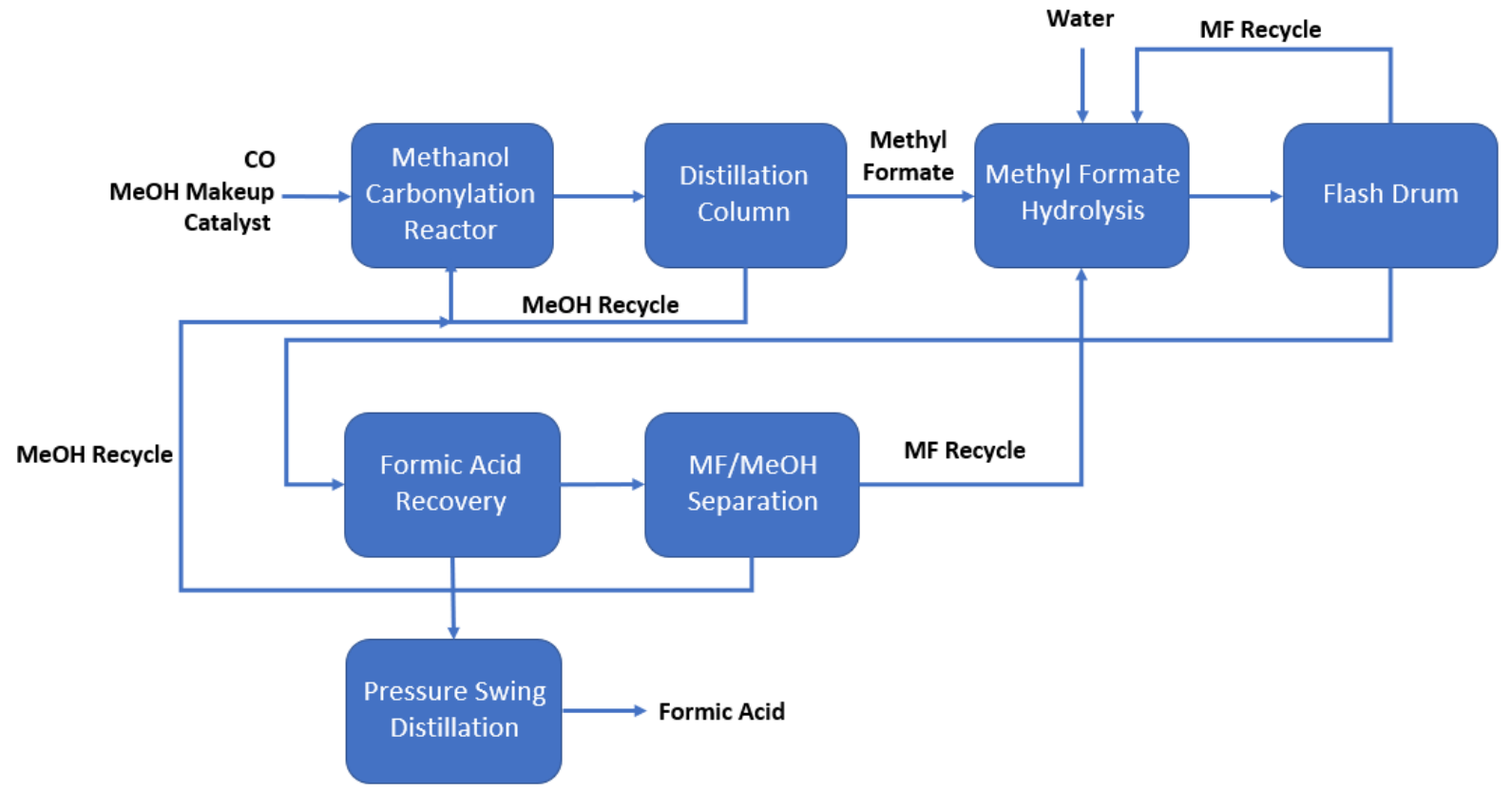

Figure A-9. Block flow diagram for formic acid production via Kemira-Leonard process 


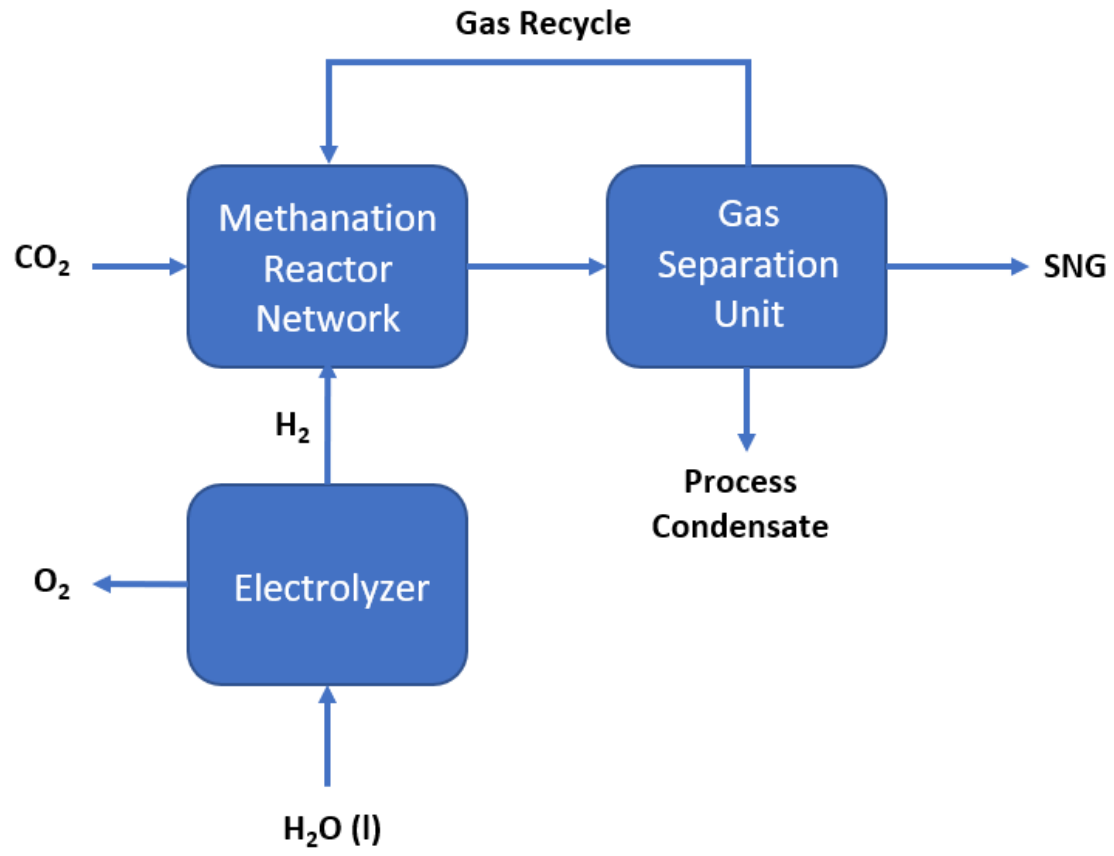

Figure A-10. Block flow diagram for methane production via Sabatier and water electrolysis 